\title{
Modelagem por Semi-Espaços Definidos Implicitamente
}

\author{
Marcelo Ferreira Siqueira
}

Orientador: Prof. Dr. Antônio Castelo Filho

Dissertação apresentada ao Instituto de Ciências Matemáticas de São Carlos - USP, como parte dos requisitos para obtenção do título de Mestre em Ciências: Área - Ciências de Computação e Matemática Computacional. 
Aos meus pais, Roberto e Dilma, por tudo.

Aos meus irmãos, Beto e Raquel.

À minha avó, Mailde. 


\section{Agradecimentos}

Ao Professor Dr. Antônio Castelo Filho pela orientação, dedicação, paciência, ensinamentos, valorização e amizade no decorrer do desenvolvimento deste trabalho.

À Professora Dra. Maria Cristina Ferreira de Oliveira pela preciosa revisão do texto desta dissertação, além de incentivo e ensinamentos como pesquisadora do grupo de Computação Gráfica e Processamento de Imagens no ICMSC-USP.

À Professora Dra. Agma Juci Machado Traina pelo apoio e ensinamentos como professora e pesquisadora do grupo de Computação Gráfica e Processamento de Imagens no ICMSC-USP. MEDUSA.

Ao Professor Dr. Geovan Tavares pelas sugestões dadas e pela utilização do software

Ao Professor Hélio Lopes pelo código do tradutor de expressões numéricas e lógicas utilizado neste trabalho.

Ao amigo Sadao Massago pelas inúmeras dúvidas elucidadas referentes à teoria matemática envolvida neste trabalho.

Aos amigos e companheiros Carlos Lenz e Ana Liddy pelos trabalhos em conjunto no (SM) ${ }^{2}$.

Às amigas Rosana e Claudinha pelo auxflio na digitação e escolha do estilo do texto desta dissertação.

Aos professores Jackson de Carvalho, Luís Damasceno, Nilda Cerqueira, Pedro Maia e Carlos Augusto pelo incentivo e recomendação. convivência.

À Poliana pelo amor, carinho, paciência e companheirismo demonstrados ao longo de nossa

Ao casal amigo José Otávio e Maria Ângela pelo acolhimento e incentivo.

A todos os amigos e colegas do ICMSC, especialmente, José Craveiro, Carlos Aparecido, Flávia, Claudinha, Rosana, Carlos Lenz, Sadao, Josiane, Fábio, Rogério, Vera e Marcão, pelo incentivo e por terem tornado a minha estadia em São Carlos ainda mais agradável.

A todos os professores e funcionários do ICMSC-USP que, de uma maneira ou de outra, colaboraram para o desenvolvimento deste trabalho.

À Capes e ao ICMSC-USP pela bolsa de mestrado concedida. 


\section{Resumo}

Esta dissertação descreve a integração da técnica de modelagem por semi-espaços e da representação implícita a um sistema de modelagem de sólidos dotado inicialmente de uma forma de representação por fronteira e da técnica de modelagem por varredura translacional e rotacional.

A representação implícita consiste em uma forma alternativa para representar os modelos descritos por semi-espaços. Cada representação implícita criada é convertida, pelo modelador, para a representação por fronteira correspondente, que é mantida como a principal forma de representação do sistema. A conversão entre as duas representaçōes ế baseada em um método simplicial de aproximação de superfícies definidas implicitamente.

A técnica de descrição por semi-espaços ampliou consideravelmente o poder descritivo do modelador, pois permite a descrição de sólidos cuja fronteira possui forma complexa, as quais não são facilmente descritas através das técnicas de varredura. A disponibilidade de duas formas de representação, implícita e por fronteira, para os modelos descritos por semi-espaços, possibilita aos procedimentos de aplicação optarem pela representação mais adequada aos seus propósitos. 


\begin{abstract}
This text describes the integration of the modeling technique by halfspaces and of an implicit representation form into a solid modeling system that supports a boundary representation form and translational and rotational sweeping as the modeling technique.

The implicit representation provides an alternative form of representing the models described by halfspaces. Each implicit representation created is converted into a corresponding boundary representation, which is kept by the system as the primary form. The conversion between representations is based on a simplicial method that aproximates implicitly defined surfaces.

The modeling technique by halfspaces considerably enhances the descriptive power of the modeler as it allows the description of solids with complex geometries that cannot be easily described by sweeping techniques. The availability of both implicit and boundary representation forms for representing the models described by halfspaces enables application procedures to select the most appropriated form in order to reach their aims.
\end{abstract}




\section{Conteúdo}

Lista de Figuras $\ldots \ldots \ldots \ldots \ldots \ldots \ldots \ldots \ldots \ldots \ldots \ldots \ldots \ldots \ldots$

Lista de Quadros $\ldots \ldots \ldots \ldots \ldots \ldots \ldots \ldots \ldots \ldots \ldots \ldots \ldots \ldots \ldots \ldots$

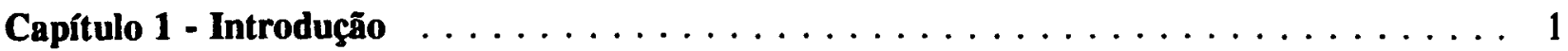

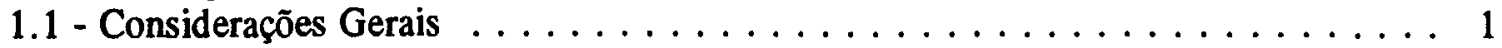

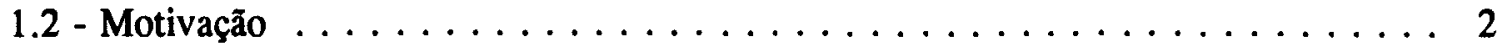

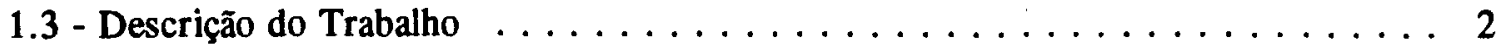

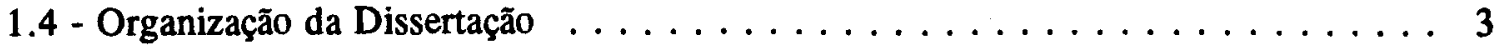

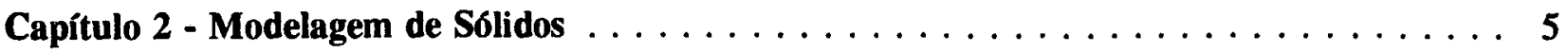

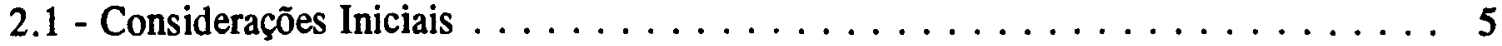

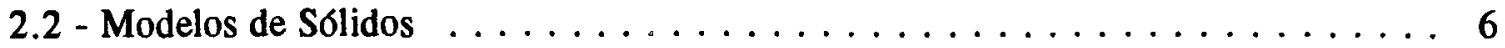

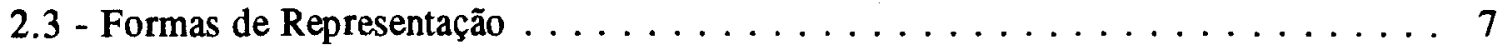

2.3.1 - Representações por Decomposição . . . . . . . . . . . 8

2.3.2 - Representações Construtivas . . . . . . . . . . . . . . 8

2.3.3 - Representações por Fronteira . . . . . . . . . . . . 9

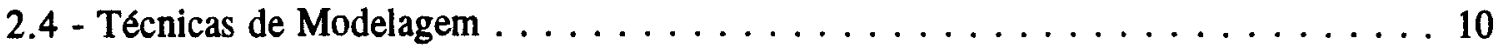

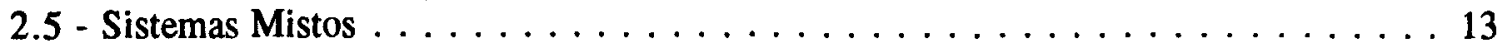

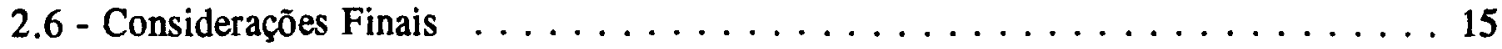

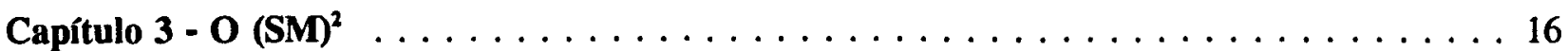

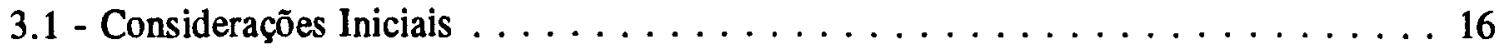

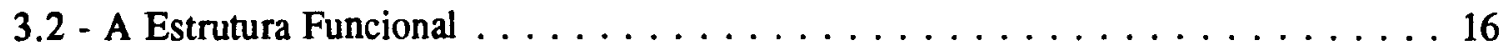

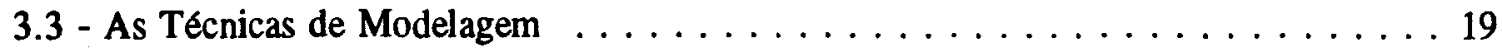

3.4 - A Arquitetura . . . . . . . . . . . . . . . . . . 20

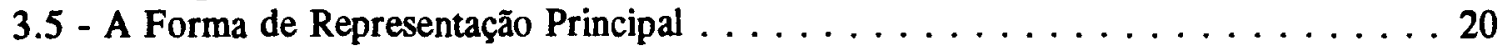

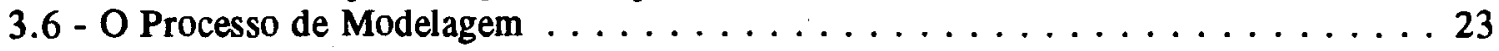

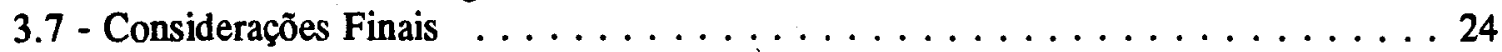

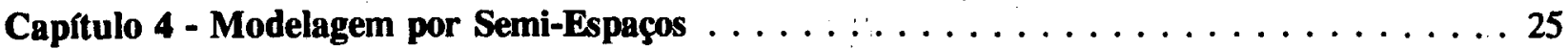

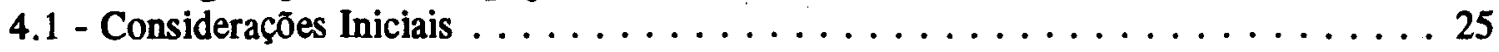

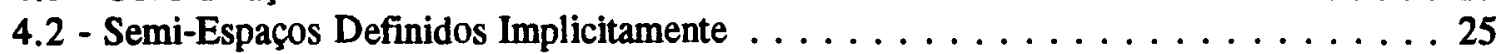

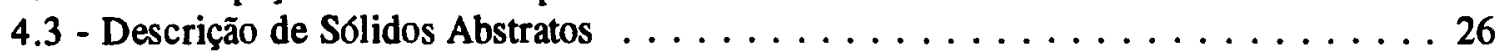

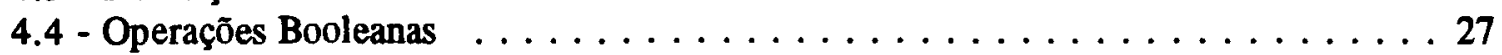

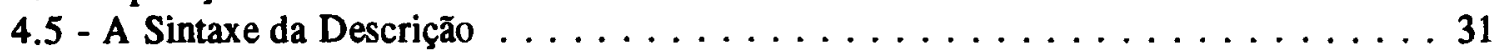

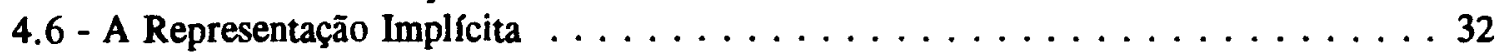

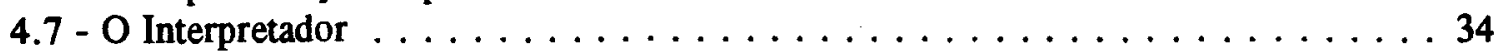

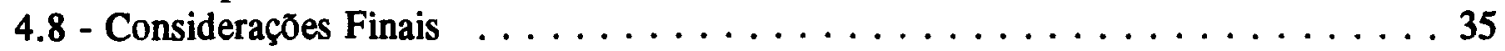




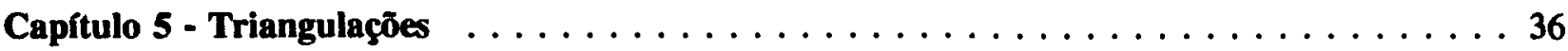

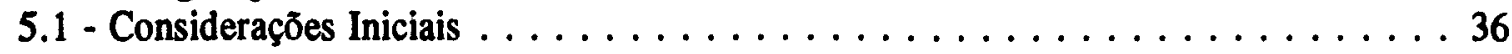

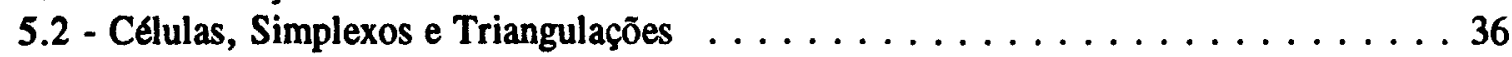

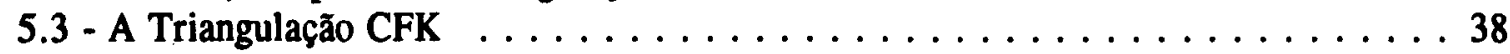

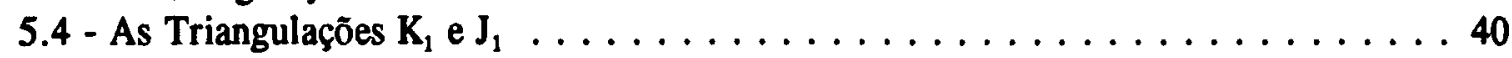

5.5 - Rotulagem ....................... 41

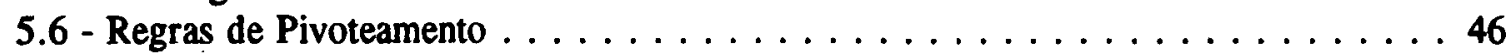

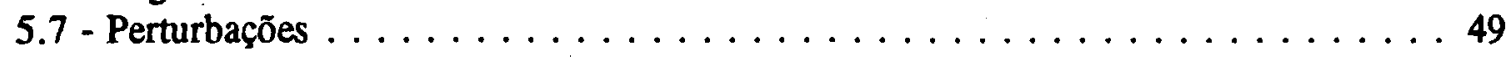

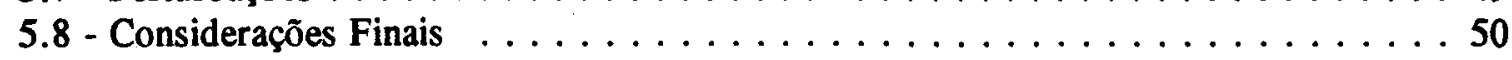

Capítulo 6 - Aproximação de Superfícies Definidas Implicitamente $\ldots \ldots \ldots \ldots \ldots \ldots$

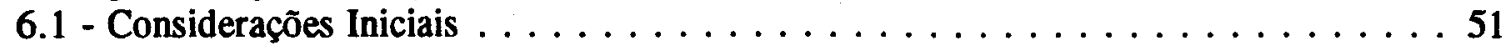

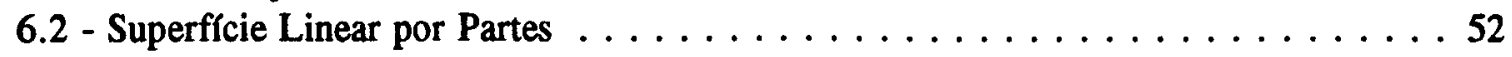

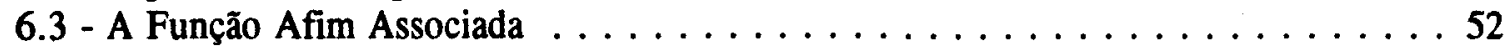

6.4 - Aproximação LP de F . . . . . . . . . . . . . . . . . 53

6.5 - Aproximação LP de Superfícies Definidas Implicitamente . . . . . . . . . . 54

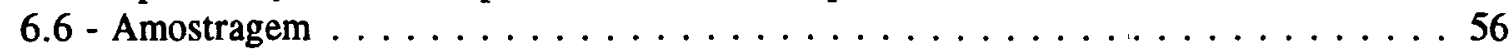

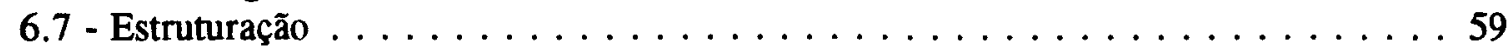

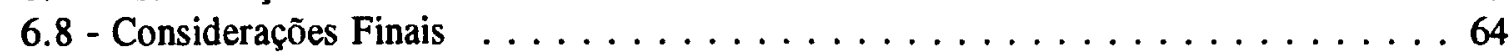

Capítulo 7 - o Procedimento de Conversão $\ldots \ldots \ldots \ldots 5$

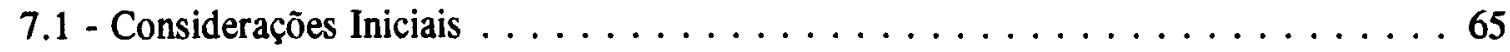

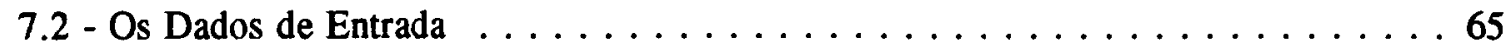

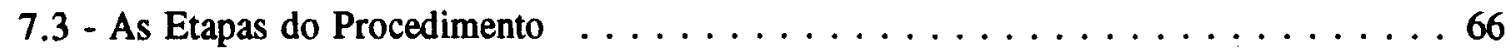

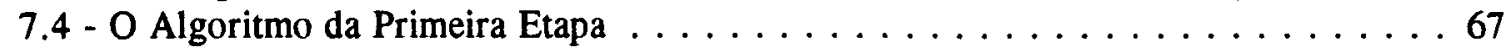

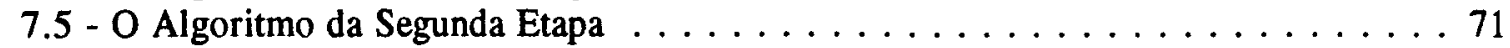

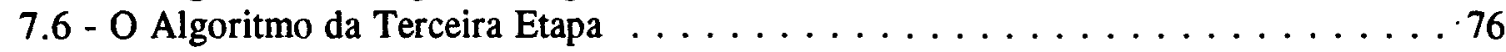

7.7 - O Algoritmo da Quarta Etapa . . . . . . . . . . . . . . . 80

7.8 - A Sequência de Operadores de Euler . . . . . . . . . . . . . 81

7.9 - Exemplos de Modelos Gerados no $(\mathbf{S M})^{2} \ldots \ldots \ldots \ldots$. . . . . . . . 87

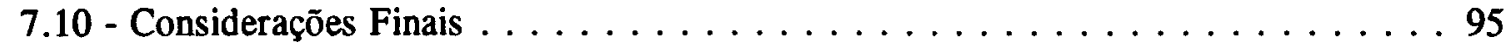

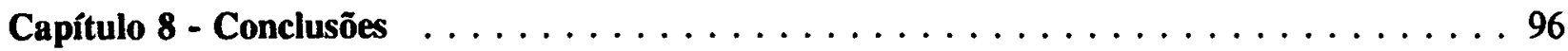

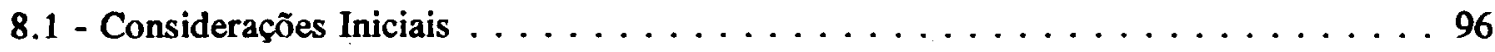

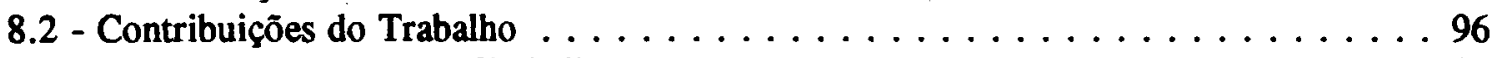

8.3 - Sugestões para Futuros Trabalhos . . . . . . . . . . . . . . . 97

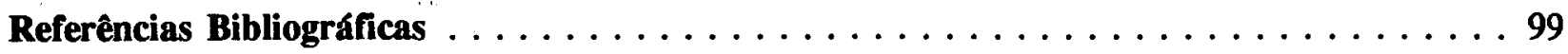




\section{Lista de Figuras}

Figura 2.1: representação wireframe de um modelo de sólido $\ldots \ldots \ldots \ldots \ldots \ldots$

Figura 2.2: subconjunto do $\mathbf{R}^{3}$ regular, compacto e conexo que não corresponde ao modelo de

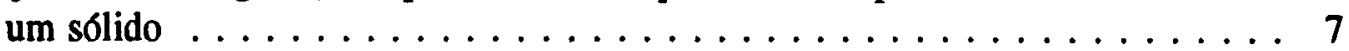

Figura 2.3: representação por decomposição de um sólido abstrato $\ldots \ldots \ldots \ldots \ldots \ldots$

Figura 2.4: representação $C S G$ de um sólido abstrato $\ldots \ldots \ldots \ldots \ldots \ldots \ldots \ldots$

Figura 2.5: BRep de um sólido abstrato $\ldots \ldots \ldots \ldots \ldots \ldots \ldots \ldots \ldots$

Figura 2.6: varredura rotacional e varredura translacional $\ldots \ldots \ldots \ldots \ldots \ldots \ldots \ldots$

Figura 2.7: operação local de arredondamento $\ldots \ldots \ldots \ldots \ldots \ldots \ldots \ldots \ldots \ldots$

Figura 2.8: arquitetura com representação principal $C S G \ldots \ldots \ldots \ldots \ldots \ldots$

Figura 2.9: arquitetura com a $B R e p$ como representação principal $\ldots \ldots \ldots \ldots \ldots \ldots$

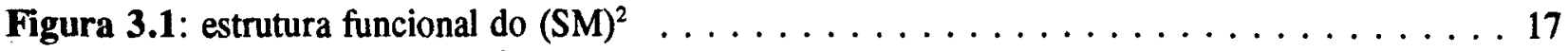

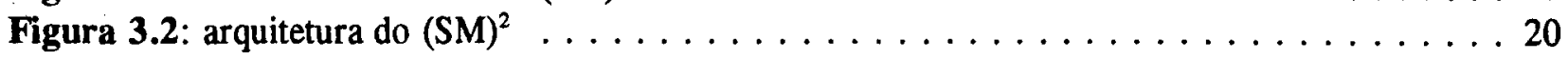

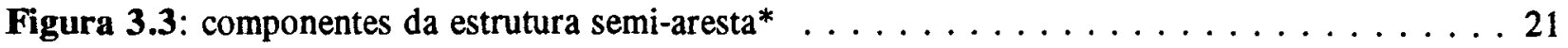

Figura 3.4: ação dos operadores de Euler MVFSS, MEV, MEF, KEMR e KFMRH . . . . . 22

Figura 3.5: fluxo de dados durante o processo de modelagem do $(\mathrm{SM})^{2} \ldots \ldots \ldots \ldots$

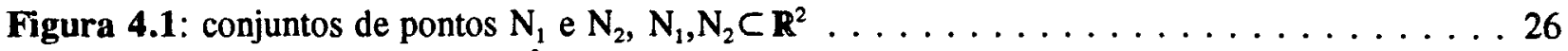

Figura 4.2: o conjunto $N_{1}, N_{1} \subset \mathbf{R}^{2}$, com interior desconexo $\ldots \ldots \ldots \ldots \ldots \ldots$

Figura 4.3: sólidos abstratos descritos por: (a) F, D e "<" e (b) F, D e " > " . . . . . . 28

Figura 4.4: 0 conjunto $N_{U}=N_{1} \cup N_{2}, N_{1}, N_{2} \subset \mathbb{R}^{2}$, obtido através de $F_{U} \ldots \ldots \ldots \ldots$

Figura 4.5: o conjunto $N_{n}=N_{1} \cap N_{2}, N_{1}, N_{2} \subset R^{2}$, obtido através de $F_{n} \ldots \ldots \ldots \ldots$

Figura 4.6: sólidos abstratos com interior dado por: (a) " $<"$ e (b) " > . . . . . . . . . 30

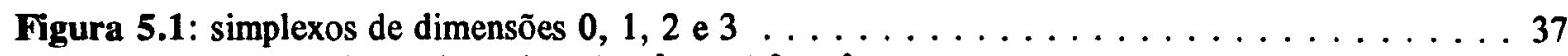

Figura 5.2: a triangulação $C F K$ do cubo $\mathrm{I}^{2}=[0,1]^{2} \subset \mathbf{R}^{2} \ldots \ldots \ldots \ldots \ldots \ldots$

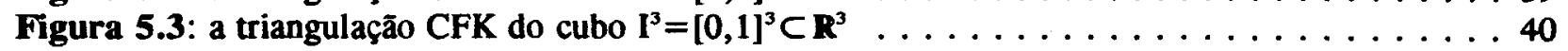

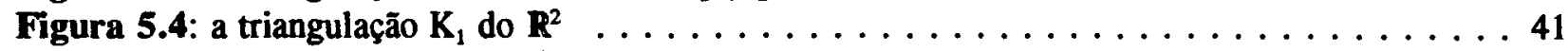

Figura 5.5: a triangulação $\mathrm{J}_{1}$ do $\mathbf{R}^{2} \ldots \ldots \ldots \ldots \ldots \ldots \ldots \ldots \ldots \ldots \ldots \ldots \ldots \ldots \ldots$

Figura 5.6: decomposição de $D \subset R^{2}$ definida por $v^{c}$ e $v^{f} \operatorname{com} K=(4,3) \ldots \ldots \ldots \ldots$

Figura 5.7: rotulagem dos blocos da subdivisão de $D \subset \mathbf{R}^{2} \operatorname{com} K=(4.3) \ldots \ldots \ldots \ldots$

Figura 5.8: simplexos $\sigma_{1}=K_{1}(1,2), \sigma_{2}=K_{1}(6,1)$ e $\sigma_{3}=K_{1}(8,1)$ de $K_{1}(D, K), D \subset R^{2}$ e $K=(4,3) \ldots 45$

Figura 5.9: simplexos $\sigma_{1}=\mathrm{J}_{1}(1,2), \sigma_{2}=\mathrm{J}_{1}(6,1)$ e $\sigma_{3}=\mathrm{J}_{1}(8,1)$ de $\mathrm{J}_{1}(\mathrm{D}, \mathrm{K}), \mathrm{D} \subset \mathrm{R}^{2}$ e $\mathrm{K}=(4,3) \ldots . .46$

Figura 5.10: exemplo de regras de pivoteamento das triangulações $K_{1}$ e $J_{1}$ do $R^{2} \ldots \ldots \ldots$

Figura 5.11: as triangulaçōes $K_{1}$ e $J_{1}$ do $R^{2}$ perturbadas $\ldots \ldots \ldots \ldots \ldots \ldots$

Figura 6.1: células de dimensão: (a) 2 , (b) 1 e (c) 0 , resultantes de $F_{T}{ }^{-1}(0) \cap \sigma \ldots \ldots \ldots 5$

Figura 6.2: superfícies $L P$ resultantes das triangulações $K_{1}$ e $J_{1}$ de $D \ldots \ldots \ldots \ldots 7$

Figura 6.3: aproximação de fronteira constiturda por $S=F^{-1}(0)$ e parte de $\partial(D) \ldots \ldots \ldots 7$

Figura 6.4: as duas possíveis células de dimensão 2 resultantes de $\sigma \cap S_{\mathrm{T}} \ldots \ldots \ldots$ 
Figura 6.5: aproximação com o auxfico do método regula falsi $\ldots \ldots \ldots \ldots \ldots \ldots \ldots$

Figura 6.6: exemplos de interseção $\sigma \cap S$ quando $S$ não é transversal ao interior de $\sigma \ldots \ldots 59$

Figura 6.7: organização hierárquica das informações nos nós da árvore $\ldots \ldots \ldots \ldots$

Figura 6.8: simplexo $\sigma$ de dimensão 3 com rótulo $l(\sigma)=(0,1,3,7) \ldots \ldots \ldots \ldots$

Figura 6.9: organização das informações do nó contendo a face da figura $6.8 \ldots \ldots \ldots$. . . 61

Figura 6.10: simplexo $\sigma$ de dimensão 2 com rótulo $l(\sigma)=(0,1,3) \ldots \ldots \ldots \ldots \ldots$

Figura 6.11: organização das informações do nó contendo a face da figura $6.10 \ldots \ldots$. . . . 63

Figura 6.12: face "recortada" identificada pelo rótulo $l(\sigma)=(0,1,3)$ de um simplexo $\sigma$ de

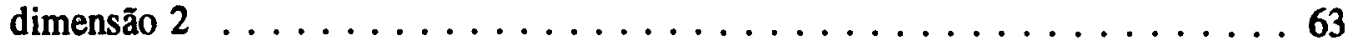

Figura 6.13: organização das informações do nó contendo a face da figura $6.12 \ldots \ldots \ldots 4$

Figura 7.1: modelo cuja fronteira possui duas componentes conexas de $S=F^{-1}(0) \ldots \ldots$. . . 74

Figura 7.2: o processo de "colagem de duas componentes conexas $\ldots \ldots \ldots \ldots \ldots \ldots$

Figura 7.3: modelo cuja fronteira possui duas componentes, uma externa e outra interna. . . . . 76

Figura 7.4: processo de classificação de componentes em $\mathbf{R}^{2} \ldots \ldots \ldots \ldots \ldots 77$

Figura 7.5: superfície com fronteira representada na estrutura semi-aresta* $\ldots \ldots \ldots \ldots$. . . 82

Figura 7.6: colagem de faces com: (a) uma, (b) duas e (c) três arestas pertencentes à

componente ...................... 83

Figura 7.7: junção de duas listas de arestas de fronteira $\ldots \ldots \ldots \ldots \ldots \ldots$

Figura 7.8: componente resultante da "colagem" de duas componentes $\ldots \ldots \ldots \ldots \ldots$

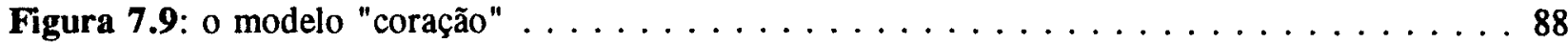

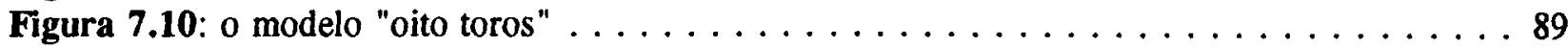

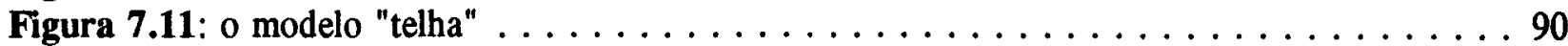

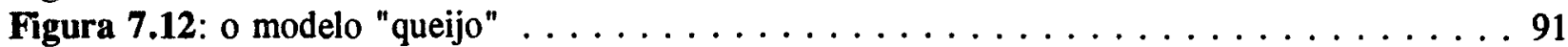

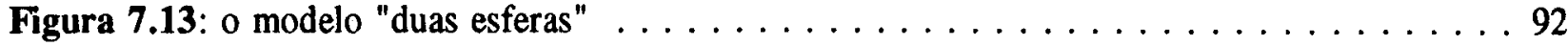

Figura 7.14: o modelo "duas esferas deslocadas" $\ldots \ldots \ldots \ldots \ldots \ldots \ldots \ldots \ldots \ldots$

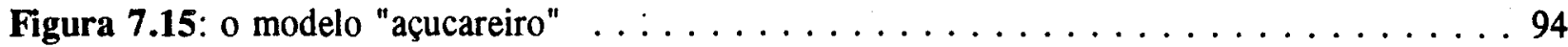




\section{Lista de Quadros}

Quadro 3.1: primitivas para instanciamento disponfveis no $(\mathrm{SM})^{2} \ldots \ldots \ldots \ldots$

Quadro 4.1: gramática livre de contexto para expressões lógicas $\ldots \ldots \ldots \ldots \ldots \ldots \ldots$

Quadro 4.2: gramática livre de contexto para expressões numéricas $\ldots \ldots \ldots \ldots \ldots \ldots \ldots$

Quadro 4.3: gramática livre de contexto para expressões logicas na forma pós-fixa . . . . . . 33

Quadro 4.4: gramática livre de contexto para expressões númericas na forma pós-fixa $\ldots \ldots \ldots 34$

Quadro 7.1: trecho correspondente à primeira etapa do algoritmo do procedimento de

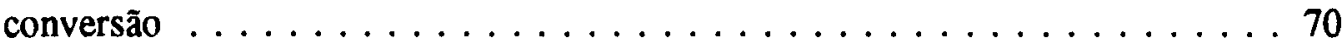

Quadro 7.2: trecho correspondente à segunda etapa do algoritmo do procedimento de conversão . . . . . . . . . . . . . . . . . . . 73

Quadro 7.3: trecho correspondente à terceira etapa do algoritmo do procedimento de conversão . . . . . . . . . . . . . . . . . . . . . . . . . 79

Quadro 7.4: trecho correspondente à quarta etapa do algoritmo do procedimento de conversão ...................... 81 


\section{Capítulo 1}

\section{Introdução}

\section{1 - Considerações Gerais}

Em geral, um modelo é uma entidade construfda artificialmente, contendo algumas (ou todas) as características de uma entidade real, a qual foi criada com o intuito de tornar possível, ou mais fácil, o estudo e observação da entidade real. O nível de detalhe e a quantidade de informações do modelo devem ser definidos com base nas necessidades impostas pelas aplicações que o utilizam. Muitos modelos são construídos, representados e manipulados adequadamente através de computador [Mä88].

Vários problemas estudados e solucionados através de modelos são inerentemente geométricos. Esta observação estimulou, a partir das duas últimas décadas, a produção de um número expressivo de pesquisas e publicações em modelagem geométrica, ou seja, métodos e sistemas voltados à construção, representação e manipulação, por computador, de modelos de objetos geométricos [ReRo92]. A modelagem geométrica faz uso de várias áreas como geometria, topologia e análise numérica. Sistemas computacionais capazes de modelar objetos geométricos constituem o núcleo central de ambientes de CAD/CAM (Computer Aided Design and Manufacture) [Re80].

A modelägem de sólidos é um ramo da modelagem geométrica que trata apenas da construção, representação e manipulação de modelos de objetos sólidos tridimensionais. Esta área de pesquisa surgiu para cobrir as limitações das técnicas de descrição e formas de representação existentes para criar e representar, respectivamente, modelos de sólidos [Re80]. Sistemas computacionais capazes de construir, representar e manipular modelos de sólidos são de grande interesse em arquitetura, construção civil, computação gráfica, visualização, visão computacional, CAD/CAM eletromecânico, entre outras áreas. Contudo, a tecnologia para a implementação de tais sistemas, em termos de hardware e software, é bastante complexa, havendo até hoje uma grande demanda por pesquisas em aspectos fundamentais, como pode ser constatado em [ReRo92], [Wo93].

As técnicas de descrição e os procedimentos de manipulação dos modelos são dependentes, quase que exclusivamente, da forma de representação utilizada. Entretanto, não existe uma forma de 
representação que suporte de maneira eficiente as principais técnicas de descrição disponíveis e seja a mais adequada para todos os tipos de aplicação. Isto fez com que os sistemas de modelagem de sólidos mais recentes adotassem mais de uma forma de representação para representar simultaneamente os modelos gerados [Mi89].

\section{2 - Motivação}

No âmbito do Instituto de Ciências Matemáticas de São Carlos (ICMSC) da Universidade de São Paulo (USP), está sendo desenvolvido um sistema computacional capaz de construir, representar e manipular modelos de sólidos, denominado Sistema de Modelagem de Sólidos Multi-representacional, $(\mathrm{SM})^{2}$, voltado para o ensino e pesquisa de tópicos em computação gráfica, visualização de objetos e CAD.

Em sua primeira versão operacional, o $(\mathrm{SM})^{2}$ possuía uma única forma de representação, a representação por fronteira, e os modelos podiam ser descritos através da técnica de varredura rotacional e translacional simples [Sc93]. A representação por fronteira é adequada, por exemplo, para aplicações como rendering de modelos e geração de instruções para máquinas de usinagem controladas numericamente. Entretanto, não suporta de forma eficiente a técnica de descrição CSG, uma das técnicas mais comuns de descrição de modelos de sólidos [Mi89].

Para permitir a representação de um número maior de modelos, bem como possibilitar que os procedimentos das aplicações que manipulam os modelos gerados sejam mais eficientes, foi proposta para o trabalho de Mestrado descrito nesta dissertação a integração da técnica de descrição por semi-espaços e da forma de representação implícita ao (SM) ${ }^{2}$. A forma de representação implícita possui características distintas da representação por fronteira, de modo que a coexistência dessas duas formas de representação amplia os benefícios potenciais do sistema. Muitos modelos possuindo geometria complexa podem ser descritos através da técnica de descrição por semi-espaços.

\section{3 - Descrição do Trabalho}

O desenvolvimento desse trabalho tornou possível a descrição de modelos de sólidos através de 
semi-espaços no $(\mathrm{SM})^{2}$. Os modelos descritos por semi-espaços são associados a representações implícitas que, posteriormente, são convertidas para as representações por fronteira correspondentes. Futuras aplicações baseadas nos modelos descritos por semi-espaços poderão optar entre a utilização da representação implícita ou da representação por fronteira desses modelos, conforme a conveniência.

A conversão da representação implícita para a representação por fronteira é realizada por um procedimento baseado em um método simplicial de aproximação de superfícies definidas implicitamente. Este método possibilita a geração das informações da representação por fronteira a partir dos dados disponíveis na representação implícita do modelo.

Esta dissertação descreve a técnica de descrição por semi-espaços e os procedimentos que viabilizaram sua implementação; apresenta o conteúdo e um procedimento de manipulação da representação implícita; discute o método simplicial no qual está baseado o procedimento de conversão; e descreve o algoritmo utilizado na implementação deste procedimento.

\section{4 - Organização da Dissertação}

O capítulo 2 contém uma introdução à modelagem de sólidos, com enfoque nas principais técnicas de descrição e formas de representação de modelos de sólidos, bem como nas arquiteturas de software dos sistemas de modelagem de sólidos existentes.

O capítulo 3 apresenta uma descrição do $(\mathrm{SM})^{2}$, que abrange a estrutura funcional e a arquitetura de software do sistema; bem como as técnicas de descrição de modelos disponfveis e a forma de representação por fronteira utilizada.

O capítulo 4 descreve a técnica de descrição de modelos por semi-espaços e a representação implícita utilizadas no $(\mathrm{SM})^{2}$. Também são descritos os procedimentos de implementação da técnica de descrição e um procedimento para manipular os dados da representação implícita.

O capítulo 5 aborda uma técnica de particionamento do espaço ambiente onde residem os modelos de sólidos representados na forma implícita. Esta técnica é utilizada pelo método de aproximação no qual está baseado o procedimento de conversão da representação implícita para a representação por fronteira.

O capítulo 6 apresenta o método simplicial de aproximação de superfícies definidas implicitamente, o qual gera os dados da representação por fronteira a partir da representação implícita 
do modelo.

O capítulo 7 descreve a implementação do procedimento de conversão da representação implícita para a representação por fronteira e, finalmente, o capítulo 8 conclui o trabalho, apresentando as suas contribuições e sugestões para futuras pesquisas. 


\section{Capítulo 2}

\section{Modelagem de Sólidos}

\section{1 - Considerações Iniciais}

Entende-se por modelagem a criação, representação e manipulação de objetos por computador. Denomina-se sistema de modelagem o sistema computacional capaz de modelar objetos [GoVe90]. $\mathrm{O}$ termo modelagem de sólidos compreende um conjunto de teorias e técnicas para a descrição e representação de objetos sólidos tal que a representação de cada modelo criado seja completa (não ambígua), isto é, contenha informações suficientes para permitir o cálculo automático de qualquer propriedade geométrica bem definida referente ao sólido modelado [Re80].

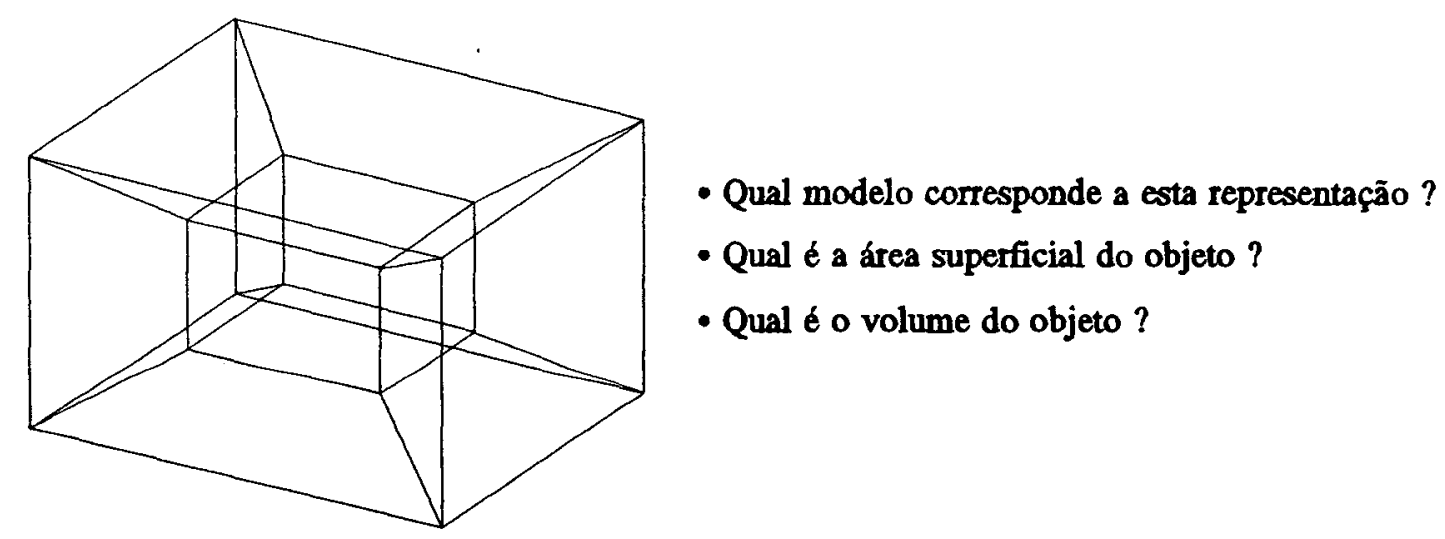

Figura 2.1: representação wireframe de um modelo de sólido

Denomina-se sistema modelador de sólidos (SMS) o sistema de modelagem de objetos sólidos. A modelagem através de um SMS envolve a criação, representação e manipulação de modelos de sólidos por computador. A criação do modelo é baseada em métodos geométricos e de análise numérica. A representação do modelo utiliza técnicas de estrutura de dados e topologia combinatória para armazenar o objeto modelado no computador. A manipulação do modelo é realizada por aplicações que têm por finalidade o estudo de propriedades do objeto modelado [GoVe90]. 
As primeiras pesquisas em modelagem de sólidos surgiram na metade dos anos 60 , tornando-se mais evidentes no início dos anos 70 , quando muitos grupos de pesquisa se estabeleceram nas principais nações industriais. As pesquisas foram motivadas pelo descontentamento, por parte de pesquisadores e usuários, com os sistemas de projeto e manufatura auxiliados por computador (Computer Aided Design and Manufacture - CAD/CAM) existentes até então e antecessores dos SMS's, que exigiam substancial intervenção do usuário na execução de tarefas de rotina [ReRo92].

O problema residia na utilização de uma forma de representação incompleta (ambígua) para os modelos de sólidos, conhecida como wireframe (fio de arame), isto é, a representação através de segmentos de reta [Fo90 et al.]. Esta representação não captura todas as informações geométricas do objeto modelado. Portanto, a maioria das questões geométricas sobre o sólido não podia ser respondida com base apenas nas informações contidas na representação (ver figura 2.1).

Este capítulo consiste em uma introdução à modelagem de sólidos e tem por finalidade auxiliar a leitura dos próximos capítulos, através da apresentação de conceitos básicos. Na seção 2.2 é apresentado o conceito de modelo de sólido, e na seção 2.3 são descritas as principais formas de representação existentes para modelos de sólidos. Na seção 2.4 , as técnicas mais comuns para descrever modelos de sólidos são abordadas. Na seção 2.5 são apresentadas as arquiteturas mais utilizadas nos modeladores de sólidos existentes.

\section{2 - Modelos de Sólidos}

Em modelagem de sólidos, os modelos são entidades matemáticas que possuem uma ligação intuitivamente clara com os objetos sólidos do mundo real e são denominados sólidos abstratos [Re80], [Mä88].

O espaço euclidiano tridimensional, $\mathbf{R}^{3}$, é uma idealização adequada do mundo real onde se encontram os objetos sólidos. Os sólidos abstratos podem ser vistos, então, como subconjuntos do $\mathbf{R}^{3}$. Isto não significa que todo subconjunto do $\mathbf{R}^{3}$ seja um sólido abstrato, isto é, capture a noção de "solidez" dos objetos sólidos do mundo real. Para que isso ocorra, tais subconjuntos devem satisfazer algumas restrições e propriedades, descritas a seguir.

Requicha ([Re80]) define um sólido abstrato como um subconjunto do $\mathbf{R}^{3}$ regular, compacto e conexo. Por conjunto regular entende-se um conjunto igual ao fecho de seu interior. Entretanto, nem 
todo subconjunto do $\mathbf{R}^{3}$ que satisfaz as restriçōes dessa definição corresponde ao modelo de um sólido (ver figura 2.2). Mäntylă ([Mä88]) propôs uma restrição adicional à definição anterior: a fronteira do modelo é uma superfície possuindo uma componente conexa. Um sólido abstrato também deve possuir a propriedade de invariância da forma independente de posição e orientação no espaço.

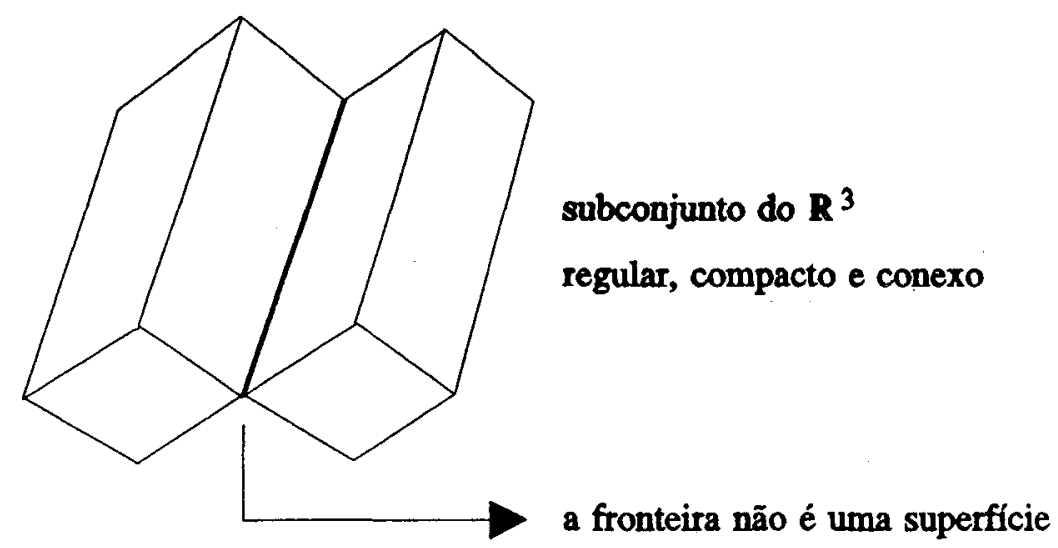

Figura 2.2: subconjunto do $\mathbf{R}^{3}$ regular, compacto e conexo que não corresponde ao modelo de um sólido

Um subconjunto do $\mathbf{R}^{3}$ regular, compacto e conexo cuja fronteira é uma superfície que possui uma componente conexa é um modelo de sólido, pois a restrição proposta por Mäntylä ([Mä88]) elimina os problemas da definição dada por Requicha ([Re80]). Entretanto, alguns subconjuntos do $\mathbf{R}^{3}$ regulares, compactos e conexos que correspondem a modelos de sólidos, como uma esfera sólida "oca", por exemplo, não satisfazem à restrição proposta por Mäntylä ([Mä88]), pois a fronteira possui mais de uma componente conexa. Portanto, propõe-se aqui uma definição mais completa: sólido abstrato é um subconjunto do $\mathbf{R}^{3}$ regular, compacto e conexo cuja fronteira é uma superfície possuindo uma ou mais componentes conexas, sendo cada componente topologicamente equivalente a uma esfera ou a um n-toro.

\section{3 - Formas de Representação}

Os modelos devem ser associados a uma estrutura simbólica passivel de ser armazenada e manipulada por computador, denominada representagão. Ao longo dos últimos vinte anos, formas de representação adequadas, isto é, completas, para sólidos abstratos foram desenvolvidas e podem ser 
agrupadas em três classes distintas: formas de representação por decomposição, formas de representação construtivas e formas de representação por fronteira [Re80], [Mä88], [GoVe90].

\subsection{1 - Representações por Decomposição}

Nas representações por decomposição, o sólido abstrato é descrito por sólidos abstratos mais simples, conhecidos como primitivas, que são combinados entre si através de uma operação denominada colagem (glue). A colagem une as primitivas sem que haja interseção entre elas. Cada primitiva representa uma parte do modelo. A figura 2.3 exemplifica um modelo representado por decomposição.

As formas de representação por decomposição mais conhecidas são enumeração espacial, octree e decomposição celular. Estas formas se diferenciam pelo tamanho, orientação e geometria das primitivas utilizadas. Modelos obtidos a partir de imagens médicas ou a serem analisados por métodos de elementos finitos são, geralmente, associados a representações por decomposição [Sh81], [Me82], [El78].

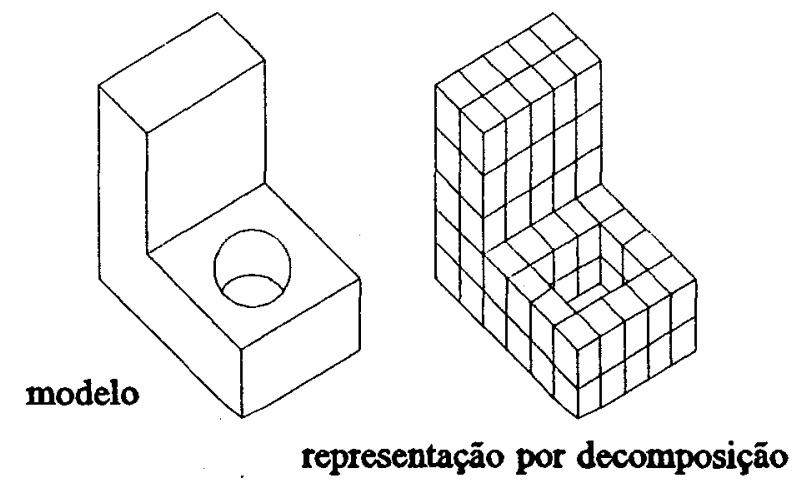

Figura 2.3: representação por decomposição de um sólido abstrato

\subsection{2 - Representações Construtivas}

Nas representações construtivas, o sólido abstrato é descrito por primitivas que são transformadas (operações de translação, rotação e escala) e combinadas entre si através de operações booleanas (união, interseção e diferença). 
A forma de representação construtiva mais comum é a Constructive Solid Geometry (CSG). A estrutura de dados associada à representação CSG é uma árvore binária onde os nós folhas correspondem às primitivas e os nós restantes indicam transformações ou operações booleanas [ReVo77]. A figura 2.4 ilustra uma representação $C S G$.
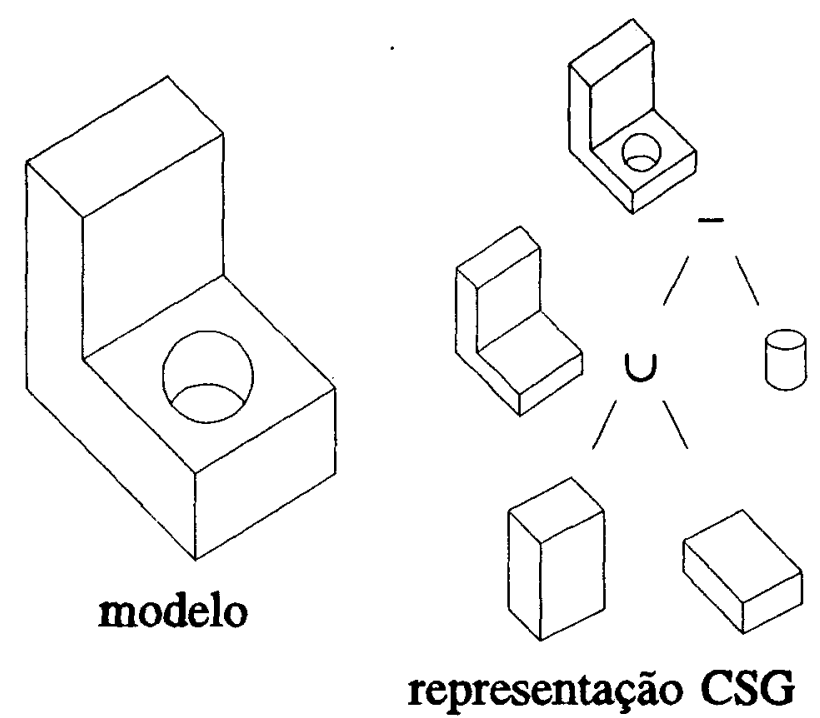

Figura 2.4: representação CSG de um sólido abstrato

As primitivas geralmente usadas são esferas, cones, elipsóides, cilindros, toros e cubos. O conjunto das primitivas disponíveis pode conter um número maior de elementos, dependendo da maneira como as primitivas são definidas. Quanto maior o número de primitivas disponíveis, maior será o poder descritivo do modelador, ou seja, a quantidade de sólidos que podem ser modelados.

As representações construtivas são adequadas para operações de análise que requerem uma classificicação de outros objetos como estando dentro, fora ou sobre o modelo analisado. Por exemplo, a classificação de uma linha em relação ao modelo é necessária para o cálculo de propriedades de massa como volume e momento de inércia, e também para a geração de imagens realísticas [Mi89].

\subsection{3 - Representações por Fronteira}

Na representação por fronteira (boundary representation - BRep), o sólido abstrato é descrito em termos de sua fronteira, comumente descrita como a união disjunta de superfícies (faces), que são 
limitadas por curvas (arestas), que por sua vez se interceptam em pontos (vértices) [Mä88]. A figura 2.5 exemplifica uma representação por fronteira.

Uma $B R e p$ descreve explicitamente a geometria e a topologia da fronteira dos sólidos abstratos, isto $e$, possui informações explícitas sobre a forma das diversas superfícies (faces), curvas (arestas) e pontos (vértices) que compõem a fronteira, bem como as relações de adjacência entre estas entidades. A BRep é adequada para operações que necessitam percorrer a fronteira do modelo, tal como a geração de instruções para uma máquina de usinagem controlada numericamente [Mi89].

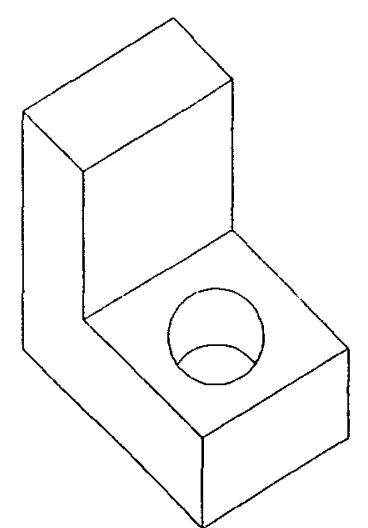

modelo

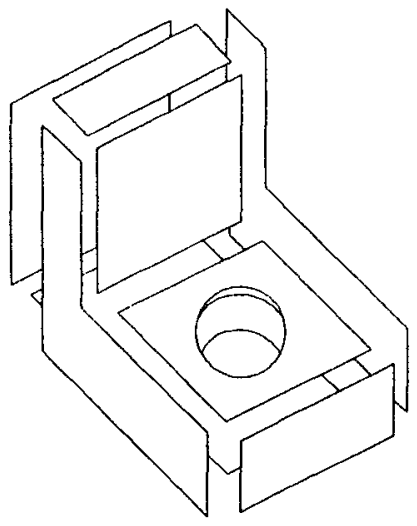

BRep

Figura 2.5: BRep de um sólido abstrato

\section{4 - Técnicas de Modelagem}

Denomina-se técnicas de modelagem as técnicas usadas para descrever modelos [GoVe90]. As técnicas de modelagem são dependentes, quase que exclusivamente, da forma de representação utilizada. Por isso, é bastante comum encontrar SMS's capazes de criar modelos complexos usando determinadas técnicas, mas que são limitados na criação de modelos simples para os quais as representações disponíveis não são adequadas [Fi91].

A técnica de modelagem por instanciamento de primitivas é uma das formas mais simples de descrição de modelos. A primitiva é definida por alguns parâmetros específicos, tais como centro e raio no caso de uma esfera, e um sólido abstrato é gerạdo através da atribuição de valores aos parâmetros. 
Os próprios parâmetros constituem uma representação para a primitiva [Re80], [Mä88].

A varredura (sweeping) constitui uma técnica de modelagem que descreve um sólido abstrato através de uma face planar fechada e uma trajetória não coplanar a face. Os tipos mais comuns de varredura são: a rotacional e a translacional (ver figura 2.6). Na varredura rotacional, a face planar é rotacionada em torno de um eixo arbitrário segundo a trajetória escolhida e o modelo equivale ao conjunto de pontos "varridos" durante a rotação. Na varredura translacional, a face planar é transladada de acordo com a trajetória escolhida [Ca90]. A técnica de varredura é apropriada para a BRep, mas também pode ser implementada em modeladores baseados em CSG [HuTa92].

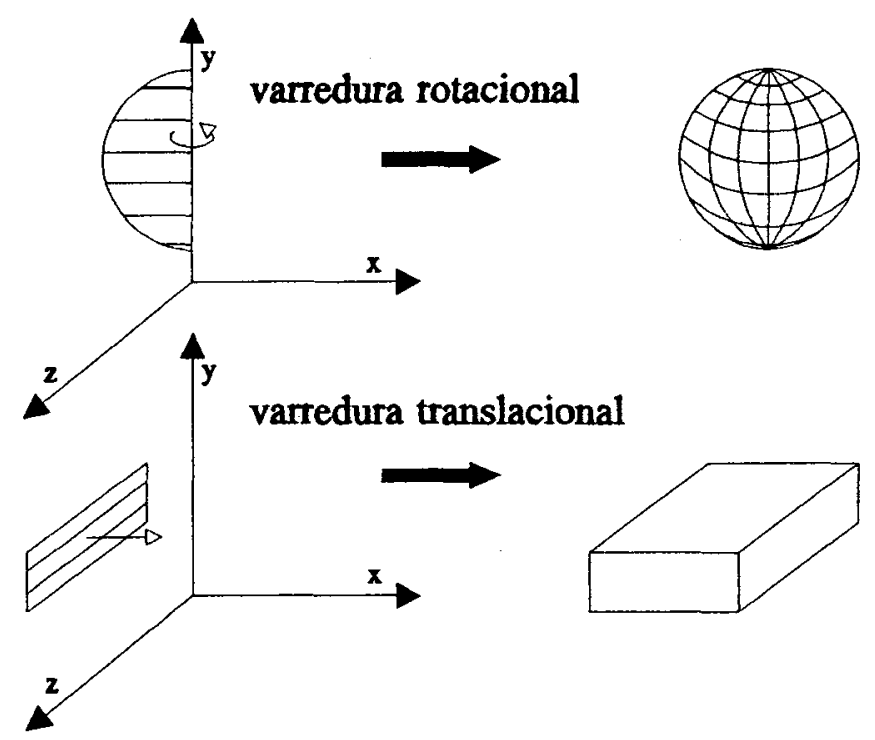

Figura 2.6: varredura rotacional e varredura translacional

A CSG constitui-se também em uma técnica de modelagem que utiliza operações booleanas, denominadas operações globais, para descrever os sólidos abstratos. Esta técnica é inerente aos modeladores com representação CSG, mas pode ser utilizada juntamente com outras formas de representação desde que estas supòrtem operações booleanas, como acontece com as representações octree e BRep [Mä88].

Outra forma de descrever modelos de sólidos é através de semi-espaços. Um semi-espaço pode ser visto como um subconjunto do $\mathbf{R}^{3}$ associado a uma função, denominada função característica, que determina se um dado ponto do $\mathbf{R}^{3}$ pertence ou não ao semi-espaço. Semi-espaços podem ser combinados através de operações booleanas para descrever sólidos abstratos assim como na técnica CSG. Um semiespaço pode ser um subconjunto ilimitado e não corresponder a um solido abstrato, de forma que os 
modeladores baseados em semi-espaços devem possuir procedimentos de validação da descrição dos modelos [Mä88].

As operações locais, operações que atuam sobre partes específicas de um único modelo, também constituem uma técnica de modelagem. Isso porque um modelo pode ser descrito grosseiramente por outra técnica e ter detalhes sutis de sua geometria descritos através delas (ver figura 2.7). A BRep favorece o uso de operações locais, ao contrário das representações por decomposição e construtivas [Mä88].

As superfícies B-Splines são bastante convenientes para a descrição de sólidos abstratos com geometria "escultural" [CaCl78], [ChGr84], [Ba87 et al.]. Além disso, os modelos podem ser visualizados facilmente. Os pontos da malha de controle utilizada para definir uma superfície oferecem uma representação alternativa e compacta. Algumas operações locais podem ser implementadas com o aux nlio de superfícies $B$-Splines [Ch88]. Entretanto, garantir a validade dos sólidos abstratos descritos através de superfícies $B$-Splines não é uma tarefa trivial [Mi86].

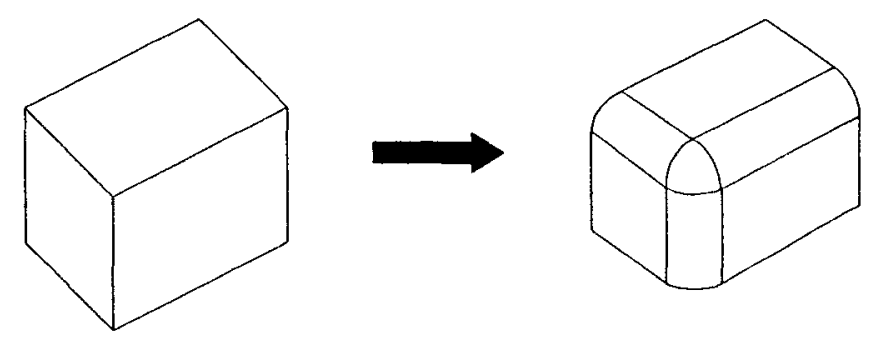

arredondamento

Figura 2.7: operação local de arredondamento

O conjunto de primitivas disponiveis em modeladores baseados em CSG pode ser descrito e representado através de superfícies B-Splines a fim de ampliar o poder de descrição [Sa87 et al]. Entretanto, a representação $C S G$ se tornará menos eficiente para a implementação de suas aplicações mais usuais, aquelas baseadas no procedimento de classificação de entidades geométricas em relação às primitivas. Isso porque a representação das primitivas por superfícies $B$-Splines não é adequada para este procedimento [Ho93].

Os SMS's voltados para CAD/CAM disponiveis no mercado utilizam, principalmente, técnicas de varredura e operações locais. As operações globais foram substituídas por operações de mais alto nível, tais como "perfurar" uma peça, que são mais familiares aos usuários e, na verdade, são definidas 
internamente como sequências de operações globais e locais [Ma93], [Ki94].

\section{5 - Sistemas Mistos}

Nenhuma das três classes de representação apresentadas na seção 2.3 é melhor do que as outras duas se considerados os modelos que podem ser representados, as técnicas de modelagem suportadas e a eficiência dos procedimentos de manipulação. Isto motivou o surgimento de sistemas de modelagem de sólidos mistos (SMSM), ou seja, sistemas que convivem com mais de uma forma de representação [Mi89], [Fi91]. Os sistemas mistos podem ser classificados em sistemas híbridos e sistemas multirepresentacionais [GoVe90].

Nos sistemas híbridos, as várias formas de representação do modelo convivem simultaneamente e tanto a criação quanto a manipulação do modelo podem ser realizadas em qualquer das representações. Nos sistemas multi-representacionais, tem-se uma representação principal do modelo, e uma ou mais representações secundárias. Estas representações alternativas são utilizadas para resolver problemas específicos que não afetam a estrutura do modelo ou para criar modelos através de uma técnica de modelagem apropriada a uma destas representações.

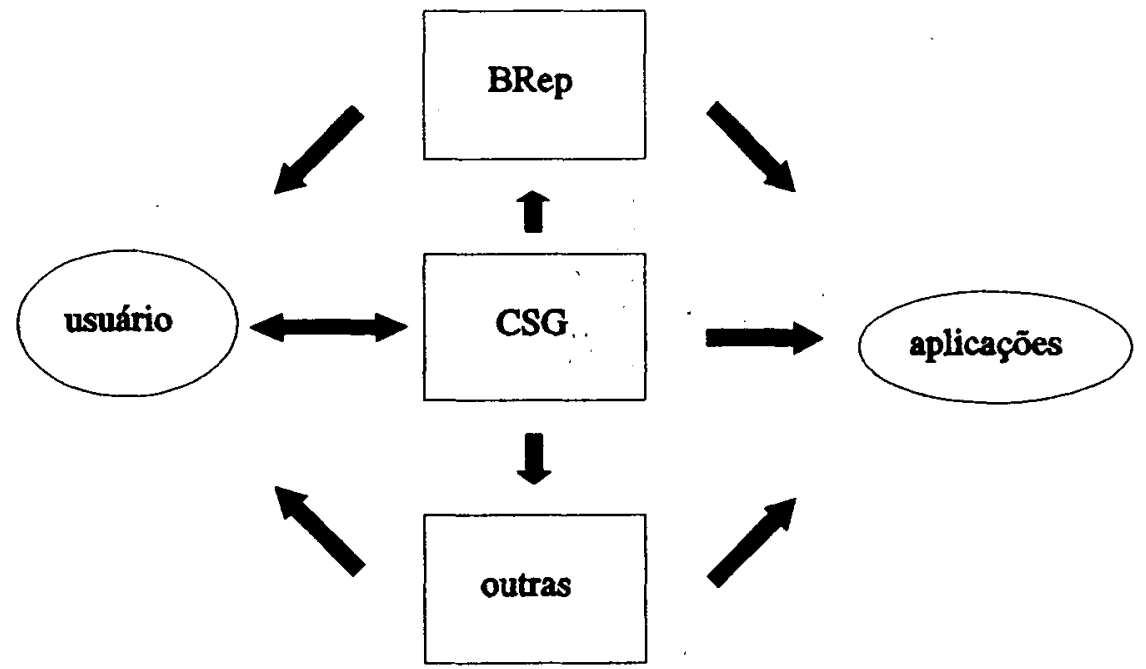

Figura 2.8: arquitetura com representação principal CSG

Os sistemas híbridos devem possuir procedimentos bidirecionais de conversão entre representações 
a fim de garantir que as operações realizadas sobre uma determinada representação sejam refletidas nas demais e vice-versa. Entretanto, ainda não existem algoritmos de conversão entre todas as representações conhecidas. Por exemplo, são conhecidos os procedimentos para converter uma representação CSG para uma BRep ([ReVo85]), enquanto que o procedimento inverso é restrito a alguns modelos simples [ShVo93].

Os sistemas multi-representacionais necessitam apenas de conversão unidirecional, pois somente a representação principal deve ser mantida consistente. A conversão ocorre quando um modelo é gerado em uma forma de representação secundária ou quando uma representação secundária precisa ser gerada a partir da representação principal para ser consultada por algum procedimento de manipulação.

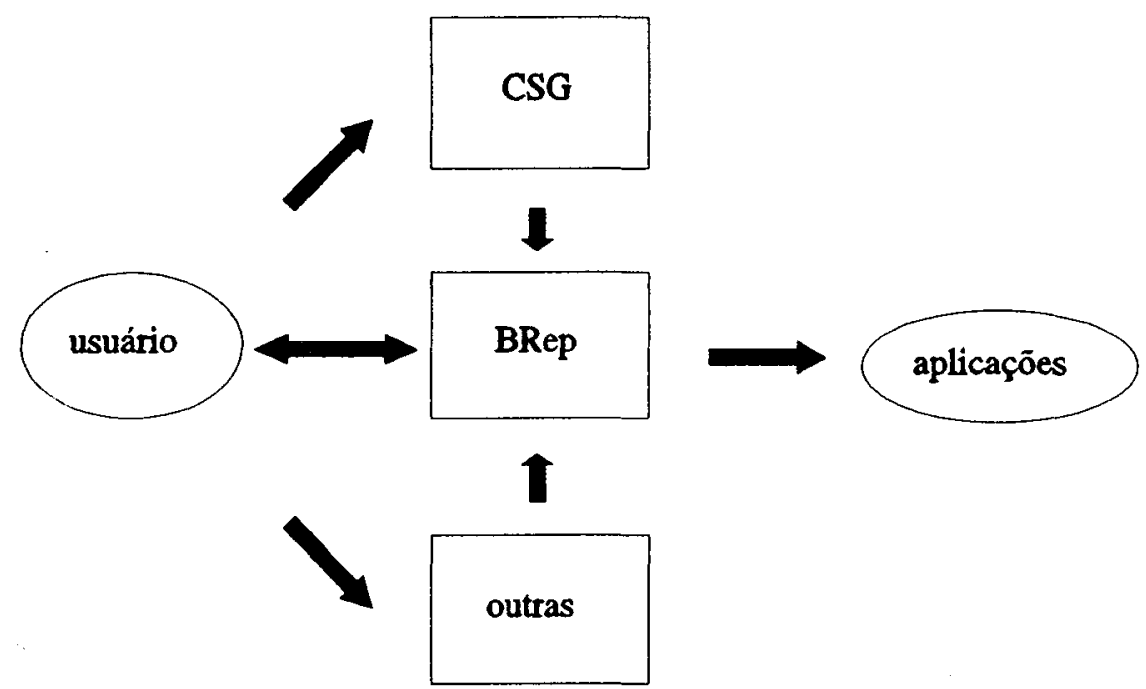

Figura 2.9: arquitetura com a BRep como representação principal

A arquitetura dos SMS's não tem se modificado significativamente nos últimos anos [ReR092]. Há modeladores com forma de representação principal CSG e secundária BRep (ver figura 2.8), e modeladores que utilizam uma BRep como representação principal e outras formas secundárias com o propósito de criação de modelos (ver figura 2.9). Muitos modeladores também utilizam representações octree para acesso por aplicações de análise do modelo.

A importância dos sistemas mistos reside exatamente na possibilidade de optar por uma determinada forma de representação que seja mais adequada para descrever ou analisar um determinado modelo. O problema do desconhecimento de um algoritmo universal de conversão entre as diversas formas de representação existentes impede a implementação de uma arquitetura ideal, na qual múltiplas 
formas de representação são mantidas, sempre de forma consistente [Mi89].

Avanços recentes em hardware dedicado provavelmente exercerão forte influência na arquitetura de futuros sistemas [ReRo92]. Alguns projetos apresentados na literatura disponível são: uma máquina processadora de voxels [Ka90], hardware para realizar operações e rendering sobre representações octree [Me84] e hardware que utiliza paralelismo em alta escala para o traçado de raios em representações CSG [RoTu91]. Hardware especial para rendering de polígonos é encontrado na maioria das estações gráficas mais avançadas disponíveis no mercado.

\section{6 - Considerações Finais}

Neste capítulo foram apresentados os conceitos de modelagem e modelos de sólidos, bem como as principais formas de representação, agrupadas em três classes: formas de representação por decomposição, formas de representação construtivas e formas de representação por fronteira. Foram introduzidas também as técnicas de modelagem por instanciamento de primitivas, por varredura, por semi-espaços, CSG, por operações locais e por superfícies $B$-Splines, e também as arquiteturas mais utilizadas nos modeladores de sólidos existentes.

Dentre as formas de representação existentes, conclui-se que não existe uma melhor do que todas as outras se considerados os modelos que podem ser representados, as técnicas de modelagem suportadas e a eficiência dos procedimentos das aplicações. Isto fez com que a arquitetura dos modeladores de sólidos evoluísse, permitindo a coexistência de mais de uma forma de representação os modelos gerados. Entretanto, uma arquitetura ideal, reunindo todas as formas de representação existentes, ainda não é viável devido à inexistência de um algoritmo de conversão universal, como discutido na seção anterior.

No capítulo 3 é descrito o (SM) $)^{2}$, um modelador de sólidos multi-representacional em desenvolvimento no ICMSC-USP cuja forma de representação principal é a BRep, e que suporta diferentes técnicas de modelagem. 


\section{Capítulo 3}

\section{O (SM) $)^{2}$}

\section{1 - Considerações Iniciais}

$\mathrm{O}(\mathrm{SM})^{2}$, Sistema de Modelagem de Sólidos Multi-representacional, é um modelador de sólidos em desenvolvimento no Instituto de Ciências Matemáticas de São Carlos (ICMSC) da Universidade de São Paulo (USP). O modelador está sendo implementado na linguagem $\mathrm{C}$, utilizando o sistema de janelas XWindow e seu toolkit XView [He91], em uma estação de trabalho Sparc 2 da Sun Microsystems.

Em sua primeira versão operacional, o (SM) ${ }^{2}$ era dotado de uma única forma de representação, a BRep. Os sólidos abstratos eram descritos por varredura rotacional e translacional simples e visualizados através do desenho das arestas de sua fronteira, sem nenhum recurso adicional para uma visualização mais "realística" [Sc93].

$\mathrm{O}(\mathrm{SM})^{2}$ possui, atualmente, uma arquitetura multi-representacional cuja representação principal é a BRep e a única representação secundária é a representação implícita, que é uma forma de representação construtiva. A coexistência das formas de representação implícita e por fronteira exigiu a implementação de um procedimento de conversão da representação implícita para a BRep. As técnicas de modelagem disponíveis são instanciamento de primitivas, vários tipos de varredura rotacional e translacional, e semi-espaços. Alguns procedimentos para visualização realística estão operacionais [Ma94a et al.].

Neste capítulo, são apresentadas a estrutura funcional do (SM) (seção 3.2) e as técnicas de modelagem disponíveis (seção 3.3). A arquitetura do software do sistema (seção 3.4), a forma de representação principal (seção 3.5), o processo de modelagem (seção 3.6) também são introduzidos.

\section{2 - A Estrutura Funcional}

$\mathrm{O}(\mathrm{SM})^{2}$ é composto por cinco módulos funcionais: o módulo de comunicação (interface), o 
módulo de modelagem, o módulo de representação, o módulo de visualização e o módulo gerenciador de arquivos, como mostrado na figura 3.1.

O módulo de comunicação é constituído por um conjunto de procedimentos que manipulam uma interface gráfica através da qual o usuário interage com o $(\mathrm{SM})^{2}$. As tarefas a serem realizadas pelo modelador são descritas através da interface e capturadas pelos procedimentos deste módulo que ativam procedimentos de outros módulos responsáveis por suas execuções. Os resultados das tarefas são recebidos pelos procedimentos do módulo de comunicação e exibidos por estes através da interface.

$\mathrm{O}$ módulo de modelagem contém os procedimentos que interpretam as descrições de um novo modelo ou de uma modificação (através das técnicas de modelagem disponíveis no (SM) ${ }^{2}$ ), e a seguir acionam os procedimentos do módulo de representação para criar ou alterar, respectivamente, uma representação. O procedimento de conversão da representação implícita para a Brep faz parte, também, do módulo de modelagem.

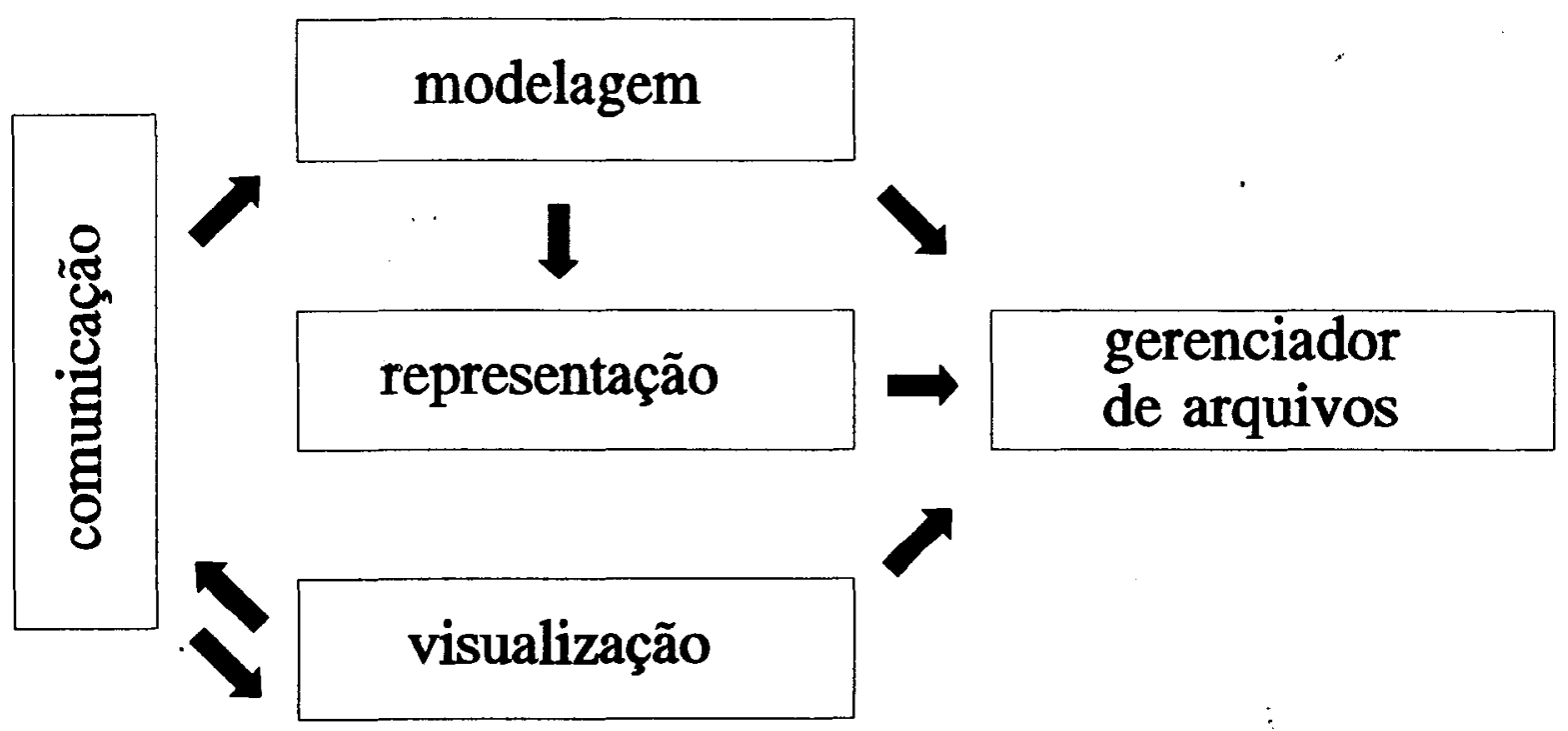

Figura 3.1: estrutura funcional do (SM)

O módulo de representação é formado pelos procedimentos que criam e modificam as representações dos sólidos abstratos. Cada forma de representação do $(\mathrm{SM})^{2}$ possui uma estrutura de dados e procedimentos especificos de manipulação da estrutura. As informações das representações são lidas por procedimentos de outros módulos, mas são criadas e modificadas apenas pelos procedimentos do módulo de representação.

O módulo de visualização é constituído por procedimentos que permitem exibir de forma realística 
os sólidos abstratos representados pelo (SM) ${ }^{2}$. Este módulo se encontra em fase de desenvolvimento e estão disponíveis procedimentos para realizar transformações geométricas (rotação, translação e alteração de escala), projeção perspectiva, projeção paralela e iluminação usando o modelo constant shading [Fo90 et al.]. Recursos mais elaborados, tais como iluminação usando o modelo Phong shading, transparência, sombreamento e textura, estão previstos [Ce94].

\begin{tabular}{|c|c|c|c|c|c|}
\hline \multirow[t]{2}{*}{ Primitiva } & \multicolumn{2}{|c|}{ Forma } & \multicolumn{3}{|c|}{ Preenchimento } \\
\hline & Reta & Oblíqua & Maciço & Oco & Vazado \\
\hline Bloco & & & & & \\
\hline Cubo & $X$ & & $\mathbf{X}$ & $X$ & $\mathrm{X}$ \\
\hline Ortoedro & $X$ & $X$ & $\mathrm{X}$ & $\mathrm{X}$ & $X$ \\
\hline Romboedro & $\mathrm{X}$ & $\mathrm{X}$ & $\mathrm{X}$ & $\mathrm{X}$ & $\mathrm{X}$ \\
\hline Trapezoide & $\mathrm{X}$ & $\mathrm{X}$ & $X$ & $\mathrm{X}$ & $X$ \\
\hline Paralelepípedo & $X$ & $X$ & $\mathrm{X}$ & $\mathrm{X}$ & $X$ \\
\hline Prisma & & & & & \\
\hline Regular inscrito & $\mathrm{X}$ & $X$ & $\mathbf{X}$ & $\mathrm{X}$ & $X$ \\
\hline Regular circunscrito & $\mathrm{X}$ & $X$ & $\mathbf{X}$ & $\mathrm{X}$ & $\mathbf{X}$ \\
\hline Qualquer & $\mathrm{X}$ & $\mathrm{X}$ & $\mathrm{X}$ & $\mathrm{X}$ & $\mathrm{X}$ \\
\hline Pirâmide (e tronco) & & & $X$ & $\mathrm{X}$ & $\mathrm{X}$ \\
\hline Regular inscrita & $\mathrm{X}$ & $\mathrm{X}$ & $X$ & $\mathrm{X}$ & $X$ \\
\hline Regular circunscrita & $\mathrm{X}$ & $\mathrm{X}$ & $\mathrm{X}$ & $\mathrm{X}$ & $\mathrm{X}$ \\
\hline Qualquer & $\mathrm{X}$ & $\mathrm{X}$ & $\mathrm{X}$ & $\mathrm{X}$ & $\mathrm{X}$ \\
\hline Cilindro & & & & & \\
\hline Convencional & $X$ & $\mathrm{X}$ & $\mathbf{X}$ & $\mathbf{X}$ & $\mathbf{X}$ \\
\hline Elíptico & $\mathrm{X}$ & $\mathrm{X}$ & $\mathrm{X}$ & $\mathrm{X}$ & $\mathrm{X}$ \\
\hline Cone (e tronco) & & & & & \\
\hline Convencional & $\mathrm{X}$ & $\mathrm{X}$ & $\mathbf{X}$ & $\mathrm{X}$ & $\mathrm{X}$ \\
\hline Eliptico & $\mathbf{X}$ & $\mathrm{X}$ & $\mathbf{X}$ & $\mathbf{X}$ & $\mathbf{x}$ \\
\hline Esfera & & & $\mathbf{X}$ & $\mathbf{X}$ & \\
\hline $\begin{array}{l}\text { Toro } \\
\text { Convencional } \\
\text { Elíptico }\end{array}$ & & & $\begin{array}{l}X \\
X\end{array}$ & $\begin{array}{l}\mathrm{X} \\
\mathrm{X}\end{array}$ & \\
\hline
\end{tabular}

Quadro 3.1: primitivas para instanciamento disponíveis no (SM)

O módulo gerenciador de arquivos contém os procedimentos que manipulam os arquivos utilizados pelo $(\mathrm{SM})^{2}$. Todas as operações de leitura e escrita em disco são realizadas pelos procedimentos deste módulo. Os arquivos manipulados pelo $(\mathrm{SM})^{2}$ são arquivos temporários gerados pelos diversos módulos do modelador durante a execução de seus procedimentos, arquivos contendo as informações das 
representações e arquivos contendo imagens realísticas dos sólidos abstratos geradas pelo módulo de visualização.

Todos os módulos do $(\mathrm{SM})^{2}$ foram implementados na linguagem C padrão ANSI ([KeRi88]) e podem ser compilados em outras plataformas utilizando um compilador $C$ padrão ANSI sem necessidade de mudanças, com exceção do módulo de comunicação, que foi implementado utilizando os procedimentos da biblioteca Xview e poderá ser refeito para plataformas não compatíveis com esta biblioteca.

\section{3 - As Técnicas de Modelagem}

A descrição de modelos no $(\mathrm{SM})^{2}$ pode ser realizada através das seguintes técnicas: instanciamento de primitivas, varredura translacional, varredura rotacional e semi-espaços. Cada uma destas técnicas é implementada por um submódulo distinto do módulo de modelagem.

As primitivas disponíveis para instanciamento podem possuir diversas resoluções, ser de forma reta ou oblfqua, maciças, ocas ou vazadas (ver quadro 3.1). Além dos tipos básicos de varredura translacional e rotacional, estão presentes as seguintes variações: varredura translacional cônica, varredura translacional com torção e varredura rotacional helicoidal [Ca90].

Os sólidos abstratos descritos por instaciamento de primitivas ou por varredura são representados por uma BRep. Esta representação foi estendida para conter informações sobre a forma de descrição dos modelos, de modo a permitir que alguns procedimentos de manipulação se tornem mais eficientes. Por exemplo, o cálculo do volume de um sólido é realizado mais facilmente através dos parâmetros da primitiva, no caso de modelos descritos por instanciamento de primitivas, do que através dos dados inerentes à $B$ Rep.

Cada modelo descrito através de semi-espaços é associado a uma representação implícita que é convertida para uma BRep pelo (SM) ${ }^{2}$. A BRep mantém uma "ligação" com a representação implícita de modo que os procedimentos de manipulação possam ter acesso a esta representação a partir da BRep. A geração da representação implícita e a sua conversão são realizadas de forma conjunta e percebidas como um único processo. 


\section{4 - A Arquitetura}

$\mathrm{O}(\mathrm{SM})^{2}$ possui uma arquitetura multi-representacional cuja BRep é a representação principal (ver figura 3.2). A representação implícita, secundária, é mantida não apenas com o propósito de viabilizar a técnica de modelagem por semi-espaços, mas também para ser utilizada por procedimentos de manipulação. Isto faz com que o (SM) ${ }^{2}$ apresente uma arquitetura mais eficiente do que outros modeladores multi-representacionais com representação principal BRep (ver figura 2.9).

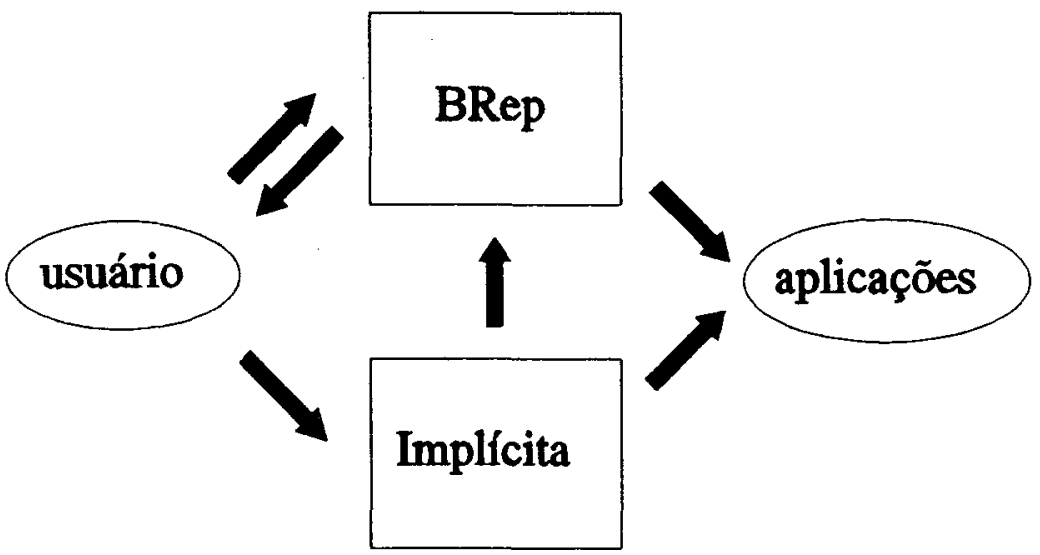

Figura 3.2: arquitetura do $(\mathrm{SM})^{2}$

Está prevista a inclusão da técnica CSG cujas primitivas serão sólidos abstratos descritos através das técnicas existentes e representadas por fronteira. Ou seja, as primitivas serão descritas por instanciamento, varredura ou semi-espaços e representadas na BRep. Isto requer a implementação de procedimentos para realizar operações booleanas sobre BRep's [Mă88]. A incorporação de operações locais e superfícies $B$-Splines tạmbém está prevista.

\section{5 - A Forma de Representação Principal}

A representação por fronteira (BRep) adotada pelo $(\mathrm{SM})^{2}$ como representação principal é conhecida por representação por fronteira poliedral. Nela, as faces são sempre planares e um sólido abstrato com fronteira "curvada" é representado por aproximação. Por exemplo, uma esfera é representada como se fosse um poliedro, enquanto um cubo é representado de forma exata. 


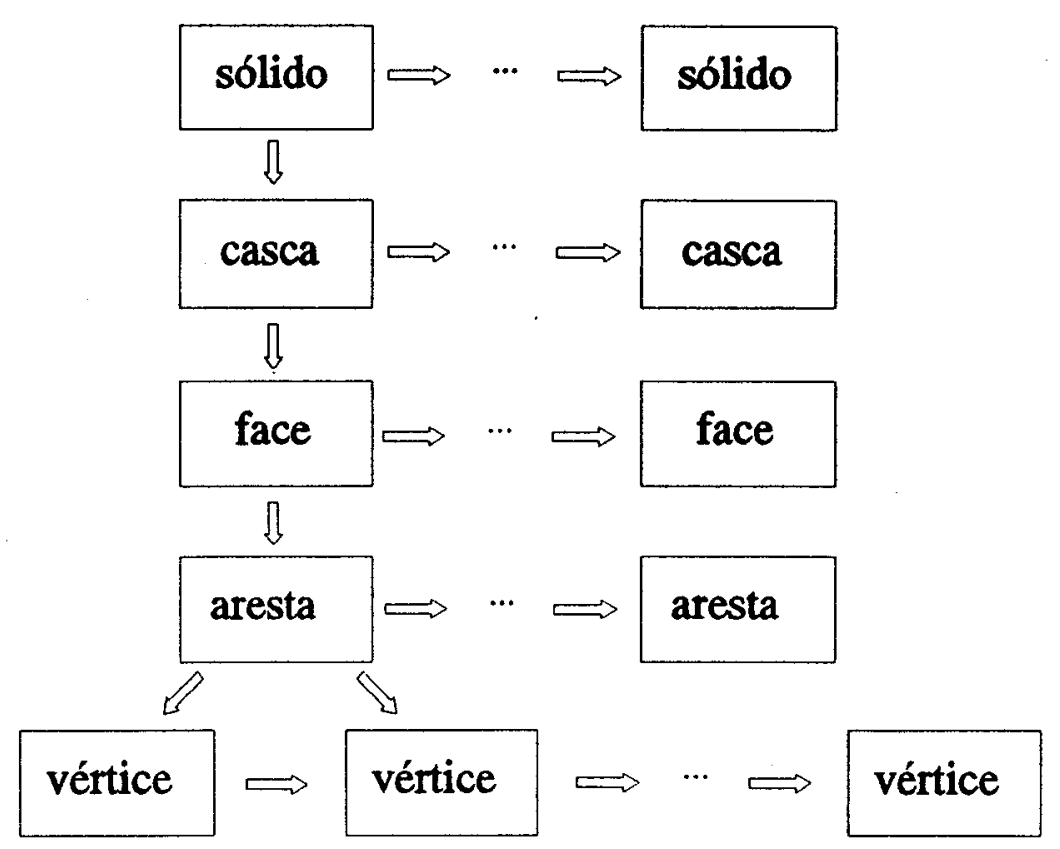

Figura 3.3: componentes da estrutura semi-aresta*

A estrutura de dados associada à representação principal é denominada semi-aresta* [Ma94b et al.] e é uma variação da estrutura semi-aresta (half-edge) desenvolvida por Mäntylä [Mä88]. A semi-aresta* é composta por uma hierarquia de listas (figura 3.3). Esta estrutura é capaz de armazenar as informações referentes à geometria e às relações de adjacência entre os elementos topológicos (vértices, arestas e faces) da fronteira dos sólidos abstratos. A diferença básica entre as estruturas semi-aresta e semi-aresta* E a inclusão da lista de cascas na hierarquia da semi-aresta*, onde um elemento casca corresponde a uma componente conexa da fronteira do sólido abstrato. A lista de cascas faz com que a representação capture naturalmente a idéia de modelos cuja fronteira é composta por mais de uma componente conexa.

Os procedimentos de manipulação das estruturas de dados das BRep's são conhecidos como operadores de Euler [Mä88]. Qualquer BRep válida (que representa um sólido abstrato) pode ser construída por uma sequência de operadores de Euler. Cada um destes operadores possui um operador inverso, de modo que uma BRep pode ser destrufda, ou uma modificação pode ser desfeita, através da aplicação da sequência de operadores inversos que anula a sequência de construção ou modificação. Por convenção, os operadores de Euler possuem uma notação abreviada, formada pela letra inicial (maiúscula) de algumas das seguintes palavras: make, kill, split, join, vertex, edge, face, shell, solid, hole e ring. Por 
exemplo, a palavra MEV significa Make Edge Vertex.

\section{MVFSS}

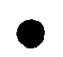

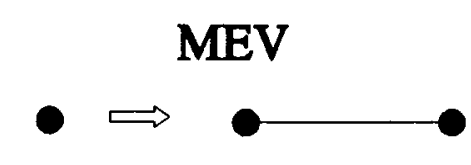

KEMR

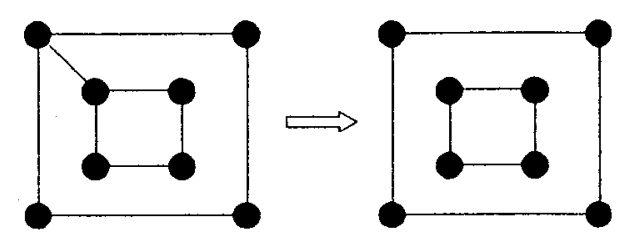

\section{MEF}

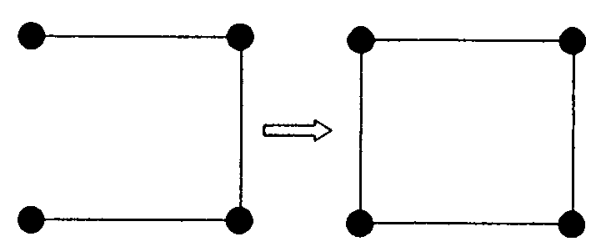

KFMRH

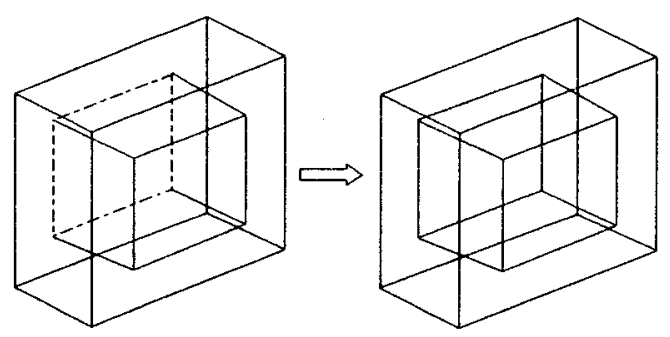

Figura 3.4: ação dos operadores de Euler MVFSS, MEV, MEF, KEMR e KFMRH

O operador MVFSS (Make Vertex Face Shell Solid) inicializa a estrutura semi-aresta*, criando os elementos mínimos da estrutura, e é o primeiro operador usado na geração de uma nova representação. O operador MEV (Make Edge Vertex) adiciona um vértice e uma aresta à estrutura. $\mathrm{O}$ operador MEF (Make Edge Face) cria uma aresta entre dois vértices existentes para gerar uma nova face. O operador KEMR (Kill Edge Make Ring) elimina uma aresta, dividindo a fronteira da face (curva limitante) em duas componentes conexas. O operador KFMRH (Kill Face Make Ring Hole) elimina uma face, criando um "buraco" no modelo. A figura 3.4 ilustra a ação destes operadores.

Os operadores KVFSS (Kill Vertex Face Shell Solid), KEV (Kill Edge Vertex), KEF (Kill Edge Face), MEKR (Make Edge Kill Ring) e MFKRH (Make Face Kill Ring Hole) são os operadores inversos de MVFSS, MEV, MEF, KEMR e KFMRH, respectivamente. Os operadores MEV, KEV, MEF, KEF, KEMR e MEKR são considerados operadores de ação local, enquanto KFMRH e MFKRH são considerados de ação global. 


\section{6 - O Processo de Modelagem}

O processo de modelagem de um SMS especifica, basicamente, a forma semântica pela qual as representações são criadas e alteradas internamente, ou seja, é o responsável pela especificação da semântica do fluxo de dados do sistema. As técnicas de modelagem e as formas de representação estão relacionadas com as características externas do sistema, mas é o processo de modelagem que determina seu nível de eficiência e robustez. As técnicas de modelagem ou formas de representação adicionadas ao sistema devem adaptar-se ao fluxo de dados imposto pelo processo de modelagem [Fi91].

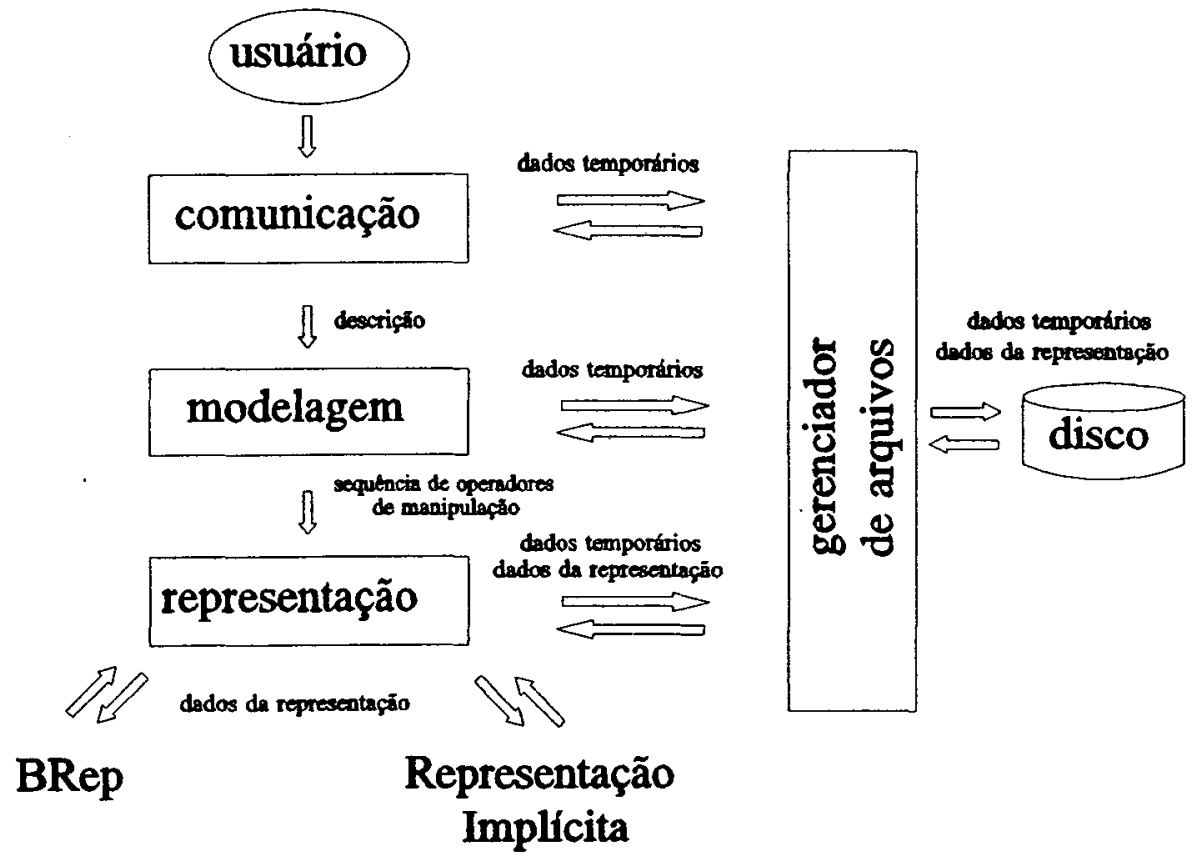

Figura 3.5: fluxo de dados durante o processo de modelagem do (SM) ${ }^{2}$

Os módulos de comunicação, modelagem e representação são responsáveis pelo processo de modelagem do (SM) ${ }^{2}$. O módulo gerenciador de arquivos auxilia o processo sem exercer nenhum controle sobre ele. $\mathrm{O}$ módulo de comunicação realiza a interação com o usuário coletando os dados necessários para a execução das técnicas de modelagem através dos procedimentos do módulo de modelagem que interpretam a descrição e acionam uma sequência de operadores de Euler (procedimentos do módulo de representação) para criar ou modificar uma BRep. A figura 3.5 apresenta o fluxo de dados correspondente ao processo de modelagem do $(\mathrm{SM})^{2}$. 
A descrição de sólidos abstratos por semi-espaços gera um fluxo adicional, pois o módulo de modelagem aciona procedimentos do módulo de representação que criam ou modificam uma representação implícita, e a seguir, através do procedimento de conversão, gera uma sequência de operadores de Euler para criar ou modificar a BRep correspondente à representação implícita.

\section{7 - Considerações Finais}

A técnica de modelagem por semi-espaços, a forma de representação implícita e o procedimento de conversão da representação implícita para a $B R e p$ poliedral constituem a contribuição deste trabalho para o (SM) ${ }^{2}$. A técnica de modelagem por semi-espaços possibilita a descrição de muitos modelos com geometria complexa. A representação implícita pode ser utilizada em aplicações para as quais a BRep poliedral é menos adequada. O procedimento de conversão é importante para viabilizar a coexistência da BRep poliedral e da representação implícita.

No capítulo 4, a técnica de modelagem por semi-espaços e a forma de representação implícita são descritas detalhadamente. Os capítulos 5, 6 e 7 são dedicados ao procedimento de conversão. 


\section{Capítulo 4}

\section{Modelagem por Semi-Espaços}

\section{1 - Considerações Iniciais}

Este capítulo trata da modelagem de sólidos através de semi-espaços e descreve como essa técnica foi implementada no (SM) ${ }^{2}$. Na seção 4.2 é apresentada as definições formais de semi-espaços e semiespaços definidos implicitamente. Na seção 4.3 é discutida uma técnica de modelagem de sólidos abstratos usando um único semi-espaço. Na seção 4.4 é descrito como a técnica de modelagem por semi-espaços foi estendida para descrever sólidos abstratos através de operações booleanas sobre dois ou mais semiespaços. Na seção 4.5 é apresentada a sintaxe para descrição de modelos utilizada no (SM) ${ }^{2}$, enquanto que na seção 4.6 é discutida a representação implícita, representação secundária associada aos sólidos abstratos descritos por semi-espaços. Finalmente, na seção 4.7, um procedimento de manipulação da representação implícita, fundamental no processo de modelagem do (SM) ${ }^{2}$, é comentado.

\section{2 - Semi-Espaços Definidos Implicitamente}

Todo subconjunto $M \subset \mathbf{R}^{\mathrm{n}}$ pode ser imaginado como possuindo uma função característica $F_{M}: R^{n} \rightarrow\{0,1\}$ que determina se um ponto $P \in R^{n}$. pertence ou não a $M$, ou seja, $F_{M}$ deve satisfazer $F_{M}(P)=1$ se $P \in M$ e $F_{M}(P)=0$ se $P \notin M$. A função $F_{M}$ pode ser vista como uma forma de representação para o subconjunto $M$. Entretanto, para muitos subconjuntos, encontrar a função característica é uma tarefa diff́cil, senão impossível [Mä88].

Para alguns subconjuntos $\mathbf{M}, \mathbf{M} \subset \mathbf{R}^{3}$, de interesse na descrição de sólidos abstratos, a fronteira, $\partial(M)$, é uma superfície diferenciável $S, S \subset R^{3}$, definida implicitamente, isto $e, \partial(M)=S$ e $S=F^{-1}(c)=\left\{(x, y, z) \in R^{3} \mid F(x, y, z)=c\right\}$ onde $F: R^{3} \rightarrow R$ e, se $(x, y, z) \in S$, então $\nabla F(x, y, z) \neq(0,0,0)$. Diz-se também que $S$ é a imagem inversa de $F$ no ponto $c \in R$. A superfície $S$ divide $R^{3}$ em dois subconjuntos: $S_{-}=\left\{(x, y, z) \in R^{3} \mid F(x, y, z)<c\right\}$ e $S_{+}=\left\{(x, y, z) \in R^{3} \mid F(x, y, z)>c\right\}$ e, portanto, os subconjuntos $S_{-} \cup S$ 
e $S_{+}$US são denominados de semi-espaços. $O$ interior de $M$, int(M) é um dos subconjuntos $S_{-}$ou $S_{+}$, pois $\partial(M)=S$, dar $M=S, \cup S$ ou $M=S, \cup S$.
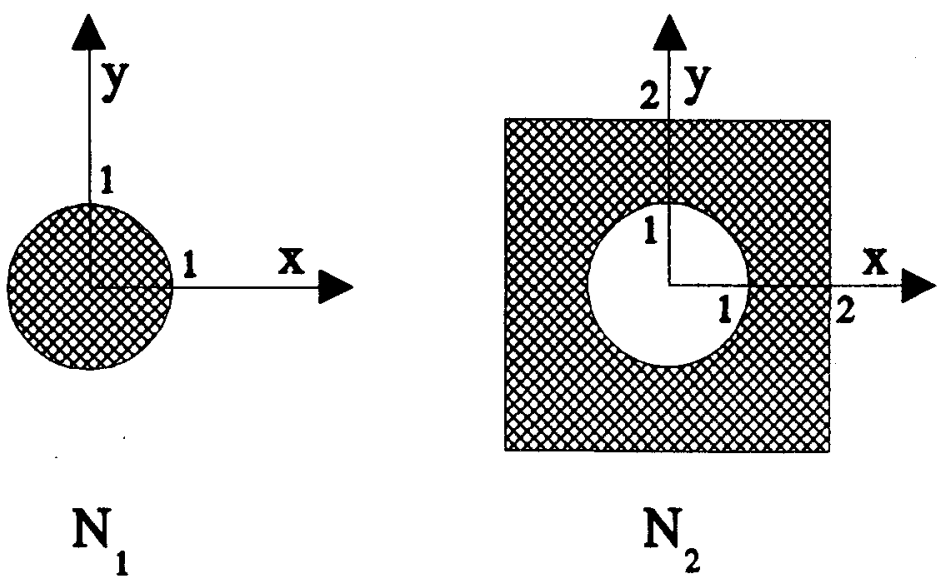

Figura 4.1: conjuntos de pontos $\mathrm{N}_{1}$ e $\mathrm{N}_{2}, \mathrm{~N}_{1}, \mathrm{~N}_{2} \subset R^{2}$

A função $F$ pode ser vista como a função característica $F_{M}$ de $M$, pois se $M=S_{-} \cup S$ e $P \in R^{3}$, então $F(P) \leq c$ se $P \in M$ e $F(P)>c$ se $P \notin M$. De modo análogo, se $M=S_{+} \cup S$, então $F(P) \geq c$ se $P \in M$ e $F(P)<c$ se $P \notin M$. O semi-espaço $M$ é dito ser definido implicitamente e $F$ consiste numa representação de $\mathbf{M}$. Esfera, toro e o conjunto $\mathbf{R}^{2} \times \mathbf{R}_{+}$são exemplos de semi-espaços que podem ser definidos implicitamente através de funções características conhecidas.

\section{3 - Descrição de Sólidos Abstratos}

Um semi-espaço $\mathbf{M}$ definido implicitamente corresponde a um ou mais solidos abstratos desde que $\mathbf{M}$ seja limitado, pois as demais restrições para garantir que um subconjunto do $\mathbf{R}^{3}$ seja um sólido abstrato (ver seção 2.2) podem ser deduzidas a partir da definição de semi-espaço dada na seção anterior. Uma alternativa para "forçar" que $M$ seja limitado é definir um domínio compacto $D, D \subset \mathbf{R}^{3}$, onde $F_{M}$, a função característica de $M$, seja considerada.

Para efeito de ilustração, considere um exemplo em $R^{2}$ : sejam dois conjuntos de pontos $N_{1}$ e $N_{2}$, o domínio $D=[-2,2] \times[-2,2]$, a função $G: D \subset R^{2} \rightarrow R$, onde $G(x, y)=x^{2}+y^{2}-1$, e a curva $C=G^{-1}(0)$. Suponha que $N_{1}=C$ - $\cup C$ e $N_{2}=C_{+} \cup C$, então $\partial\left(N_{1}\right)=C$ e $\operatorname{int}\left(N_{1}\right)=C_{-}$, enquanto $\partial\left(N_{2}\right)=C \cup \partial(D)$ e $\operatorname{int}\left(\mathrm{N}_{2}\right)=\mathrm{C}_{+} \cap \operatorname{int}(\mathrm{D})$ como mostrado na figura 4.1. Observe que se o domínio da função $\mathbf{G}$ fosse o $\mathbf{R}^{2}$, 
o subconjunto $C_{+}$seria ilimitado e, consequentemente, $N_{2}$ também. A fronteira de $N_{2}, \partial\left(N_{2}\right)$, é formada por duas componentes conexas: $\mathrm{C}$ e $\partial(\mathrm{D})$. A fronteira de $\mathrm{N}_{1}$ poderia ser constiturda por parte do bordo de $D$ se $G(x, y)=(x-2)^{2}+y^{2}-1$. Por outro lado, $N_{1}$ possuiria o interior, int $\left(N_{1}\right)$, desconexo, como se fosse dois conjuntos de pontos distintos, se $G(x, y)=x^{2}-y^{2}-1$, como ilustrado na figura 4.2.

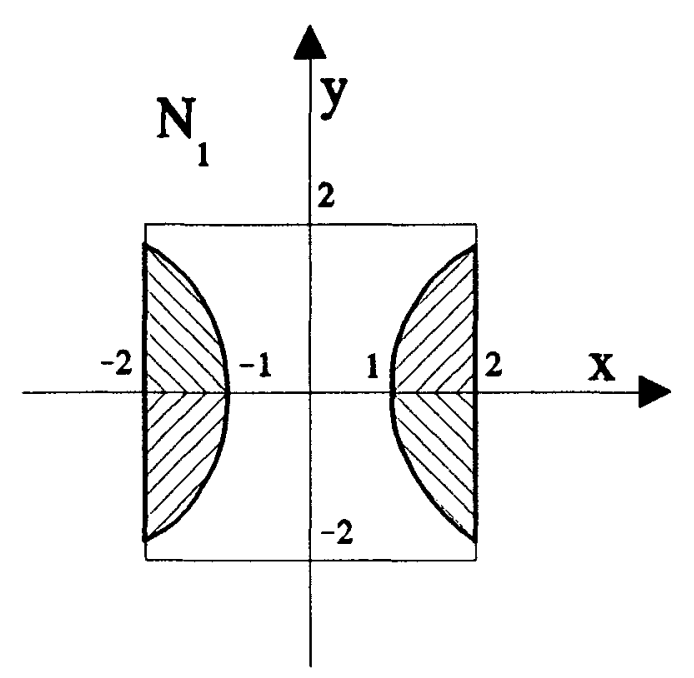

Figura 4.2: o conjunto $N_{1}, N_{1} \subset \mathbf{R}^{2}$, com interior desconexo

No (SM) ${ }^{2}$, a descrição de sólidos abstratos através de um semi-espaço é feita através da definição da função característica $F$ do semi-espaço e do domínio $D$ onde $F$ é considerada. Além de $F$ e $D$, um sinal de desigualdade ("<" ou ">") indica, respectivamente, um dos conjuntos $S_{\text {_ ou }} \mathrm{S}_{+}$como o interior do semi-espaço. A figura 4.3 contém dois sólidos abstratos descritos pela função característica $F(x, y, z)=(x-1)^{2}+(y-1)^{2}+(z+1)^{2}-1$, domínio $D=[-1,1] \times[-1,1] \times[-1,1]$, e interior indicado por "<" (figura 4.3 (a)) e " $>$ " (figura 4.3 (b)).

\section{4 - Operações Booleanas}

A operação de concordância (blending) de superfícies é muito usada em sistemas de modelagem de superfícies para construir modelos complexos de superfícies a partir de outros mais simples [HoHo85], [Wa89], [Ca92]. Esta operação gera uma superfície a partir de duas ou mais superfícies [GoVe90]. Operações booleanas (união, interseção e diferença) efetuadas sobre semi-espaços definidos implicitamente podem ser realizadas por intermédio da operação de concordância. 

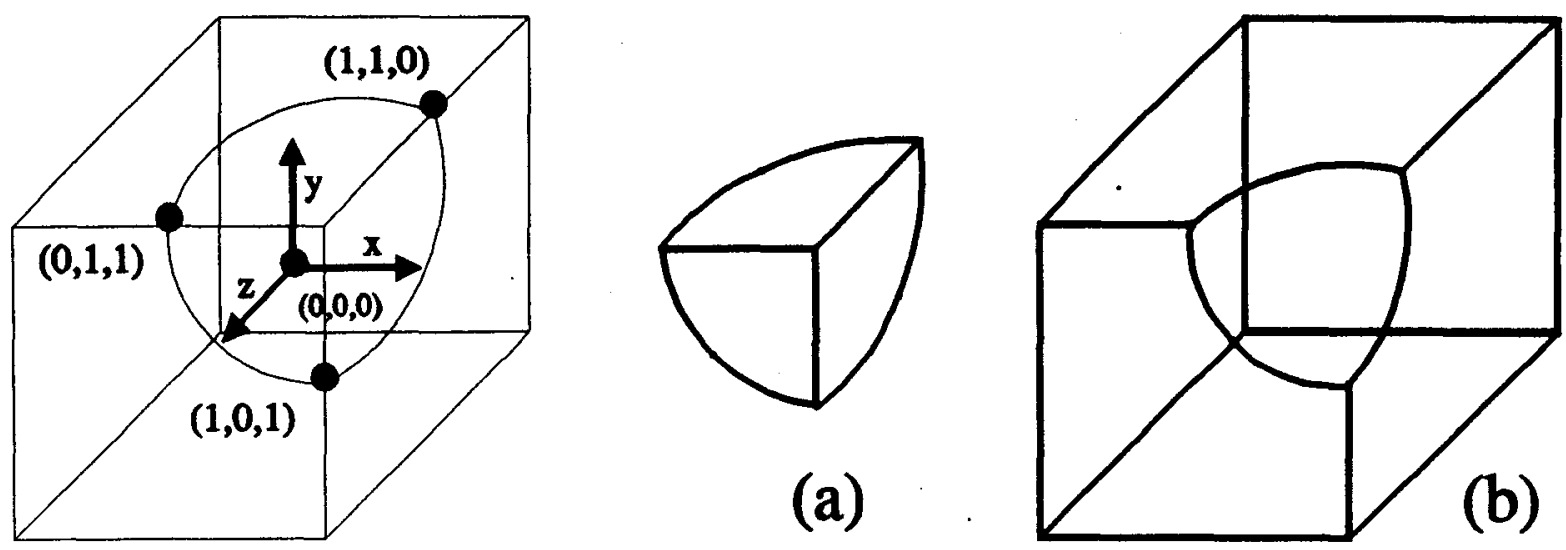

Figura 4.3: sólidos abstratos descritos por: (a) F, D e "<" e (b) F, D e " > "

Sejam $M_{1}, \ldots, M_{n}$ semi-espaços e $S_{1}, \ldots, S_{n}$ superfícies diferenciáveis definidas por $F_{1}, \ldots, F_{n}$, onde $F_{i}: R^{3} \rightarrow R, F_{i}(x, y, z) \geq 0, S_{i}=F_{i}^{-1}(1)$ e $M_{i}=S_{i-} \cup S_{i}$, para $i=1, \ldots, n$. Os semi-espaços $M_{\cup}=M_{1} \cup M_{2} \ldots \cup M_{n}$ e $M_{n}=M_{1} \cap M_{2} \cdots \cap M_{n}$ possuem as fronteiras, $\partial\left(M_{U}\right)$ e $\partial\left(M_{n}\right)$, definidas por $\partial\left(M_{U}\right)=\partial\left(S_{1-} \cup S_{2-} \cdots\right.$ $\left.\cup S_{n-}\right)=F_{U}^{-1}(1) \quad$ e $\quad \partial\left(M_{n}\right)=\partial\left(S_{1-} \cap S_{2-} \quad \ldots \quad \cap S_{n-}\right)=F_{n}^{-1}(1) \quad$ tal que $F_{U}=\min \left\{F_{1}, \ldots, F_{n}\right\} \quad$ e $F_{n}=\max \left\{F_{1}, \ldots, F_{n}\right\}$, onde $\min$ e $\max$ são funções que obtêm o elemento de valor mínimo e máximo, respectivamente, do conjunto $\left\{F_{1}, \ldots, F_{n}\right\}[R i 73]$. As funções $F_{U}$ e $F_{n}$ realizam a operação de concordância sobre as superfícies $S_{1}, \ldots, S_{n}$ para obter $\partial\left(M_{U}\right)$ e $\partial\left(M_{n}\right)$, nesta ordem.
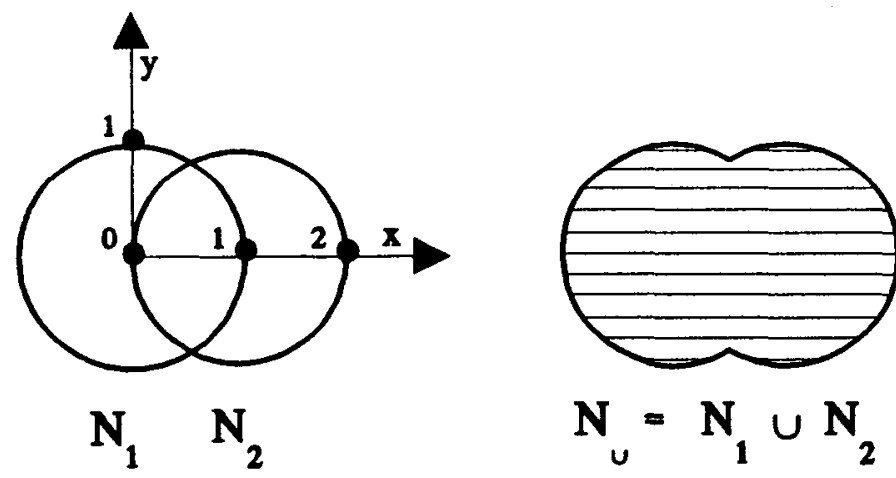

Figura 4.4: o conjunto $N_{U}=N_{1} \cup N_{2}, N_{1}, N_{2} \subset R^{2}$, obtido através de $F_{u}$

Como exemplo, considere dois conjuntos do $R^{2}, N_{1}$ e $N_{2}$, as funções $G_{1}, G_{2}: R^{2} \rightarrow R$ dadas por $G_{1}(x, y)=x^{2}+y^{2}$ e $G_{2}(x, y)=(x-1)^{2}+y^{2}$ e as curvas $C_{1}=G_{1}^{-1}(1)$ e $C_{2}=G_{2}^{-1}(1)$ tais que $N_{1}=C_{1-} \cup C_{1}$ e $N_{2}=C_{2-} \cup C_{2}$. $O$ conjunto $N_{U}=N_{1} \cup N_{2}$ possui a fronteira definida por $\partial\left(N_{U}\right)=\partial\left(C_{1-} \cup C_{2-}\right)=F_{U}{ }^{-1}(1)$, onde $F_{U}=\min \left\{G_{1}, G_{2}\right\}$, como mostrado na figura 4.4. De forma análoga, a fronteira $\partial\left(N_{n}\right), N_{n}=N_{1} \cap N_{2}$, 
é definida por $\partial\left(N_{n}\right)=\partial\left(C_{1} \cap \cap C_{2-}\right)=F_{n}^{-1}(1), F_{n}=\max \left\{G_{1}, G_{2}\right\}$, como ilustrado na figura 4.5.

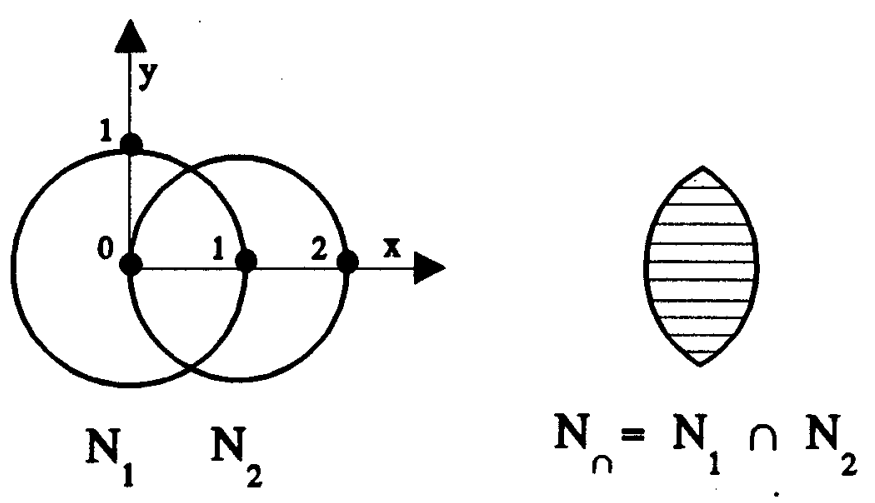

Figura 4.5: o conjunto $N_{n}=N_{1} \cap N_{2}, N_{1}, N_{2} \subset R^{2}$, obtido através de $F_{n}$

Pode-se escrever as funçôes $F_{U}$ e $F_{n}$ da seguinte forma:

$$
\begin{aligned}
& F_{U}=\lim _{p \rightarrow \infty}\left(F_{1}{ }^{p}+\cdots+F_{n}{ }^{p}\right)^{\frac{1}{p}}=\min \left\{F_{1}, \cdots, F_{n}\right\} e \\
& F_{\cap}=\lim _{p \rightarrow \infty}\left(F_{1}{ }^{-p}+\cdots+F_{n}{ }^{-p}\right)^{-\frac{1}{p}}=\max \left\{F_{1}, \cdots, F_{n}\right\} .
\end{aligned}
$$

As funções $F_{U}$ e $F_{n}$ definidas através de min e max não definem, em geral, superfícies diferenciáveis. Para que isso ocorra, aproxima-se $F_{U} \cong\left(F_{1}{ }^{p}+\ldots+F_{n}\right)^{\frac{1}{p}}$ e $F_{n} \cong\left(F_{1}{ }^{-p}+\cdots+F_{n}{ }^{-p}\right)^{-\frac{1}{p}}$, fazendo "p" suficientemente grande [GoTa89]. Para "p" não muito grande, obtém-se o efeito de arredondamento na região de interseção das superficies dos semi-espaços.

As operações booleanas de união e interseção sobre semi-espaços foram implementadas no (SM) ${ }^{2}$. através das funções $F_{U}$ e $F_{n}$. Em adição a estas operações, tem-se a operação de diferença, também implementada através de $F_{n}$, pois a diferença entre dois semi-espaços, $\mathbf{M}_{1}-\mathbf{M}_{2}$, corresponde à interseção do primeiro com o complementar do segundo, $M_{1} \cap\left\lceil M_{2}\right.$. Muitos sólidos abstratos com geometria complexa podem ser descritos facilmente através de operações de união, interseção e diferença sobre semi-espaços definidos implicitamente, assim como na técnica CSG.

A forma de descrição de um sólido abstrato através da definição de F, D e " < " ou " > " para um único semi-espaço, como foi visto na seção anterior, difere da descrição através de operações booleanas sobre dois ou mais semi-espaços apenas na definição da função F. Na descrição por um único 
booleanas sobre dois ou mais semi-espaços apenas na definição da função F. Na descrição por um único semi-espaço, a função F é a função característica do semi-espaço, dada por sua expressão numérica. Na descrição por operações booleanas, a função $\mathrm{F}$ é uma expressão lógica onde os operandos são as funções características dos semi-espaços envolvidos nas operações booleanas e os operadores são " $U$ ", " $\cap$ " e " -" indicando união, interseção e diferença, respectivamente. Cada função característica da expressão lógica possui sua própria expressão numérica e a função $\mathrm{F}$ é a função característica do semi-espaço resultante da expressão lógica. Por exemplo, a função $\mathrm{F}$ da descrição do sólido abstrato resultante da união de duas esferas com funções características $F_{1}$ e $F_{2}$ é dada pela expressão lógica " $F_{1}$ união $F_{2}$ " onde $F_{1}$ e $F_{2}$ são dadas pelas expressões numéricas $" x^{2}+y^{2}+z^{2 n}$ e " $(x-1)^{2}+y^{2}+z^{2 "}$ respectivamente.
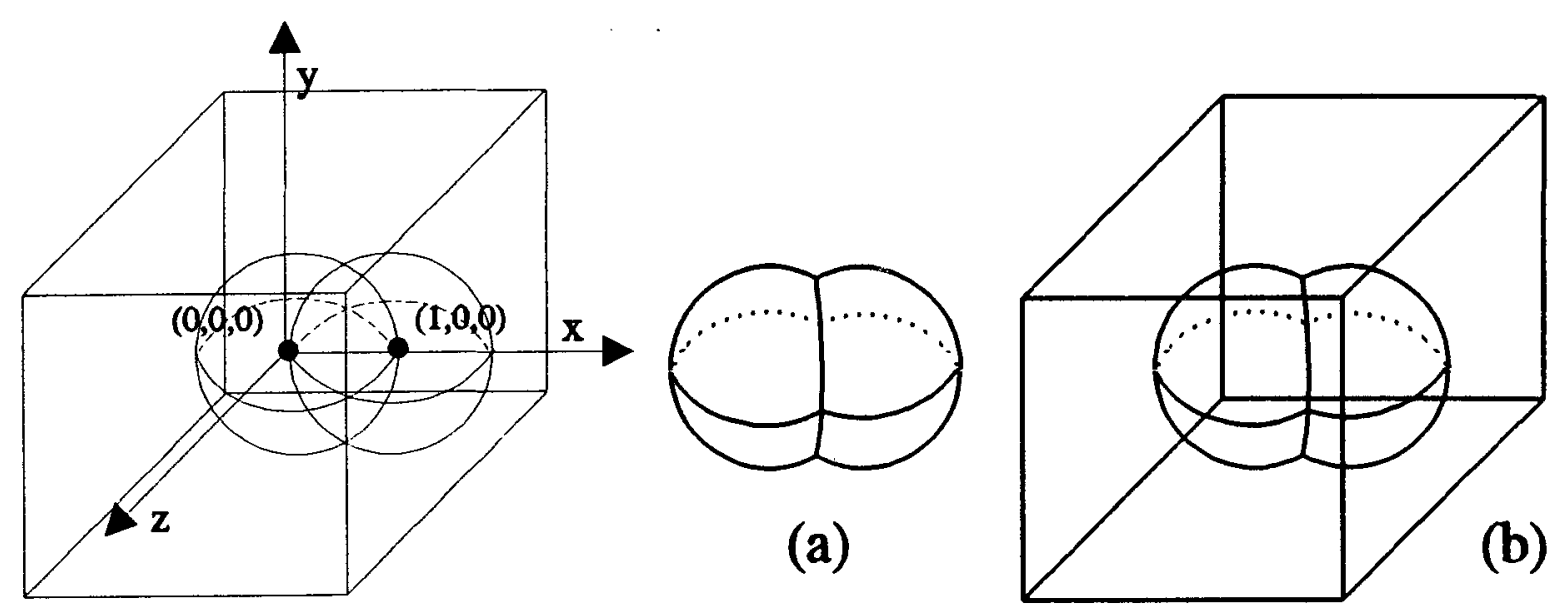

Figura 4.6: sólidos abstratos com interior dado por: (a) "<" e (b) "> "

Os semi-espaços envolvidos na descrição por operações booleanas possuem o interior dado, arbitrariamente, pelo conjunto $S_{-}$, de forma que não há necessidade de indicar o interior destes semiespaços. Entretanto, o sólido abstrato resultante da descrição pode ter o interior dado por $S_{-}$ou $S_{+}$, o que é indicado pelo uso de " < " ou "> ", respectivamente. Se o conjunto $S_{-}$(sinal " <") for escolhido, o sólido abstrato corresponderá ao semi-espaço resultante das operações booleanas. Por exemplo, a descrição $F, D$ e " $<$ ", onde $F=F_{1}$ união $F_{2}, \quad F_{1}(x, y, z)=x^{2}+y^{2}+z^{2}, \quad F(x, y, z)=(x-1)^{2}+y^{2}+z^{2}$ e $D=[-3,3] \times[-3,3] \times[-3,3]$, corresponde ao sólido abstrato da figura 4.6 (a), enquanto $F, D$ e " $>$ ", ao sólido abstrato da figura 4.6 (b). 


\section{5 - A Sintaxe da Descrição}

A descrição de um sólido abstrato através de semi-espaços no $(\mathrm{SM})^{2}$ é processada por um submódulo do módulo de modelagem denominado semi-espaços. Este submódulo analisa a sintaxe da descrição, composta por F, D e " <" ou "> ", e a seguir ativa procedimentos do módulo de representação para gerar a representação implícita do modelo. Esta representação é, em seguida, convertida para uma BRep poliedral correspondente através do procedimento de conversão.

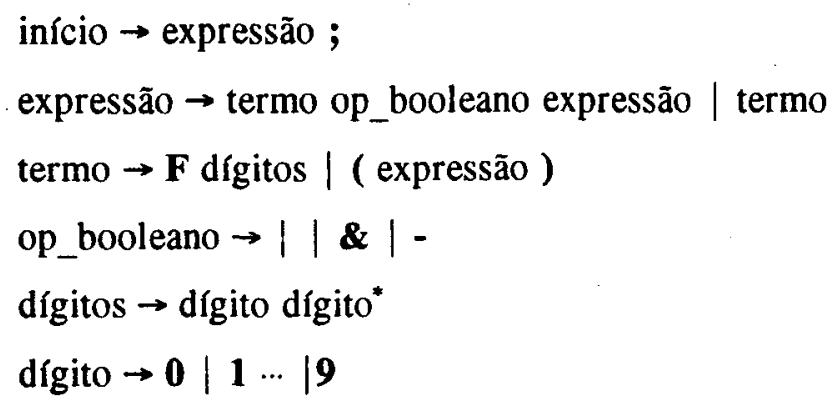

Quadro 4.1: gramática livre de contexto para expressões lógicas

A análise sintática da descrição se reduz, basicamente, à análise da sintaxe da função $F$, pois a sintaxe de $\mathrm{D}$ é facilmente verificada e a sintaxe da indicação de interior, através dos sinais " < " $\mathrm{e}$ " > ", é verificada e sua correção garantida pelo módulo de comunicação. O procedimento que realiza a análise sintática é um parser recursivo descendente ([Ah86 et al.]) para expressões lógicas e numéricas. As sintaxes destas expressões são definidas pelas gramáticas livres de contexto apresentadas nos quadros 4.1 e 4.2, respectivamente, usando a notação BNF e expressões regulares ([HoUl79]).

Nas expressões lógicas, os caracteres "|", "\&" e "-" correspondem aos operadores lógicos de união, interseção e diferença, respectivamente. Os operandos, que correspondem às funções características, são representados pela letra "F" seguida de um indice (número natural) que identifica cada função. Por exemplo, a descrição correta para " $F_{1}$ união $F_{2}$ " e " $F_{1} \mid F_{2}$ ".

Nas expressões numéricas, os símbolos "+", "-", "*", "/" e "A" indicam os operadores de adição, subtração/unário, multiplicação, divisão e potência, respectivamente. As letras "x", "y" e "z" correspondem às variáveis das funções características. As abreviações "abs", "sqrt", "log", "In", "exp", "sen", "cos", "tan", "asen", "acos" e "atan" indicam as funções valor absoluto, raiz quadrada, logaritmo na base 10, logaritmo natural, exponencial, seno, cosseno, tangente, arco seno, arco cosseno e arco tangente. Por exemplo, a descrição correta da expressão numérica da função característica 
$F(x, y, z)=x^{2}+y^{2}+z^{2}-1 e^{\prime \prime} x^{\wedge} 2+y^{\wedge} 2+z^{\wedge} 2-1 "$.

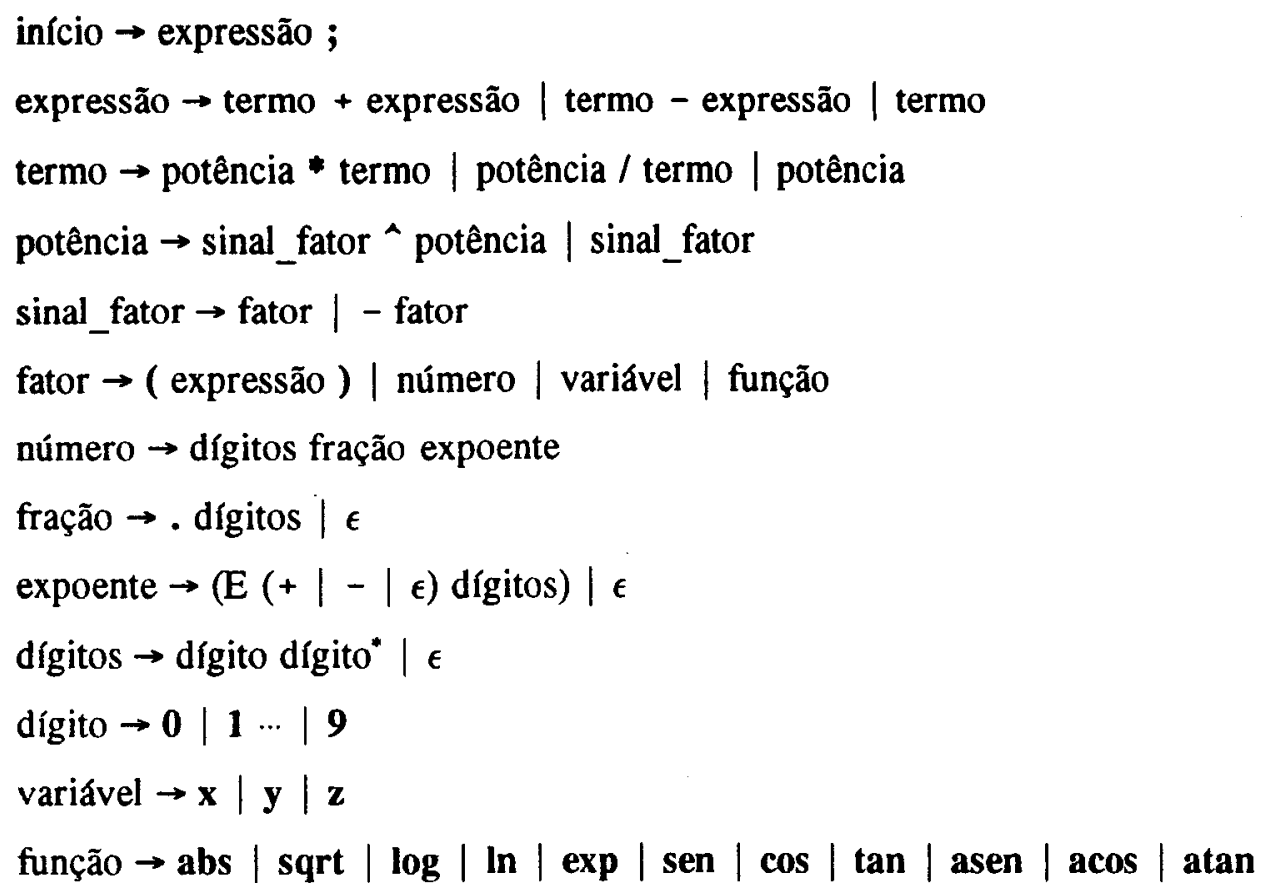

Quadro 4.2: gramática livre de contexto para expressões numéricas

A sintaxe da descrição $\mathrm{F}, \mathrm{D}$ e "<" ou " $>$ " é verificada pelo parser, enquanto a semântica é analisada apenas durante o processo de conversão da representação implícita para a BRep poliedral. Isto porque nem toda função implícita define uma superfície diferenciável como imagem inversa, ou seja, $S=F^{-1}(c)$ ([El81]), não sendo possível deduzir, com base apenas na forma sintática, se a descrição da função está semanticamente correta.

\section{6 - A Representação Implícita}

Uma representação implícita é gerada, no (SM)2, para cada sólido abstrato descrito por semiespaços, através de um procedimento do módulo de representação denominado tradutor, que é acionado pelo submódulo semi-espaços. Este procedimento gera um código para a função $\mathrm{F}$ a partir da descrição fornecida que, juntamente com D e "<" ou " > e outras informações, compõem a representação implícita.

O código gerado pelo tradutor para a função $F$ corresponde à tradução de sua expressão numérica (ou, se mais de um semi-espaço está envolvido na descrição, sua expressão lógica e expressões numéricas 
associadas) para a forma pós-fixa. As expressões nesta forma podem ser mais facilmente manuseadas pelos procedimentos de manipulação. A sintaxe da representação gerada não precisa ser verificada, pois a sintaxe de $\mathrm{D}$ e "<" ou " $>$ " é analisada durante a descrição, o tradutor sempre gera código sintaticamente correto para uma descrição sintaticamente correta da função $\mathrm{F}$ e as informações adicionais são geradas pelo $(\mathrm{SM})^{2}$ com sintaxe correta. As gramáticas livres de contexto dos quadros 4.3 e 4.4 definem a sintaxe do código gerado na forma pós-fixa para as expressões lógicas e as expressões numéricas, respectivamente.

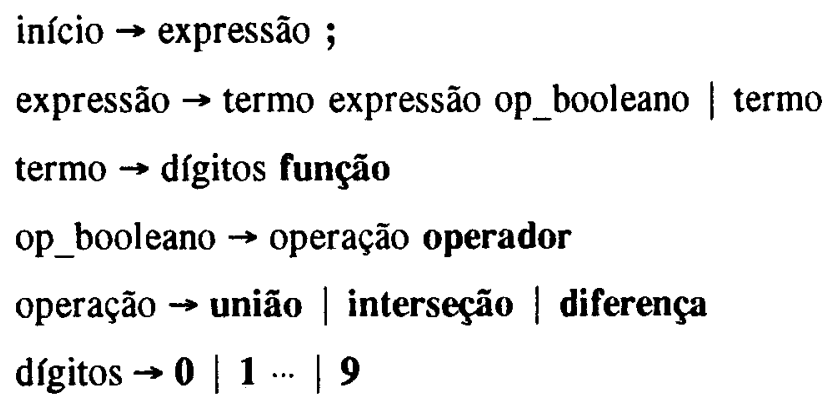

Quadro 4.3: gramática livre de contexto para expressões lógicas na forma pós-fixa

Na gramática para expressões lógicas (ver quadro 4.3), os símbolos função, operador, união, interseção e diferença são constantes numéricas. A constante função segue o índice que identifica a função, enquanto operador segue uma das constantes que corresponde às operações booleanas disponíveis: união, interseção e diferença.

Na gramática para expressões numéricas (ver quadro 4.4), os símbolos operador, adição, subtração, multiplicação, divisão, unário, potência, constante, variável, função, abs, sqrt, log, ln, exp, sen, cos, tan, asen, acos e atan são constantes numéricas. A constante operador segue uma das constantes correspondentes às operações aritméticas disponfveis: adição, subtração, multiplicação, divisão, unário e pot. A constante função segue uma das constantes correspondentes às funções disponíveis: abs, sqrt, log, In, exp, sen, cos, tan, asen, acos e atan. A constante variável segue um indice que identifica uma das variáveis " $x$ ", "y" e " $z$ ", enquanto constante segue um número real.

A utilização de constantes numéricas ao invés de caracteres ou cadeias de caracteres como nas gramáticas dos quadros 4.1 e 4.2 facilita a tarefa de avaliação das expressões, pois os símbolos das expressões são identificados mais rapidamente [Ah86 et al.]. Observe que "número" corresponde a um número real na gramática do quadro 4.4 , enquanto que pode ser associado a um número inteiro ou real na gramática do quadro 4.2. Isto significa que os números contidos na(s) expressão(ões) numérica(s) de 
F podem ser do tipo inteiro, mas são posteriormente transformados para real na representação pós-fixa.

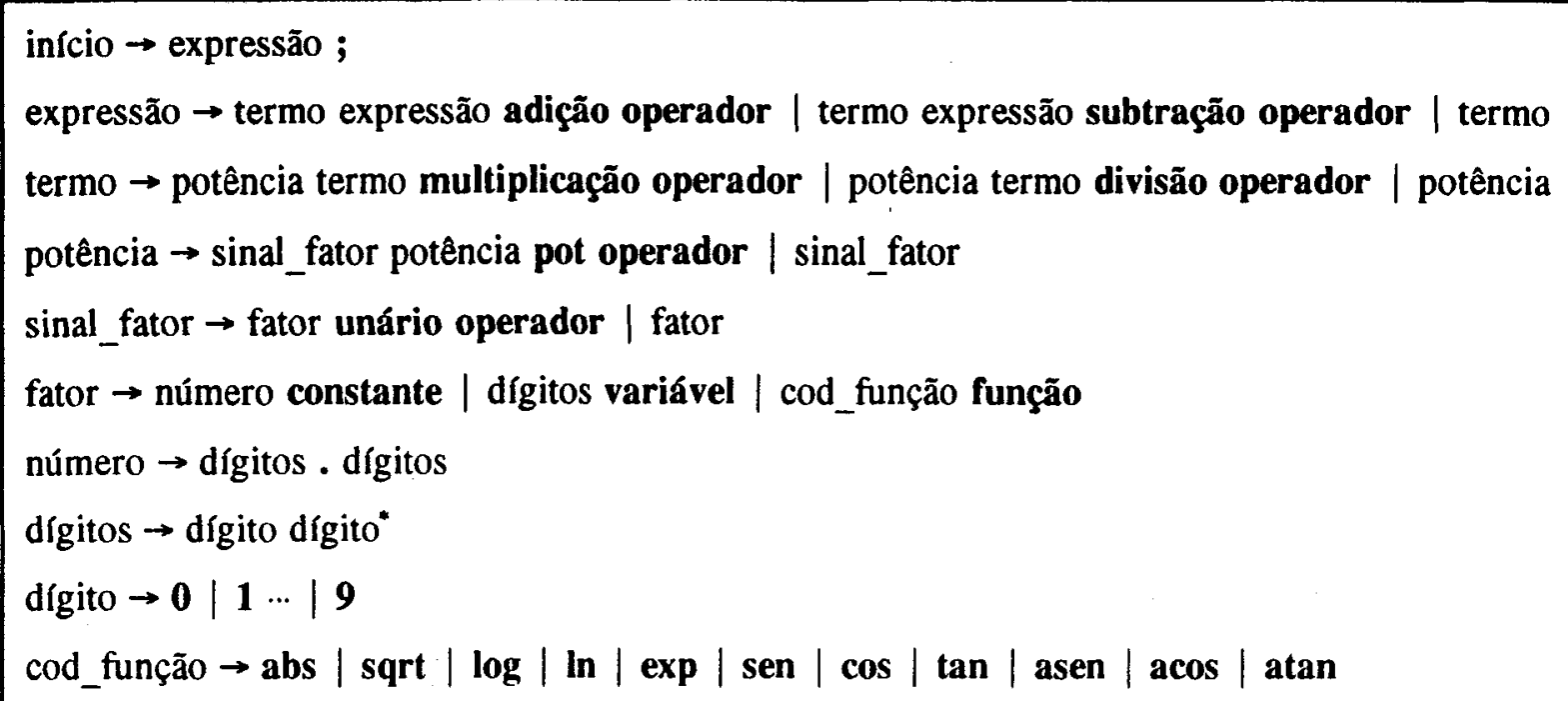

Quadro 4.4: gramática livre de contexto para expressões númericas na forma pós-fixa

As informações que compõem a representação implf́cita são: número de expressões numéricas, número de símbolos do código gerado para $\mathrm{F}$, código da(s) expressão(ões) numérica(s), código da expressão lógica (se houver), D, "<" ou "> ", número de componentes conexas da fronteira do sólido abstrato e um ponto pertencente a cada uma das componentes conexas.

Um ponto pertencente a cada componente conexa da fronteira é uma informação útil para garantir a não ambiguidade da representação implícita, pois, como foi visto na seção 4.3, a descrição F, D e " < " ou " $>$ " pode gerar um semi-espaço com interior desconexo e correspondendo a mais de um sólido abstrato. O conhecimento sobre um ponto em cada componente conexa da fronteira auxilia os procedimentos de manipulação na dedução do modelo correspondente à representação implícita (como será demonstrado no capítulo 6), no caso de F, D e " <" ou " > " definirem um semi-espaço com interior desconexo.

\section{7 - O Interpretador}

O código da função $\mathrm{F}$ contido na representação implícita deve ser avaliado para muitas aplicações baseadas nesta representação, bem como durante o procedimento de conversão da representação implícita para a BRep poliedral. Portanto, foi desenvolvido um procedimento, denominado interpretador, para 
avaliar as expressões logicas e numéricas que definem a função $F$ na representação implícita. Este procedimento está contido no módulo de representação e é utilizado durante a conversão, podendo, também, servir aos procedimentos das aplicações.

$\mathrm{O}$ interpretador atua como uma máquina virtual que possui uma memória, onde o código de $\mathrm{F}$, o resultado da avaliação e os valores de " $x "$ ", " $y$ " e "z" são armazenados, e uma unidade de processamento capaz de resolver expressões lógicas e aritméticas. A estrutura de dados associada à memória é um vetor de elementos numéricos. Cada elemento do vetor corresponde a um símbolo do código de $\mathrm{F}$, ou ao resultado de uma expressão numérica ou de uma expressão lógica, ou ao valor das variáveis " $x$ ", "y" e "z". A unidade de processamento calcula o valor de F para "x", "y" e "z" dados, lendo da memória os elementos das expressões e armazenando nela os resultados intermediários e o resultado final. A expressão lógica é resolvida pelo interpretador através da utilização das funções $F_{\cup} e$ $F_{n}$.

\section{8 - Considerações Finais}

Neste capítulo, foi apresentada a técnica de modelagem por semi-espaços definidos implicitamente usada no (SM) $)^{2}$, a qual permite que sólidos abstratos sejam descritos por operações booleanas sobre semiespaços de maneira análoga à técnica CSG. Um modelo descrito por semi-espaços é associado a uma representação implícita, que constitui uma forma de representação secundária do $(\mathrm{SM})^{2}$, a qual é posteriormente convertida para uma $B R e p$ poliedral, que é a representação primária.

O mecanismo de entrada de dados, bem como o conteúdo da representação implícita e o processo de geração dessa representação foram apresentados. Os capítulos 5, 6 e 7 são dedicados ao procedimento de conversão da representação implícita para a BRep poliedral. Este procedimento utiliza o procedimento interpretador descrito na seção 4.7 . 


\section{Capítulo 5}

\section{Triangulações}

\section{1 - Considerações Iniciais}

Triangulações são de uso frequente em teoria da aproximação, métodos de elementos finitos, análise numérica, e modelagem geométrica, entre outras áreas, com a finalidade de subdividir uma região de interesse em partes mais simples. Neste trabalho, a região de interesse é o domínio $D \subset \mathbf{R}^{3}$, onde reside o sólido abstrato descrito, no (SM) $)^{2}$, por F, D e "<" ou " > ".

Neste capítulo, são abordadas as triangulações denominadas $K_{1}$ e $J_{1}$, usadas para particionar 0 domínio D no (SM) ${ }^{2}$. Na seção 5.2 são apresentados os conceitos de célula, simplexo e triangulação. Na seção 5.3 é definida a triangulação CFK. Na seção 5.4 são descritas as triangulações $K_{1}$ e $J_{1}$, derivadas da triangulação CFK. Na seção 5.5 é apresentado um processo combinatório para representar os elementos das triangulações $\mathrm{K}_{1}$ e $\mathrm{J}_{1}$. Na seção 5.6 são definidas as regras de pivoteamento das triangulações $K_{1}$ e $J_{1}$, e na seção 5.7 é abordado um processo de perturbação para as triangulações $K_{1}$ e $\mathrm{J}_{1}$.

\section{2 - Células, Simplexos e Triangulações}

Os resultados desta seção foram obtidos de [Ea76].

Dado um conjunto de pontos $v_{0}, \ldots, v_{n} \in \mathbf{R}^{\mathrm{m}}$, define-se célula convexa afim gerada por estes pontos como o conjunto $\sigma=\left[v_{0}, \ldots, v_{n}\right]$, tal que

$$
\left[v_{0}, \ldots, v_{n}\right]=\left\{v \in \mathbb{R}^{m} ; \sum_{i=0}^{n} \lambda_{i} v_{i}=v, \sum_{i=0}^{n} \lambda_{l}=1 \text { e } \lambda_{i} \geq 0\right\}
$$

A dimensão de $\sigma, \operatorname{dim}(\sigma)$, é igual ao maior número de vetores linearmente independentes do conjunto $\left\{v_{1}-v_{0}, \ldots, v_{n}-v_{0}\right\}$. 
Uma coleção $C$ de células convexas afins é dita uma decomposição celular de um conjunto $\mathrm{DC} \mathbf{R}^{\mathrm{m}}$ se:

- $\mathrm{D}=\cup_{\sigma, \sigma \in \mathrm{C}}$

- se $\sigma_{1}, \sigma_{2} \in C$, então $\sigma_{1} \cap \sigma_{2}=\varnothing$ ou $\sigma_{1} \cap \sigma_{2} \in C$;

- todo subconjunto compacto de D intercepta um número finito de células de D.

Uma decomposição celular $C$ de $D \subset \mathbf{R}^{\mathrm{m}}$ é uma variedade linear por partes de dimensão $n$ quando:

- todas as células de $\mathrm{C}$ têm dimensão menor ou igual a $\mathbf{n}$;

- existe pelo menos uma célula de $C$ com dimensão n;

- toda célula de dimensão $n-1$ de $C$ está contida em uma ou duas células de dimensão $n$ de $C$;

- toda célula de dimensão menor que n-1 está contida em alguma célula de dimensão $n$.

Representa-se uma variedade linear por partes pelo par (D,C).

Se $(D, C)$ é uma variedade linear por partes de dimensão $n$, denomina-se fronteira de $(D, C) o$ conjunto das células de dimensão $n-1$ de $C$, tais que cada uma destas células está contida em apenas uma célula de dimensão $\mathrm{n}$ de $\mathrm{C}$.

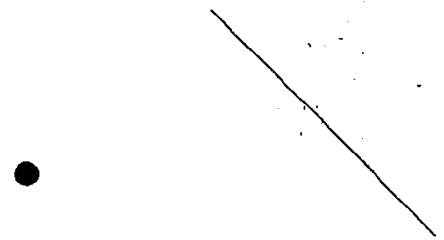

dimensão 0 dimensão 1

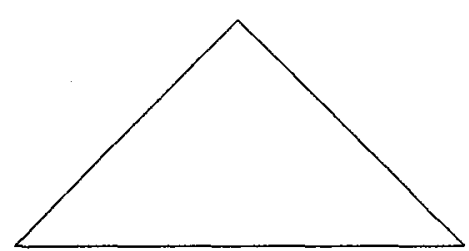

dimensão 2

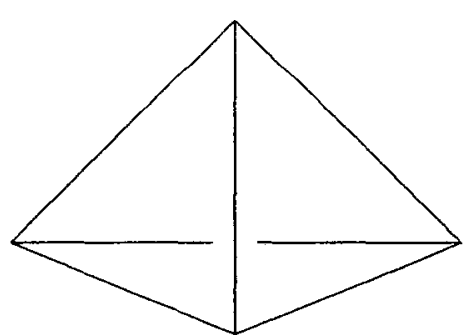

dimensão 3

Figura 5.1: simplexos de dimensões $0,1,2$ e 3

Uma célula convexa afim $\sigma=\left[\mathrm{v}_{0}, \ldots, \mathrm{v}_{\mathrm{n}}\right]$ de $\mathbf{R}^{\mathrm{m}}$ é chamada simplexo $\operatorname{se} \operatorname{dim}(\sigma)=\mathrm{n}$, isto $e$, um simplexo $\mathbf{n}$-dimensional é uma célula convexa afim de dimensão $n$ gerada por $n+1$ pontos. Por exemplo, os simplexos de dimensão 0 são pontos, os de dimensão 1 são segmentos de reta, os de dimensão 2 são 
triângulos e os de dimensão 3 são tetraedros, como mostrado na figura 5.1 .

Uma decomposição celular $C$ de $D \subset \mathbf{R}^{m}$ é chamada triangulação de $\mathrm{D}$, se todas as células de $\mathrm{C}$ são simplexos. Uma variedade linear por partes $(D, C)$ é dita ser uma variedade triangulada se $C$ é uma triangulação.

Dado um simplexo $\sigma=\left[v_{0}, \ldots, v_{n}\right]$ de $\mathbf{R}^{m}$ e $\left\{w_{0}, \ldots, w_{k}\right\} \subset\left\{v_{0}, \ldots, v_{n}\right\}$, a célula convexa afim $\tau=\left[w_{0}, \ldots, w_{k}\right]$ é denominada face de dimensão $k$ de $\sigma$. As faces de $\sigma$ geradas por um único ponto são chamadas vértices de $\sigma$; por dois pontos, arestas de $\sigma$; e por n pontos, facetas de $\sigma$.

Dado um simplexo $\sigma=\left[v_{0}, \ldots, v_{n}\right]$ de $\mathbf{R}^{\mathrm{m}}$, define-se:

- a fronteira de $\sigma, \partial(\sigma)$, como a união de todas as faces de dimensão n-1 de $\sigma$;

- o baricentro de $\sigma, \quad b(\sigma)=\frac{1}{n+1} \sum_{i=0}^{n} v_{i}$;

- o diâmetro de $\sigma, \rho(\sigma)=\max \left\{\left\|\mathrm{v}_{\mathrm{i}}-\mathrm{v}_{\mathrm{j}}\right\| ; \mathrm{i}, \mathrm{j}=0, \ldots, \mathrm{n}\right\}$;

- o raio de $\sigma, r(\sigma)=\min \{\|v-b(\sigma)\| ; v \in \partial(\sigma)\}$;

- a robustez de $\sigma, \theta(\sigma)=\mathrm{r}(\sigma) / \rho(\sigma)$.

Se T é uma triangulação de $D \subset \mathbb{R}^{\mathrm{m}}$, define-se:

- o diâmetro de $\mathrm{T}, \rho(\mathrm{T})=\sup \{\rho(\sigma) ; \sigma \in \mathrm{T} \operatorname{com} \operatorname{dim}(\sigma)>0\}$;

- a robustez de T, $\theta(\mathrm{T})=\inf \{\theta(\sigma) ; \sigma \in \mathrm{T} \operatorname{com} \operatorname{dim}(\sigma)>0\}$.

\section{3 - A Triangulação CFK}

Os resultados desta e das seções 5.4, 5.5, 5.6 e 5.7 foram obtidos de [Ca92].

Considere o cubo unitário $I^{\mathrm{m}}=[0,1]^{\mathrm{m}} \subset \mathbf{R}^{\mathrm{m}}$.

Sejam $\pi:\{1, \ldots, \mathrm{m}\} \rightarrow\{1, \ldots, \mathrm{m}\}$ uma permutação de $\{1, \ldots, \mathrm{m}\}$, representada pela $\mathrm{m}$-upla ordenada $\pi=\left(\pi_{1}, \ldots, \pi_{m}\right)$, e $\left\{e_{1}, \ldots, e_{m}\right\}$ a base canónica do $\mathbf{R}^{m}$.

Considere o simplexo $\sigma_{\mathrm{z}}=\left[\mathrm{v}_{0}, \ldots, \mathrm{v}_{\mathrm{m}}\right]$, onde 


$$
\begin{aligned}
& v_{0}=(0, \ldots, 0) \in I^{m} e \\
& v_{t}=v_{t-1}+e_{x_{1}}=v_{0}+e_{x_{1}}+\ldots+e_{x_{i}}, \quad i=1, \ldots, n .
\end{aligned}
$$

É fácil verificar que $\sigma_{\pi}$ é um simplexo de dimensão $\mathrm{m}$ contido em $\mathrm{I}^{\mathrm{m}}$.

Define-se a triangulação CFK (Coxeter-Freudenthal-Kuhn) como o conjunto dos simplexos $\sigma_{*}$ e suas faces, tal que $\pi$ é uma permutação de $\{1, \ldots, m\}$. Então, $\left(I^{m}, C F K\right)$ é uma variedade triangulada de dimensão $\mathrm{m}$ com fronteira.

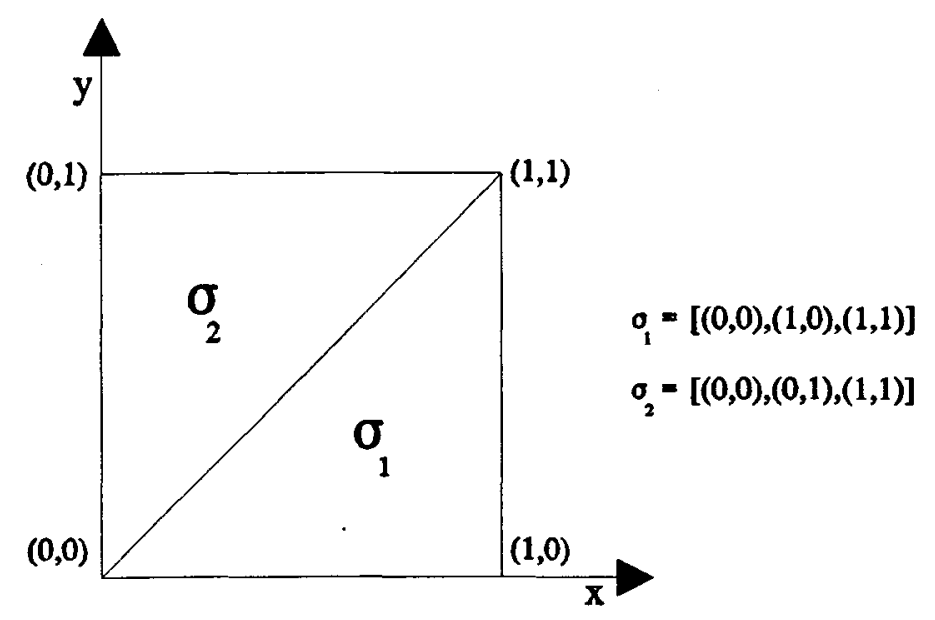

Figura 5.2: a triangulação $C F K$ do cubo $I^{2}=[0,1]^{2} \subset \mathbf{R}^{2}$

Como exemplo, considere a triangulação CFK de $\mathrm{I}^{2}=[0,1]^{2} \subset \mathbb{R}^{2}$ apresentada na figura 5.2. Sejam $\pi:\{1,2\} \rightarrow\{1,2\}$ e $\left\{e_{1}, e_{2}\right\}$ a base canônica do $\mathbf{R}^{2}$, os simplexos $\sigma_{1}$ e $\sigma_{2}$ são obtidos como segue:

Para $\pi=(1,2)$, tem-se que:

$$
\begin{aligned}
& v_{0}=(0,0), \\
& v_{1}=v_{0}+e_{\pi_{1}}=v_{0}+e_{1}=(0,0)+(1,0)=(1,0) e \\
& v_{2}=v_{1}+e_{x_{2}}=v_{1}+e_{2}=(1,0)+(0,1)=(1,1) .
\end{aligned}
$$

Então, $\sigma_{1}=[(0,0),(1,0),(1,1)]$.

Para $\pi=(2,1)$, tem-se que: 


$$
\begin{aligned}
& v_{0}=(0,0), \\
& v_{1}=v_{0}+e_{r_{1}}=v_{0}+e_{2}=(0,0)+(0,1)=(0,1) e \\
& v_{2}=v_{1}+e_{r_{2}}=v_{1}+e_{1}=(0,1)+(1,0)=(1,1) .
\end{aligned}
$$

Logo, $\sigma_{2}=[(0,0),(0,1),(1,1)]$.

O mesmo pode ser feito com o cubo $\mathrm{P}=[0,1]^{3} \subset \mathbf{R}^{3}$, como mostrado na figura 5.3.

Observe que existe uma relação biunívoca entre $\pi$ e $\sigma_{\pi}$. Por conseguinte, a triangulação CFK de $\mathrm{I}^{\mathrm{m}}$ contém $\mathrm{m}$ ! simplexos de dimensão $\mathrm{m}$.

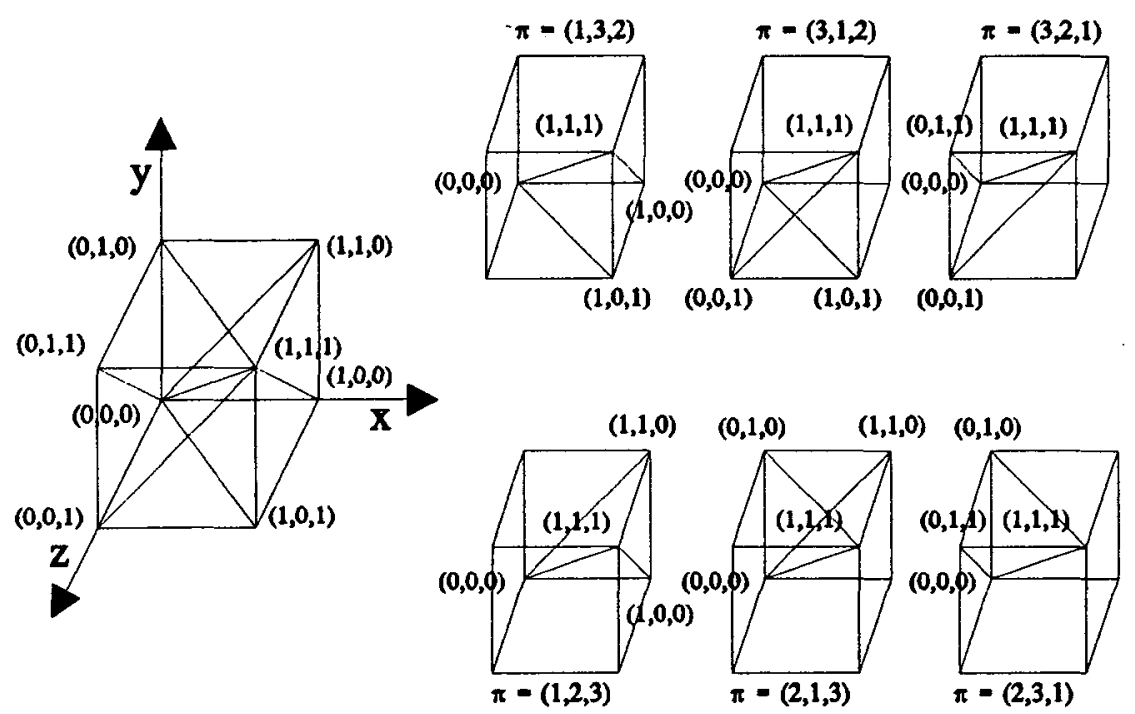

Figura 5.3: a triangulação CFK do cubo $I^{3}=[0,1]^{3} \subset R^{3}$

\section{4 - As Triangulações $K_{1}$ e $J_{1}$}

As triangulações $K_{1}$ e $J_{1}$ são derivadas da triangulação CFK.

Para se obter a triangulação $K_{1}$ de $\mathbf{R}^{\mathrm{m}}$, translada-se a variedade triangulada (I ${ }^{\mathrm{m}}, \mathrm{CFK}$ ), ou seja, para cada $v_{0} \in Z^{m}$ e $\pi$ uma permutação de $\{1, \ldots, m\}$, define-se $\sigma=K_{1}\left(v_{0}, \pi\right)=\left[v_{0}, \ldots, v_{m}\right]$, onde 


$$
v_{i}=v_{i-1}+e_{x_{i}}=v_{0}+e_{x_{1}}+\ldots+e_{x_{i}}, i=1, \ldots, m
$$

A triangulação $K_{1}$ de $R^{m}$ é formada pelos simplexos $K_{1}\left(v_{0}, \pi\right)$ e suas faces. A figura 5.4 ilustra a triangulação $K_{1}$ do $R^{2}$. O simplexo $\sigma$ é descrito por $v_{0}=(1,1)$ e $\pi=(1,2)$.

Para se obter a triangulação $\mathrm{J}_{1}$ de $\mathbf{R}^{\mathrm{m}}$, reflete-se $\left(\mathrm{I}^{\mathrm{m}}, \mathrm{CFK}\right)$ com relação às faces de dimensão $\mathrm{m}-1$ de $I^{m}$, ou seja, para cada $v_{0} \in\left\{v=\left(v_{1}, \ldots, v_{m}\right) \in Z^{m} ; v_{i}\right.$ é par $\}, s=\left(s_{1}, \ldots, s_{m}\right) \in\{-1,1\}^{m}$ e $\pi$ uma permutação de $\{1, \ldots, m\}$, define-se $\sigma=J_{1}\left(v_{0}, \pi, s\right)=\left[v_{1}, \ldots, v_{m}\right]$, onde

$$
v_{i}=v_{i-1}+s_{x_{i}} e_{x_{i}}=v_{0}+s_{x_{1}} e_{x_{1}}+\cdots+s_{x_{i}} e_{x_{1}}, \quad i=1, \ldots, m
$$

A triangulação $\mathrm{J}_{1}$ é formada pelos simplexos $\mathrm{J}_{1}\left(\mathrm{v}_{0}, \pi, \mathrm{s}\right)$ e suas faces. A figura 5.5 mostra a triangulação $J_{1}$ do $R^{2}$. O simplexo $\sigma$ 'é descrito por $\mathrm{v}_{0}=(2,2), \pi=(1,2)$ e $\mathrm{s}=(-1,1)$.

Em [To76], é dada uma demonstração de que $K_{1}$ e $J_{1}$ são triangulações do $\mathbb{R}^{m} e$, portanto, de que $\left(\mathbb{R}^{\mathrm{m}}, \mathbf{K}_{1}\right)$ e $\left(\mathbb{R}^{\mathrm{m}}, \mathrm{J}_{1}\right)$ são variedades trianguladas de dimensão $\mathbf{m}$.

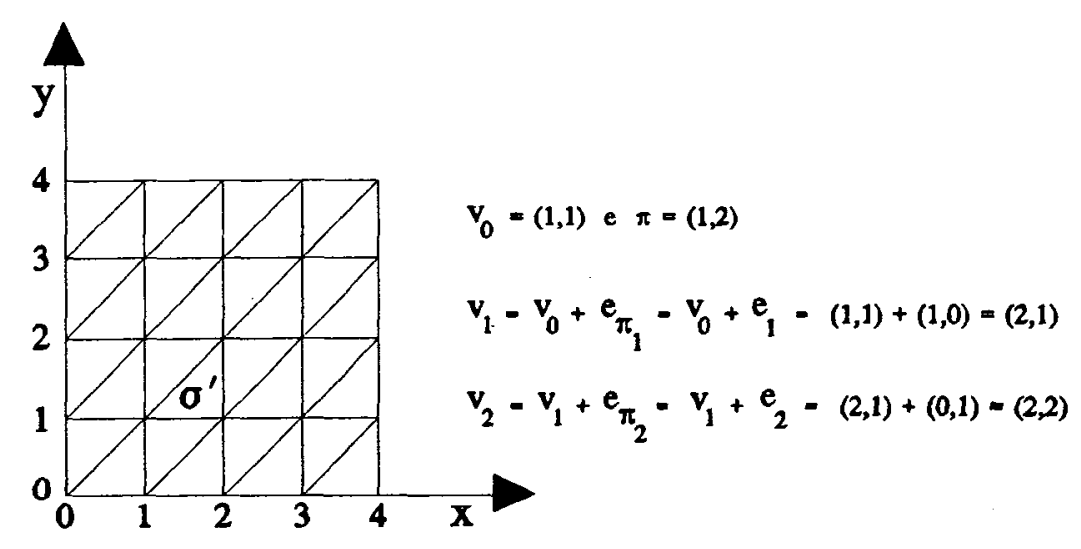

Figura 5.4: a triangulação $K_{1}$ do $R^{2}$

\section{5 - Rotulagem}

Considere o conjunto $D \subset \mathbf{R}^{\mathrm{m}}$, tal que $D=\left[v_{1}{ }^{\mathrm{c}}, \mathrm{v}_{1}{ }^{\mathrm{f}}\right] \times \cdots \times\left[\mathrm{v}_{\mathrm{m}}{ }^{\mathrm{c}}, \mathrm{v}_{\mathrm{m}}{ }^{\mathrm{f}}\right]$, onde $\mathrm{v}^{\mathrm{c}}, \mathrm{v}^{\mathrm{f}} \in \mathbf{R}^{\mathrm{m}}, \mathrm{v}_{\mathrm{i}}^{\mathrm{c}}<\mathrm{v}_{\mathrm{i}}^{\mathrm{f}}$ para $i=1, \ldots, m$. Sejam $K \in Z^{m}$ e $\delta \in R^{m}$, tais que $k_{i}>0$ e $\delta_{i}=\left(v_{i}^{f}-v_{i}^{c}\right) / K_{i}$ para $i=1, \ldots, m$.

As triangulaçōes $K_{1}$ e $J_{1}$ podem perfeitamente ser obtidas em $D$. Seja $G=N_{1} \times N_{2} \times \cdots \times N_{m}$, 
onde $N_{i}=\left\{0,1, \ldots, K_{i}-1\right\}, i=1, \ldots, m$, e $q(g)=\left[v_{1}^{c}+g_{1} \delta_{1}, v_{1}{ }^{c}+\left(g_{1}+1\right) \delta_{1}\right] \times \ldots \times\left[v_{m}{ }^{c}+g_{m} \delta_{m}, v_{m}{ }^{c}+\left(g_{m}+1\right) \delta_{m}\right]$ um bloco da decomposição de $\mathrm{D}$, onde $\mathrm{g}=\left(\mathrm{g}_{1}, \ldots, \mathrm{g}_{\mathrm{m}}\right)$ pertence a $\left\{0, \ldots, \mathrm{K}_{1}-1\right\} \times \ldots \times\left\{0, \ldots, \mathrm{K}_{\mathrm{m}}-1\right\}$. Observe que $\mathrm{q}(\mathrm{g})$ equivale ao cubo unitário $\mathrm{I}^{\mathrm{m}}=[0,1]^{\mathrm{m}} \subset \mathbf{R}^{\mathrm{m}}$ transladado e com escala alterada. De fato, basta considerar a base $\left(\delta_{1} e_{1}, \ldots, \delta_{m} e_{m}\right)$ e tomar o vértice $v_{0}$ do cubo $I^{m}$ como sendo $v_{0}+v^{c}=(0,0,0)+v^{c}$. A restrição das triangulações $v^{c}+\delta K_{1} e v^{c}+\delta J_{1}$ de $R^{m}$ a $D$, triangula $D$. A figura 5.6 exemplifica a decomposição de $D \subset R^{2}$ definido por $v^{c}$ e $v^{f}$ com $K=(4,3)$ e as $m$-uplas $g=\left(g_{1}, \ldots, g_{m}\right)$ associadas a cada bloco.

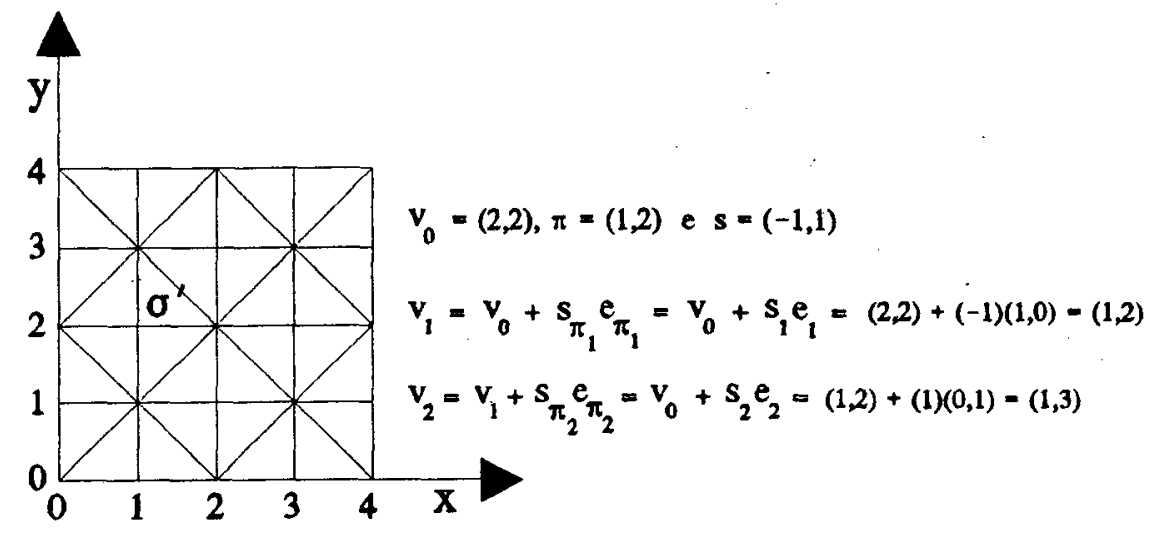

Figura 5.5: a triangulação $J_{1}$ do $\mathbb{R}^{2}$

Cada simplexo $\sigma$ de dimensão $\mathrm{m}, \sigma=\mathrm{K}_{1}\left(\mathrm{v}_{0}, \pi\right)$, da triangulação $\mathrm{K}_{1} \mathrm{e}$, portanto, da triangulação $\mathbf{v}^{\mathfrak{c}}+\delta \mathrm{K}_{1}$ pode ser representado por dois vetores de números inteiros: $v_{0}$ e $\pi$. De modo análogo, nas triangulações $\mathrm{J}_{1}$ e $\mathrm{v}^{\mathrm{c}}+\delta \mathrm{J}_{1}$, um simplexo $\sigma$ de dimensão $\mathrm{m}, \sigma=\mathrm{J}_{1}\left(\mathrm{v}_{0}, \pi, \mathrm{s}\right)$, pode ser representado por três vetores de números inteiros: $v_{0}$, $\pi$ e s. Entretanto, as triangulaçōes $K_{1}(D, K)$ e $J_{t}(D, K)$ de $D$ podem ser descritas do ponto de vista combinatório através de um processo de rotulagem de tal forma que cada bloco de $\mathrm{D}$ seja representado por um número inteiro, cada simplexo $\sigma$ de dimensão $\mathrm{m}$, por dois números inteiros, e seus vértices rotulados por um número inteiro.

Cada $g \in G$ e, consequentemente, cada bloco $q(g)$ de $D$ podem ser associados a um número inteiro, $\mathrm{l}(\mathrm{g})$, do conjunto $\{0,1, \ldots, \# \mathrm{G}\}$ biunivocamente, onde \#G é o número de elementos de $\mathrm{G}$, como segue:

$$
l(g)=\sum_{i=0}^{m} b_{i} g_{i}
$$

onde $b_{1}=1, b_{i}=b_{i-1} \cdot K_{i-1}$. Para obter $g$ a partir de $l(g)$, utiliza-se as relações recorrentes: 


$$
\left\{\begin{array}{l}
g_{i}=\left[\frac{l(g)}{K_{i}}\right]_{l(g) \leftarrow l(g) \bmod K_{i}} \quad i=m, \ldots, 1,
\end{array}\right.
$$

onde o símbolo $[\mathrm{x}]$ representa o maior inteiro que é menor ou igual a $\mathrm{x}$. O número $\mathrm{l}(\mathrm{g})$ é o rótulo do bloco $q(\mathrm{~g})$. A figura 5.7 ilustra a rotulagem dos blocos da subdivisão de $D \subset \mathbf{R}^{2}$ com $K=(4,3)$ mostrada na figura 5.6.

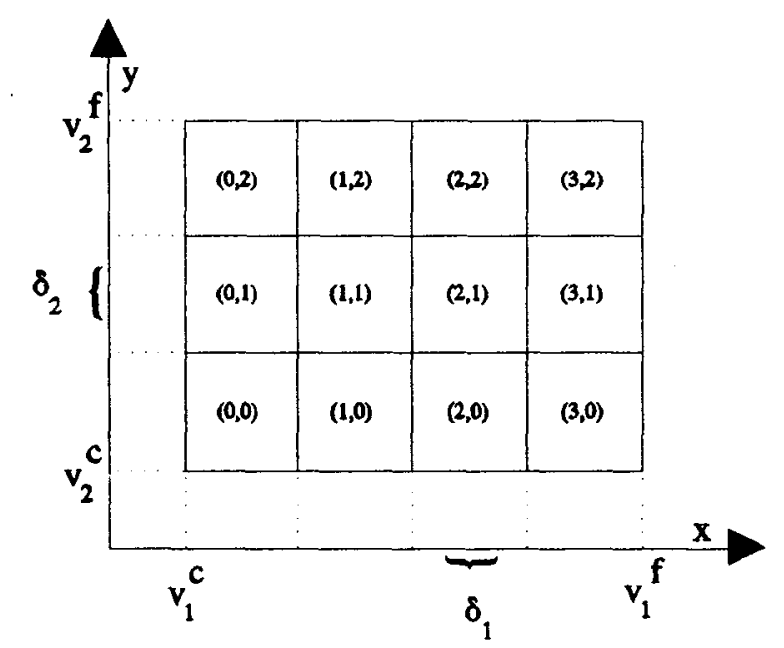

Figura 5.6: decomposição de $D \subset \mathbb{R}^{2}$ definida por $v^{\mathbb{e}}$ e $v^{f} \operatorname{com} K=(4,3)$

$O$ conjunto dos vértices do cubo unitário $\mathrm{I}^{\mathrm{m}}$ é equivalente a $\mathrm{G}$ com $\mathrm{K}_{\mathrm{i}}=2, \mathrm{i}=1, \ldots, \mathrm{m}$. Portanto, estes vértices podem ser rotulados da mesma forma que G. Por exemplo, se $v=\left(v_{1}, \ldots, v_{m}\right)$ é um vértice de $I^{m}, l(v)$ é o rótulo de $v$, onde $l(v)=v_{1} \cdot 1+v_{2} \cdot 2+\cdots+v_{m} \cdot 2^{m-1}$. Observe que esta rotulagem corresponde a uma representação na base 10 os vértices de $\mathrm{I}^{\mathrm{m}}$ se estes forem considerados como números binários, isto $e, l(v)=v_{1} \cdot 2^{0}+v_{2} \cdot 2^{i}+\cdots+v_{m} \cdot 2^{m-1}$.

Cada bloco $\mathrm{q}(\mathrm{g})$ possui uma relação biunívoca com o cubo unitário $\mathrm{I}^{\mathrm{m}}$, isto $e, q(\mathrm{~g})$ é uma translação e uma alteração de escala de $I^{m}$. Se u é um vértice de $I^{m}, v=\left(v_{1}{ }^{c}+\left(g_{1}+u_{1}\right) \delta_{1}, \ldots, v_{m}{ }^{c}+\left(g_{m}+u_{m}\right) \delta_{m}\right)$ é um vértice de $q(g)$, e se $v$ é um vértice de $q(g), \Im_{g}(v)=\left(\left(v_{t}-v_{1}^{c}\right) / \delta_{1}-g_{1}, \ldots,\left(v_{m}-v_{m}^{c}\right) / \delta_{m}-g_{m}\right)$ é um vértice de $I^{m}$. Portanto, rotula-se $v$ com $l_{g}(v)=I\left(\Im_{g}(v)\right)$.

Cada permutação $\pi$ do conjunto $\{1, \ldots, \mathrm{m}\}$ pode ser associada a um número inteiro, $1(\pi)$, que corresponde ao rótulo da permutação. Em [Ca92], é apresentado um algoritmo para determinar l( $\pi$ ) dado $\pi$, e outro para recuperar $\pi$ a partir de $l(\pi)$. Para este trabalho, interessam apenas as triangulações de 
$D \subset \mathbf{R}^{3}$, portanto $\pi$ é uma das seis (3!) permutações do conjunto $\{1,2,3\}$, de modo que não há necessidade de adotar um algoritmo para rotular $\pi$.

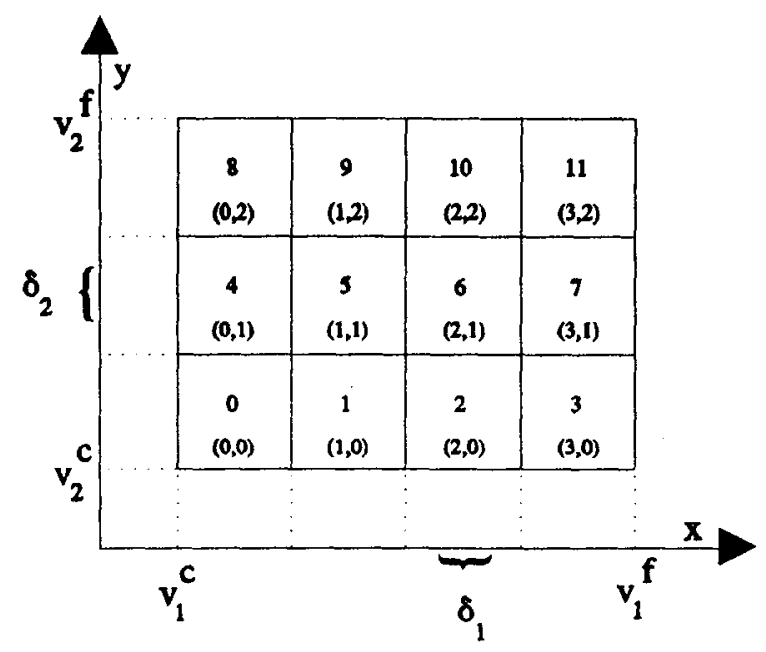

Figura 5.7: rotulagem dos blocos da subdivisão de $D \subset R^{2} \operatorname{com} K=(4.3)$

Um simplexo de dimensão $m$ da triangulação $K_{1}(D, K)$ de $D, \sigma=K_{1}(l(g), l(\pi))=\left[v_{0}, \ldots, v_{m}\right]$, é representado pelos inteiros $\mathrm{l}(\mathrm{g})$ e $\mathrm{l}(\pi)$ onde $\mathrm{g} \in \mathrm{G}$ e $\pi$ é uma permutação de $\{1, \ldots, \mathrm{m}\}$ e seus vértices são:

$$
\begin{aligned}
v_{0} & =v^{c}+\sum_{j=1}^{m} g_{j} \delta_{j} e_{j} \\
v_{i} & =v_{i-1}+\delta_{\pi_{1}} e_{\pi_{1}}= \\
& =v_{0}+\delta_{\pi_{1}} e_{\pi_{1}}+\cdots+\delta_{x_{1}} e_{x_{i}}, \quad i=1, \ldots, m .
\end{aligned}
$$

O rótulo de $\sigma$ é dado por $\mathrm{l}_{\mathrm{g}}(\sigma)=\left(\mathrm{l}_{\mathrm{g}}\left(\mathrm{v}_{\mathrm{o}}\right), \ldots, \mathrm{l}_{\mathrm{g}}\left(\mathrm{v}_{\mathrm{m}}\right)\right)$ onde

$$
\begin{aligned}
l_{g}\left(v_{0}\right) & =l\left(\Im_{g}\left(v_{0}\right)\right)=0 ; \\
l_{g}\left(v_{i}\right) & =l\left(\Im_{g}\left(v_{j}\right)\right)=l\left(\Im_{g}\left(v_{i-1}\right)\right)+2^{\pi_{i}-1}= \\
& =2^{\pi_{1}-1}+\ldots+2^{\pi_{i}-1}, \quad i=1, \ldots, m .
\end{aligned}
$$

Para exemplificar, considere a triangulação $K_{1}(D, K)$ de um domínio compacto $D \subset \mathbf{R}^{2}$ com $K=(4,3)$ mostrada na figura 5.8. Os simplexos $\sigma_{1}=K_{1}(1,2), \sigma_{2}=K_{1}(6,1)$ e $\sigma_{3}=K_{1}(8,1)$ estão nos blocos dados por $\mathrm{g}=(1,0), \mathrm{g}=(2,1)$ e $\mathrm{g}=(0,2)$, são obtidos pelas permutações $\pi=(2,1), \pi=(1,2)$ e $\pi=(1,2)$, e seus rótulos são $l_{\mathrm{g}}\left(\sigma_{1}\right)=(0,2,3), \mathrm{l}_{\mathrm{B}}\left(\sigma_{2}\right)=(0,1,3)$ e $\mathrm{l}_{\mathrm{g}}\left(\sigma_{3}\right)=(0,1,3)$ respectivamente.

Um simplexo de dimensão $m$ da triangulação $J_{1}(D, K)$ de $D, \sigma=J_{1}(l(g), 1(\pi))=\left[v_{0}, \ldots, v_{m}\right]$, é representado pelos inteiros $\mathrm{l}(\mathrm{g})$ e $\mathrm{l}(\pi)$ onde $\mathrm{g} \in \mathrm{G}$ e $\pi$ é uma permutação de $\{1, \ldots, \mathrm{m}\}, \quad s=\sum_{j=1}^{m}(-1)^{s_{j}} e_{j}, \quad$ e 
seus vértices são:

$$
\begin{aligned}
v_{0} & =v^{c}+\sum_{j=1}^{m}\left(g_{j}+g_{j} \bmod 2\right) \delta_{j} e_{j} \\
v_{i} & =v_{i-1}+\delta_{\pi_{i}} s_{z_{i}} e_{\pi_{1}}= \\
& =v_{0}+\delta_{z_{1}} s_{z_{i}} e_{\pi_{1}}+\cdots+\delta_{\pi_{i}} s_{\pi_{i}} e_{\pi_{i}}, \quad i=1, \ldots, m .
\end{aligned}
$$

Observe que o vetor $s$ foi obtido da m-upla $g \in G$.

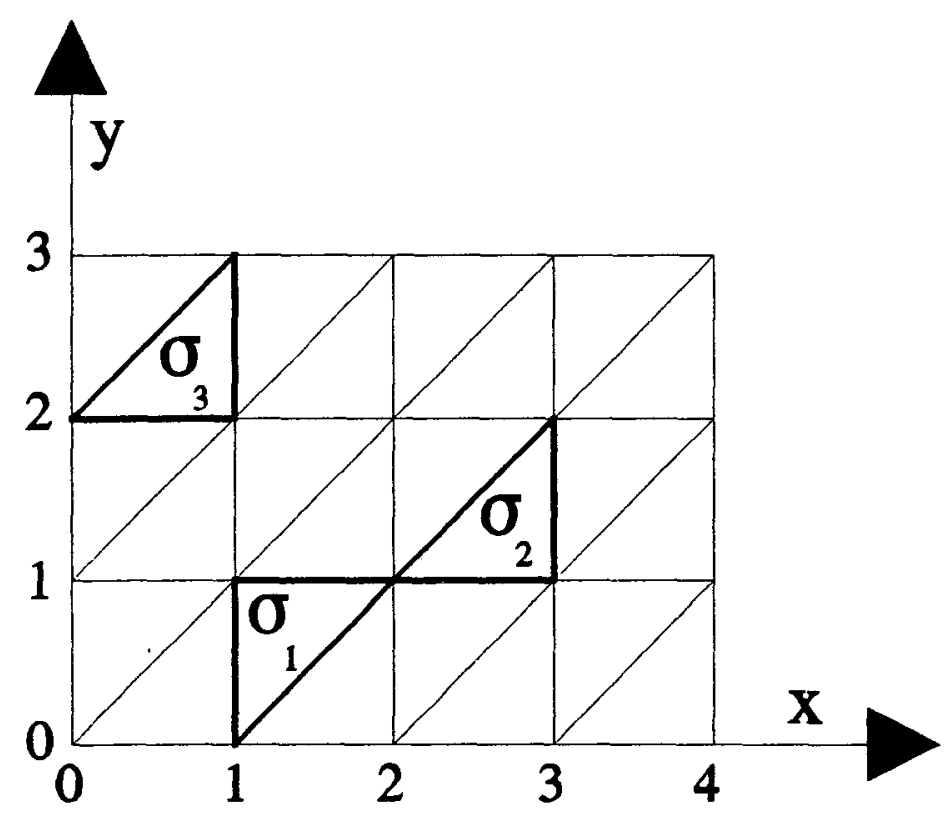

Figura 5.8: simplexos $\sigma_{1}=K_{1}(1,2), \sigma_{2}=K_{1}(6,1)$ e $\sigma_{3}=K_{1}(8,1)$ de $K_{1}(D, K), D \subset R^{2}$ e $K=(4,3)$

O rótulo de $\sigma$ é dado por $\mathrm{l}_{\mathrm{g}}(\sigma)=\left(\mathrm{l}_{\mathrm{g}}\left(\mathrm{v}_{0}\right), \ldots, \mathrm{l}_{\mathrm{g}}\left(\mathrm{v}_{\mathrm{m}}\right)\right)$ onde

$$
\begin{aligned}
l_{g}\left(v_{0}\right) & =l\left(\Im_{g}\left(v_{0}\right)\right)=\sum_{j=1}^{m}\left(g_{j} \bmod 2\right) 2^{j-1} ; \\
l_{g}\left(v_{i}\right) & =l\left(\Im_{g}\left(v_{l}\right)\right)=l\left(\Im_{g}\left(v_{i-1}\right)\right)+s_{\pi_{i}} 2^{\pi_{i}-1}= \\
& =l\left(\Im_{g}\left(v_{0}\right)\right)+s_{\pi_{i}} 2^{\pi_{1}-1}+\ldots+s_{\pi_{i}} 2^{\pi_{i}-1}, \quad i=1, \ldots, m .
\end{aligned}
$$

Para exemplificar, considere a triangulação $J_{1}(D, K)$ do domínio $D \subset R^{2}$ com $K=(4,3)$ ilustrada na figura 5.9. Os simplexos $\sigma_{1}=\mathrm{J}_{1}(1,2), \sigma_{2}=\mathrm{J}_{1}(6,1)$ e $\sigma_{3}=\mathrm{J}_{1}(8,1)$ estão nos blocos $\mathrm{g}=(1,0), \mathrm{g}=(2,1)$ e $g=(0,2)$, são obtidos pelas permutações $\pi=(2,1), \pi=(1,2)$ e $\pi=(1,2)$ e seus rótulos são $l_{8}\left(\sigma_{1}\right)=(1,3,2)$, $l_{g}\left(\sigma_{2}\right)=(2,3,1)$ e $l_{B}\left(\sigma_{3}\right)=(0,1,3)$, respectivamente. 
Se $\sigma=\mathrm{K}_{1}(\mathrm{l}(\mathrm{g}), \mathrm{l}(\pi))=\left[\mathrm{v}_{0}, \ldots, \mathrm{v}_{\mathrm{m}}\right]$ e $\quad \tau=\left[v_{r_{0}}, \ldots, v_{r_{\mathrm{r}}}\right] \quad$ é uma face de dimensão $\mathrm{n}<\mathrm{m}$ de $\sigma$, rotula-se $\tau$ por $l(\tau)=\left(l_{g}\left(v_{r_{0}}\right), \ldots, l_{g}\left(\nu_{r_{n}}\right)\right)$. Os simplexos de dimensão $n<m$ de $J_{1}(\mathrm{D}, \mathrm{K})$ são rotulados de maneira análoga.

O processo de rotulagem possibilita representar de forma mais compacta os blocos da subdivisão de $\mathrm{D}$ e os simplexos das triangulações $\mathrm{K}_{1}$ e $\mathrm{J}_{1}$ de $\mathrm{D}$. Além disso, permite operar com os vértices dessas triangulações através dos rótulos ao invés dos próprios vértices.

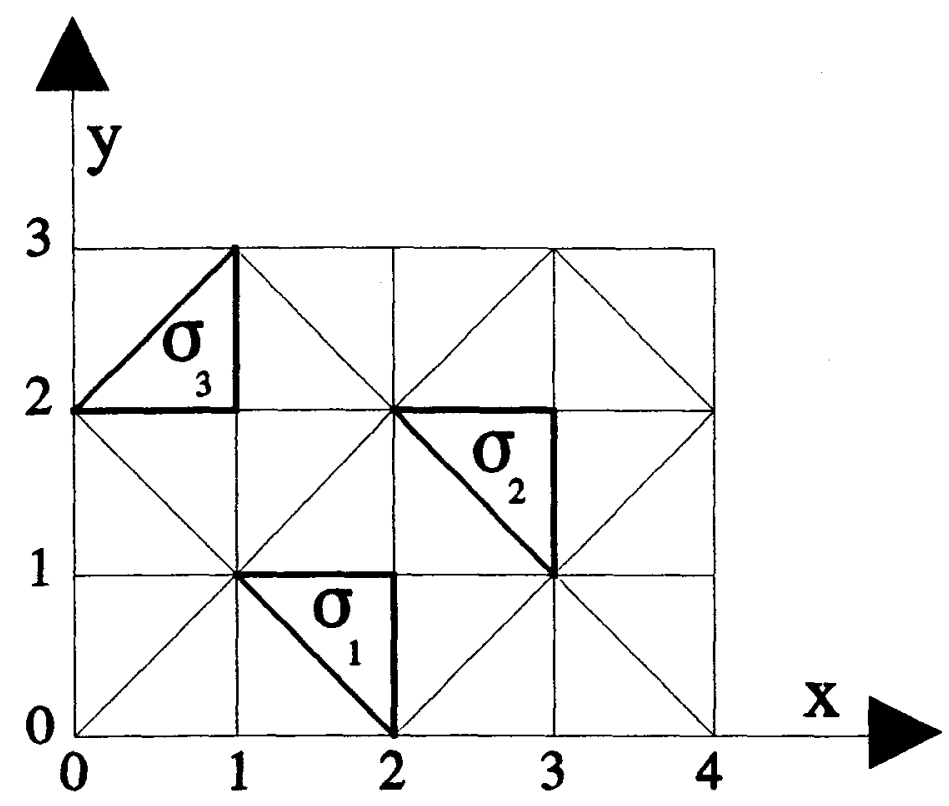

Figura 5.9: simplexos $\sigma_{1}=\mathrm{J}_{1}(1,2), \quad \sigma_{2}=\mathrm{J}_{1}(6,1)$ e $\sigma_{3}=\mathrm{J}_{1}(8,1)$ de $\mathrm{J}_{1}(\mathrm{D}, \mathrm{K}), \mathrm{D} \subset \mathrm{R}^{2}$ e $\mathrm{K}=(4,3)$

\section{6 - Regras de Pivoteamento}

Regras de pivoteamento de uma triangulação são regras tais que, dado um simplexo de dimensão $\mathbf{m}, \sigma=\left[v_{0}, \ldots, v_{i-1}, v_{i}, v_{i+1}, \ldots, v_{m}\right]$, para cada face $\left[v_{0}, \ldots, v_{i-1}, v_{i+1}, \ldots, v_{m}\right], i=1, \ldots, m$, é possível obter um simplexo de dimensão $m, \quad \sigma_{i}=\left[v_{0}, \ldots, v_{i-1}, \nu_{i}, v_{i+1}, \ldots, v_{m}\right], \quad$ que também contém esta face, denominado i-ésimo pivoteado de $\sigma$ ou pivoteado de $\sigma$ pelo vértice $v_{i}$. 
As triangulações $K_{1}$ e $J_{1}$ possuem regras de pivoteamento distintas visto que a disposição dos simplexos difere nestas triangulações, como pode ser constatado nas figuras 5.4 e 5.5 .

Para a triangulação $K_{1}$ de $\mathbf{R}^{\mathrm{m}}$, a regra de pivoteamento é a seguinte:

Se $\sigma=K_{1}\left(\mathrm{~V}_{0}, \pi\right)=\left[\mathrm{v}_{0}, \ldots, \mathrm{v}_{\mathrm{i}-1}, \mathrm{~V}_{\mathrm{i}}, \mathrm{V}_{\mathrm{i}+1}, \ldots, \mathrm{V}_{\mathrm{m}}\right]$, o i-ésimo pivoteado de $\sigma$ é o simplexo $\sigma_{\mathrm{i}}=\mathrm{K}_{1}\left(\mathrm{v}_{0}{ }^{\prime}, \pi^{\prime}\right)$ dado por $v_{0}^{\prime}$ e $\pi^{\prime}$ como a seguir:

$$
\begin{aligned}
& i=0 \Rightarrow\left\{\begin{array}{l}
v_{0}^{\prime}=v_{0}+e_{\pi_{1}} \\
\pi^{\prime}=\left(\pi_{2}, \ldots, \pi_{m}, \pi_{1}\right)
\end{array}\right. \\
& 0<i<m \Rightarrow\left\{\begin{array}{l}
v_{0}^{\prime}=v_{0} \\
\pi^{\prime}=\left(\pi_{1}, \ldots, \pi_{i-1}, \pi_{i+1}, \pi_{i}, \pi_{i+2}, \ldots, \pi_{m}\right)
\end{array}\right. \\
& i=m \Rightarrow\left\{\begin{array}{l}
v_{0}^{\prime}=v_{0}-e_{\pi_{m}} \\
\pi^{\prime}=\left(\pi_{m}, \pi_{1}, \ldots, \pi_{m-1}\right)
\end{array} .\right.
\end{aligned}
$$

Para a triangulação $J_{1}$ de $\mathbb{R}^{m}$, a regra de pivoteamento é a seguinte:

Se $\sigma=\mathrm{J}_{1}\left(\mathrm{v}_{0}, \pi, \mathrm{s}\right)=\left[\mathrm{v}_{0}, \ldots, \mathrm{v}_{\mathrm{i}-1}, \mathrm{v}_{\mathrm{i}}, \mathrm{v}_{\mathrm{i}+1}, \ldots, \mathrm{v}_{\mathrm{m}}\right]$, o i-ésimo pivoteado de $\sigma$ é o simplexo $\sigma_{\mathrm{i}}=\mathrm{J}_{1}\left(\mathrm{v}_{0}, \pi^{\prime}, \mathrm{s}^{\prime}\right)$ dado por $v_{0}^{\prime}$ e $\pi$ ' como a seguir:

$$
\begin{aligned}
& i=0 \Rightarrow\left\{\begin{array}{l}
v_{0}^{\prime}=v_{0}+2 s_{\pi_{1}} e_{\pi_{1}} \\
\pi^{\prime}=\pi \\
s^{\prime}=s-2 s_{\pi_{1}} e_{\pi_{1}}
\end{array}\right. \\
& 0<i<m \Rightarrow\left\{\begin{array}{l}
v_{0}^{\prime}=v_{0} \\
\pi^{\prime}=\left(\pi_{1}, \ldots, \pi_{i-1}, \pi_{i+1}, \pi_{i}, \pi_{i+2}, \ldots, \pi_{m}\right) \\
s^{\prime}=s
\end{array}\right. \\
& i=m \Rightarrow\left\{\begin{array}{l}
v_{0}^{\prime}=v_{0} \\
\pi^{\prime}=\pi \\
s^{\prime}=s-2 s_{\tau_{-}} e_{\pi_{m}} .
\end{array}\right.
\end{aligned}
$$

A figura 5.10 exemplifica as regras de pivoteamento para as triangulações $\left(K_{1}, \mathbf{R}^{2}\right)$ e $\left(J_{1}, \mathbf{R}^{2}\right)$. Os simplexos $\sigma_{0}=\left[v_{1}, v_{2}, \hat{v}_{0}\right], \sigma_{1}=\left[v_{0}, \hat{v}_{1}, v_{2}\right]$ e $\sigma_{2}=\left[\hat{v}_{2}, v_{0}, v_{1}\right]$ são pivoteados de $\sigma=\left[v_{0}, v_{1}, v_{2}\right]$ pelos vértices $v_{0}$, $v_{1}$ e $v_{2}$, respectivamente, na triangulação $\left(K_{1}, R^{2}\right)$. Na triangulação $\left(J_{1}, R^{2}\right)$, os simplexos pivoteados de $\sigma=\left[v_{0}, v_{1}, v_{2}\right]$ pelos vértices $v_{0}, v_{1}$ e $v_{2}$ são $\sigma_{0}=\left[\hat{v}_{0}, v_{1}, v_{2}\right], \sigma_{1}=\left[v_{0}, \hat{v}_{1}, v_{2}\right]$ e $\sigma_{2}=\left[v_{0}, v_{1}, \hat{v}_{2}\right] \quad$ nesta ordem.

As regras de pivoteamento podem ser aplicadas sobre os rótulos dos simplexos da seguinte maneira: 


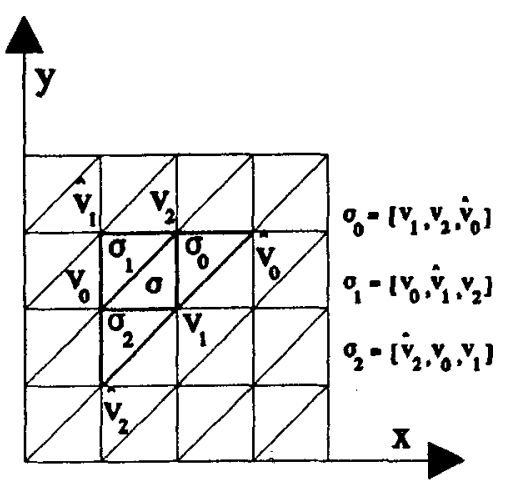

$\left(K_{1}, \mathbf{R}^{2}\right)$

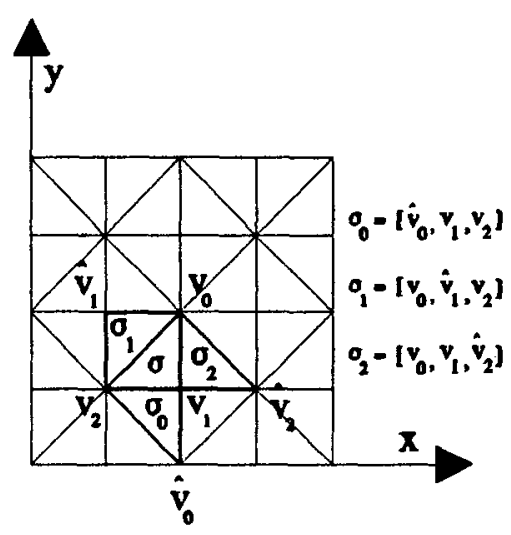

$\left(J_{1}, \mathbb{R}^{2}\right)$

Figura 5.10: exemplo de regras de pivoteamento das triangulações $K_{1}$ e $J_{1}$ do $\mathbf{R}^{2}$

Seja $\sigma=\mathrm{K}_{1}(\mathrm{l}(\mathrm{g}), \mathrm{l}(\pi))=\left[\mathrm{V}_{0}, \ldots, \mathrm{v}_{\mathrm{m}}\right]$. O i-ésimo pivoteado de $\sigma$ é:

$$
\begin{aligned}
& \begin{array}{l}
i=0 \\
g_{\pi_{1}}<K_{\pi_{1}-1}
\end{array} \Rightarrow\left\{\begin{array}{l}
\sigma_{0}=K_{1}\left(l\left(g^{\prime}\right), l\left(\pi^{\prime}\right)\right)=\left[v_{1}, v_{2}, \ldots, v_{m}, v_{0}+\delta_{\pi_{i}} e_{\pi_{1}}\right] \\
g^{\prime}=g+e_{\pi_{1}} \\
\pi^{\prime}=\left(\pi_{2}, \ldots, \pi_{m}, \pi_{1}\right) \\
l_{g}^{\prime}\left(\sigma_{0}\right)=\left(l_{g}\left(v_{1}\right)-2^{\pi_{1}-1}, \ldots, l_{g}\left(v_{m}\right)-2^{\pi_{1}-1}, l_{g}\left(v_{m}\right)\right)
\end{array}\right. \\
& 0<i<m \Rightarrow\left\{\begin{array}{l}
\sigma_{i}=K_{1}\left(l(g), l\left(\pi^{\prime}\right)\right)=\left[v_{0}, \ldots, v_{i-1}, v_{i-1}-v_{i}+v_{i+1}, v_{i+1}, \ldots, v_{m}\right] \\
\pi^{\prime}=\left(\pi_{1}, \pi_{i-1}, \pi_{i+1}, \pi_{i}, \pi_{i+2}, \ldots, \pi_{m}\right) \\
l_{g}\left(\sigma_{i}\right)=\left(l_{g}\left(v_{0}\right), \ldots, l_{g}\left(v_{i-1}\right), l_{g}\left(v_{i-1}\right)-l_{g}\left(v_{i}\right)+l_{g}\left(v_{i+1}\right), l_{g}\left(v_{i+1}\right), \ldots, l_{g}\left(v_{m}\right)\right)
\end{array}\right. \\
& g_{x_{-m}>0}>0 \Rightarrow\left\{\begin{array}{l}
\sigma_{m}=K_{1}\left(l\left(g^{\prime}\right), l\left(\pi^{\prime}\right)\right)=\left[v_{0}-\delta_{m_{m}} e_{\pi_{m}}, v_{0}, v_{1}, \ldots, v_{m-1}\right] \\
g^{\prime}=g-e_{\pi_{m}} \\
\pi^{\prime}=\left(\pi_{m}, \pi_{1}, \ldots, \pi_{m-1}\right) \\
l_{g}^{\prime}\left(\sigma_{m}\right)=\left(l_{g}\left(\dot{v}_{0}\right), l_{g}\left(v_{0}\right)+2^{\pi_{m}-1}, \ldots, l_{g}\left(v_{m-1}\right)+2^{\pi_{m}-1}\right) .
\end{array}\right.
\end{aligned}
$$

Seja $\sigma=\mathrm{J}_{1}(\mathrm{l}(\mathrm{g}), \mathrm{l}(\pi))=\left[\mathrm{v}_{0}, \ldots, \mathrm{v}_{\mathrm{m}}\right]$. O i-ésimo pivoteado de $\sigma$ é: 


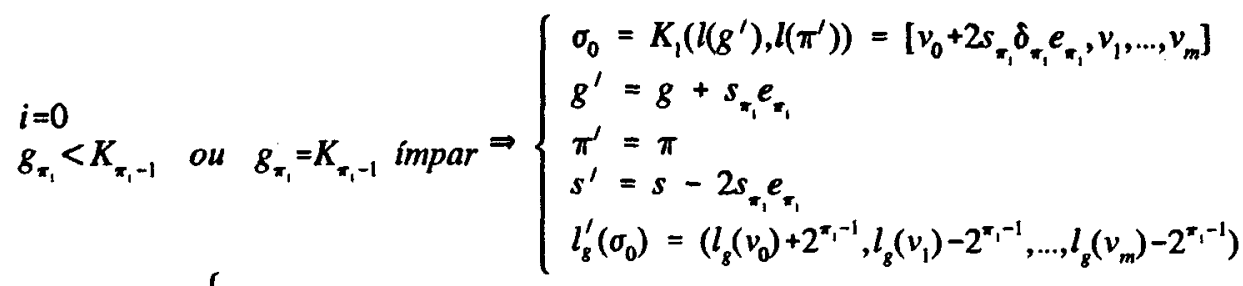

$$
\begin{aligned}
& 0<i<m \Rightarrow\left\{\begin{array}{l}
\sigma_{i}=J_{1}\left(l(g), l\left(\pi^{\prime}\right)\right)=\left[v_{0}, \ldots, v_{i-1}, v_{i-1}-v_{i}+v_{i+1}, v_{i+1}, \ldots, v_{m}\right] \\
\pi^{\prime}=\left(\pi_{1}, \pi_{i-1}, \pi_{i+1}, \pi_{i}, \pi_{i+2}, \ldots, \pi_{m}\right) \\
s=s^{\prime} \\
l_{g}\left(\sigma_{i}\right)=\left(l_{g}\left(v_{0}\right), \ldots, l_{g}\left(v_{i-1}\right), l_{g}\left(v_{i-1}\right)-l_{g}\left(v_{i}\right)+l_{g}\left(v_{i+1}\right), l_{g}\left(v_{i+1}\right), \ldots, l_{g}\left(v_{m}\right)\right)
\end{array}\right. \\
& g_{\pi_{m}}>0 \Rightarrow\left\{\begin{array}{l}
\sigma_{m}=J_{1}\left(l\left(g^{\prime}\right), l\left(\pi^{\prime}\right)\right)=\left[v_{0}, v_{1}, \ldots, v_{m}-2 s_{\pi_{m}} \delta_{\pi_{m}} e_{\pi_{m}}\right] \\
g^{\prime}=g-s_{\pi_{m}} e_{\pi_{m}} \\
\pi^{\prime}=\pi \\
l_{g}^{\prime}\left(\sigma_{m}\right)=\left(l_{g}\left(v_{0}\right)+s_{\pi_{m}} 2^{\pi_{m}-1}, \ldots, l_{g}\left(v_{m-1}\right)+s_{\pi_{m}} 2^{\pi_{m}-1}, l_{g}\left(v_{m}\right)-s_{\pi_{m}} 2^{\pi_{m}-1}\right) .
\end{array}\right.
\end{aligned}
$$

\section{7 - Perturbações}

Perturbar as triangulações $K_{1}(D, K)$ e $J_{1}(D, K)$ significa substituir cada vértice $v$ de ambas as triangulações por $v_{\varepsilon}$, tal que $\left\|v-v_{\varepsilon}\right\|<\varepsilon$, onde $\varepsilon$ deve ser tomado no intervalo $(0 ;\|\delta\| / 4)$. Então, tem-se novas triangulações semelhantes a $K_{1}(D, K)$ e $J_{1}(D, K)$. A figura 5.11 exemplifica o processo de perturbação para as triangulações $K_{1}$ e $J_{1}$.

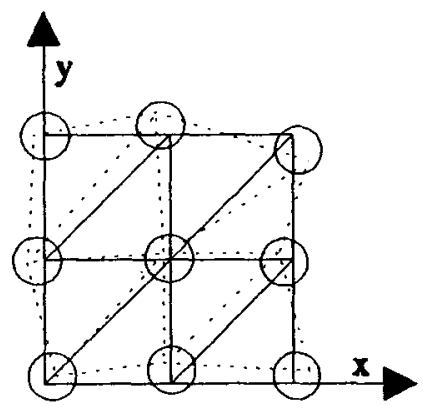

$K_{1}$ perturbada

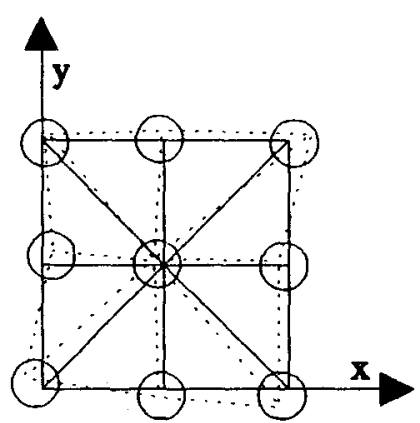

$\mathrm{J}_{1}$ perturbada

Figura 5.11: as triangulaçôes $K_{1}$ e $J_{1}$ do $R^{2}$ perturbadas

As triangulações $K_{1}(D, K)$ e $J_{1}(D, K)$ perturbadas podem ser construídas dependendo apenas de 
$\mathrm{g} \in \mathrm{G}$ e dos vértices do cubo unitário $\mathrm{I}^{\mathrm{m}}$.

Para cada vértice $v$ do cubo unitário, seja rand $(v, \varepsilon)=\left(\varepsilon_{1}, \ldots, \varepsilon_{\mathrm{m}}\right)$, onde cada coordenada é um

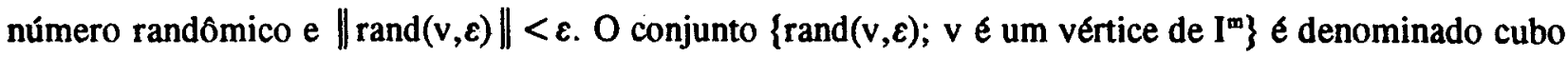
de perturbações e denotado por $\mathrm{I}^{\mathrm{m}}{ }_{\varepsilon}$. Os vértices de $\mathrm{K}_{1}(\mathrm{D}, \mathrm{K})$ e $\mathrm{J}_{1}(\mathrm{D}, \mathrm{K})$ podem ser perturbados a partir de $\mathrm{I}^{\mathrm{m}}{ }_{\varepsilon}$, refletindo-se $\mathrm{I}^{\mathrm{m}}$ com relação às suas faces de dimensão $\mathrm{n}-1 \mathrm{e}$, depois, somando-se as perturbações aos vértices correspondentes. Para cada $g \in G$ e v um vértice do cubo unitário $I^{m}$, seja $R_{g}(v)=w$, onde

$$
w_{i}=\left\{\begin{array}{c}
v_{i}, \text { se } g_{i} \text { é par } \\
1-v_{i}, \text { se } g_{i} \text { é impar, } \quad i=1, \ldots, m .
\end{array}\right.
$$

Se vé um vértice do bloco $q(g)$, define-se $v(\varepsilon)=v+\operatorname{rand}\left(R_{g}\left(\Im_{g}(v)\right), \varepsilon\right)$.

A triangulação $\mathrm{K}_{1}(\mathrm{D}, \mathrm{K})$ perturbada por $\mathrm{I}^{\mathrm{m}}{ }_{\varepsilon}$ é denotada por $\mathrm{K}_{1}\left(\mathrm{D}, \mathrm{K}, \mathrm{I}^{\mathrm{m}}{ }_{\varepsilon}\right)=\left\{\sigma(\varepsilon)=\left[\mathrm{v}_{0}(\varepsilon), \ldots, \mathrm{V}_{\mathrm{k}}(\varepsilon)\right]\right.$; $\sigma=\left[\mathrm{v}_{0}, \ldots, \mathrm{v}_{\mathrm{k}}\right] \in \mathrm{K}_{1}(\mathrm{D}, \mathrm{K})$ para $\left.0 \leq \mathrm{k} \leq \mathrm{m}\right\}$ e a triangulação $\mathrm{J}_{1}$ perturbada por $\mathrm{I}_{\varepsilon}^{\mathrm{m}}$ de $\mathrm{J}_{1}\left(\mathrm{D}, \mathrm{K}, \mathrm{I}_{\varepsilon}^{\mathrm{m}}\right)=$ $\left\{\sigma(\varepsilon)=\left[\mathrm{v}_{0}(\varepsilon), \ldots, \mathrm{v}_{\mathrm{k}}(\varepsilon)\right] ; \sigma=\left[\mathrm{v}_{0}, \ldots, \mathrm{v}_{\mathrm{k}}\right] \in \mathrm{J}_{1}(\mathrm{D}, \mathrm{K})\right.$ para $\left.0 \leq \mathrm{k} \leq \mathrm{m}\right\}$. O processo de rotulagem para $\mathrm{K}_{1}\left(\mathrm{D}, \mathrm{K}, \mathrm{I}^{\mathrm{m}}{ }_{\varepsilon}\right)$ e $J_{1}\left(D, K, I_{\varepsilon}^{m}\right)$ é o mesmo de $K_{1}(D, K)$ e $J_{1}(D, K)$.

\section{8 - Considerações Finais}

As triangulações $K_{1}$ e $J_{1}$ são usadas pelo procedimento de conversão da representação implícita para a BRep poliedral com o intuito de particionar o domínio $D \subset \mathbb{R}^{3}$, onde a função característica $F$ do semi-espaço correspondente ao sólido abstrato é considerada. Esse procedimento utiliza o processo de rotulagem para manipular de forma eficiente os elementos da triangulação, as regras de pivoteamento para "caminhar" na estrutura da triangulação e a perturbação para garantir a estabilidade numérica.

Um domínio compacto $D \subset \mathbf{R}^{\mathrm{m}}$ subdividido pelas triangulações $\mathrm{K}_{1}$ e $\mathrm{J}_{1}$ é definido sempre como um paralelepípedo em $\mathbf{R}^{\mathrm{m}}$, por isso o domínio $\mathrm{D} \subset \mathbf{R}^{3}$, onde a função característica $F$ do semi-espaço correspondente ao sólido abstrato é considerada, é descrito, no (SM) ${ }^{2}$, como uma "caixa". Além disso, as triangulações $K_{1}$ e $J_{1}$ subdividem $D \subset R^{m}$ em células equivalentes e, por esse motivo, são ditas triangulações uniformes.

No capítulo seguinte, capítulo 6, é apresentado o método usado pelo procedimento de conversão para gerar as informações da BRep poliedral a partir da representação implícita. Este método faz uso das triangulações $K_{1}$ e $J_{1}$, bem como do processo de rotulagem, das regras de pivoteamento e da perturbação. 


\section{Capítulo 6}

\section{Aproximação de Superfícies Definidas Implicitamente}

\section{1 - Considerações Iniciais}

Na representação implícita, a fronteira do sólido abstrato é descrita pelo código da função característica $F$, definida em um domínio (paralelepípedo) $D \subset \mathbf{R}^{3}$, do semi-espaço correspondente ao modelo. Na BRep poliedral, há informações explícitas sobre a geometria dos elementos topológicos da fronteira (vértices, arestas e faces) e suas relações de adjacência. A conversão da representação implícita para a BRep poliedral implica na obtenção das informações explícitas da fronteira do sólido abstrato a partir do código de F presente na representação implícita.

O procedimento de conversão da representação implícita para a BRep poliedral, implementado no $(\mathrm{SM})^{2}$, é semelhante ao procedimento de avaliação de fronteira (boundary evaluation), utilizado na conversão de representações CSG para BRep's [ReVo85], [Pe91 et al.]. A conversão é fundamentada em um método de aproximação por polígonos de superfícies definidas implicitamente, o qual gera uma superfície linear por partes que aproxima a superfície correspondente à fronteira do sólido abstrato. A superfície gerada é dada explicitamente em termos de vértices, arestas e faces. Os métodos de aproximação por polígonos de superficies definidas implicitamente são conhecidos como implicit surface tilers [B193]. O método de aproximação por polígonos presente no procedimento de conversão do (SM) ${ }^{2}$ foi utilizado por Castelo ([Ca92]), e por Tavares, Lopes e Castelo ([Ta92 et al.]) para aproximar variedades (generalizações de superfície) definidas implicitamente em $\mathbf{R}^{\mathbf{m}}$.

A aproximação de superfícies por polígonos pode ser dividida conceitualmente em duas fases: amostragem (sampling), que consiste no cálculo de pontos (vértices) da superfície de interesse, e estruturação (structuring), que é a criação da estrutura de dados para representar a superfície resultante da interpolação dos pontos calculados na fase de amostragem [FiGo92]. No método de aproximação por polígonos de superfícies definidas implicitamente utilizado no procedimento de conversão do (SM) ambas as fases, amostragem e estruturação, são realizadas com o auxnlio das triangulações $K_{1}$ ou $J_{1}$, discutidas no caṕtulo 5. Por isso, o método é dito ser simplicial. 
Neste capítulo, o método de aproximação por polígonos é apresentado. Na seção 6.2, o conceito de superfície linear por partes é abordado. Na seção 6.3 é apresentada uma função afim $F_{T}$ definida em cada simplexo da triangulação $\mathrm{K}_{1}$ ou $\mathrm{J}_{1}$. Na seção 6.4 é mostrado que a função $\mathrm{F}_{\mathrm{T}}$ é uma interpolação linear para uma função $F: D \rightarrow R$ nos vértices de cada simplexo da triangulação $K_{1}$ ou $J_{1}$ de $D$. Na seção 6.5 é mostrado que a superfície linear por partes $S_{\tau}$ é uma aproximação linear por partes para $S$, onde $S_{\mathrm{T}}=\mathrm{F}_{\mathrm{T}}^{-1}(0)$ e $S=\mathrm{F}^{-1}(0)$. Na seção 6.6 é descrito como obter os vertices da superfície linear por partes correspondente à fronteira do sólido abstrato (amostragem) e, finalmente, na seção 6.7, é apresentada a estrutura de dados para representar esta superfície (estruturação).

\section{2 - Superfície Linear por Partes}

Uma superfície linear por partes ou, simplesmente, superfície $L P S \subset \mathbb{R}^{m}$ é uma superfície que satisfaz as seguintes propriedades [GoTa89]:

- existe uma decomposição celular bidimensional $C$ de $S$;

- todas as células de $\mathrm{C}$ têm dimensão menor ou igual a 2;

- existe pelo menos uma célula de $\mathrm{C}$ com dimensão 2;

- toda célula de dimensão 1 de C está contida em uma ou duas células de dimensão 2 de C;

- toda célula de dimensão 0 de $C$ está contida em pelo menos uma célula de dimensão 2 de $C$.

Uma superfície linear por partes pode, simplesmente, ser definida como uma variedade linear por partes de dimensão 2. Um exemplo de superfície linear por partes em $\mathbf{R}^{3}$ é o conjunto formado pelas faces da fronteira de um cubo no $\mathbf{R}^{3}$.

\section{3 - A Função Afim Associada}

Os resultados apresentados nesta seção foram obtidos de [Fr91].

Seja $F: \mathbf{R}^{3} \rightarrow \mathbf{R}$ uma função diferenciável e $\sigma=\left[v_{0}, \ldots, v_{3}\right] \subset \mathbf{R}^{3}$ um simplexo.

Se $v \in \sigma$, então $v$ pode ser escrito como 


$$
v=\sum_{i=0}^{3} \lambda_{i} v_{i}, \text { onde } \sum_{i=0}^{3} \lambda_{i}=1 \text { e } \lambda_{i} \geq 0
$$

Denomina-se a função $\mathrm{F}_{\sigma}: \sigma \subset \mathbf{R}^{3} \rightarrow \mathbf{R}$, definida por

$$
F_{0}(v)=F_{\sigma}\left(\sum_{i=0}^{3} \lambda_{i} v_{i}\right)=\sum_{i=0}^{3} \lambda_{i} F\left(v_{i}\right)
$$

de função afim associada a $F$.

Como $\lambda_{0}=1-\sum_{i=0}^{3} \lambda_{i}, \quad$ v e $F_{o}$ podem ser escritos como

$$
v-v_{0}=\sum_{i=0}^{3} \lambda_{i}\left(v_{i}-v_{0}\right) \quad e \quad F_{o}(v)=F\left(v_{0}\right)+\sum_{i=0}^{3} \lambda_{i}\left(F\left(v_{i}\right)-F\left(v_{0}\right)\right) \text {. }
$$

Considere a matriz

$$
\left[v_{i}-v_{0}\right]_{3 \times 3}=\left[\begin{array}{ccc}
\left(v_{1}-v_{0}\right) & \left(v_{2}-v_{0}\right) & \left(v_{3}-v_{0}\right) \\
\left(v_{1},-v_{0}\right) & \left(v_{2},-v_{0}\right) & \left(v_{3,}-v_{0}\right) \\
\left(v_{1}-v_{0}\right) & \left(v_{2}-v_{0}\right) & \left(v_{3}-v_{0}\right)
\end{array}\right],
$$

o vetor $\left[F\left(v_{i}\right)-F\left(v_{0}\right)\right]_{1 x^{3}}=\left[\left(F\left(v_{1}\right)-F\left(v_{0}\right)\right)\left(F\left(v_{2}\right)-F\left(v_{0}\right)\right)\left(F\left(v_{3}\right)-F\left(v_{0}\right)\right)\right]$ e $\lambda^{t}=\left[\lambda_{1} \lambda_{2} \lambda_{3}\right]$. Então, tem-se que:

$$
\begin{aligned}
& {\left[v-v_{0}\right]=\left[v_{i}-v_{0}\right] \cdot \lambda \Rightarrow \lambda=\left[v_{i}-v_{0}\right]^{-1} \cdot\left[v-v_{0}\right] \Rightarrow} \\
& F_{\sigma}(v)=F\left(v_{0}\right)+\left[F\left(v_{i}\right)-F\left(v_{0}\right)\right] \cdot\left[v_{i}-v_{0}\right]^{-1} \cdot\left[v-v_{0}\right]
\end{aligned}
$$

Fazendo, $A_{o}=\left[F\left(v_{i}\right)-F\left(v_{0}\right)\right] \cdot\left[v_{i}-v_{0}\right]^{-1}$, tem-se que $F_{o}(v)=A_{o} v+b_{o}$, onde $b_{o}=F\left(v_{0}\right)-A_{o} v_{0}$. Então, $F_{o}(v)$ é uma função afim que interpola $F$ nos pontos $v_{i}, i=0, \ldots, 3$, ou seja, $F_{o} \in$ uma interpolação linear para $F$ nos vértices de $\sigma$. 


\section{4 - Aproximação LP de F}

Os resultados desta seção foram obtidos de [Ca92].

Seja $D \subset \mathbf{R}^{3}$ um domínio e T uma triangulação de $D$.

Define-se uma aproximação linear por partes para $F$ como sendo a função $F_{T}: D \rightarrow R$, onde $F_{T}(v)=F_{o}(v)$ para $v \in \sigma \in T$.

Suponha que F: $D \subset \mathbb{R}^{3} \rightarrow \mathbb{R}$ seja uma função de classe $C^{2}$ com $\left\|D^{2} F(u)\right\| \leq \alpha$ para todo $u \in D$ e $\sigma=\left[v_{0}, \ldots, v_{3}\right]$ um simplexo de D. Então, são válidos os seguintes teoremas:

Teorema 6.1 - Para todo $v \in \sigma$, tem-se que $\left\|F(v)-F_{o}(v)\right\|<\alpha \rho^{2}(\sigma) / 2$ [AlGe80].

Teorema 6.2 - Para todo $v \in \sigma$, tem-se que $\left\|\mathrm{DF}(\mathrm{v})-\mathrm{DF}_{\mathrm{o}}(\mathrm{v})\right\| \leq \alpha \rho(\sigma) / \theta(\sigma)[\mathrm{Ta} 92$ et al.].

Os teoremas 6.1 e 6.2 mostram que para cada simplexo $\sigma \in \mathrm{T}$, tem-se que $\mathrm{F}_{\sigma}$ aproxima $\mathrm{F}$ e $\mathrm{DF}_{o}$ aproxima DF desde que $T$ seja uma triangulação robusta de $D$, isto é, $\theta(T)>0$. Observe que quanto menor o valor do diâmetro da triangulação, $\rho(T)$, melhor será a aproximação de $F_{o}$ por $F$.

\section{5 - Aproximação LP de Superfícies Definidas Implicitamente}

Os resultados desta seção foram obtidos de [Ca92].

Seja $F$ : $U \subset \mathbf{R}^{3} \rightarrow \mathbb{R}$ uma função de classe $C^{2}$ tendo 0 como valor regular $(\nabla F(u) \neq(0,0,0)$, $\left.\forall u \in F^{-1}(0)\right)$, então $S=F^{-1}(0)=\{u=(x, y, z) \in U ; F(u)=0\}$ é uma superfície de classe $C^{2}$. Deseja-se obter uma aproximação para $S$ em um domínio compacto $D \subset U$, então o domínio de $F$ é restringido a $D$. Assim, existe $\alpha>0$ tal que $\left\|D^{2} F(u)\right\| \leq \alpha$ para todo $u \in D$ e, portanto, se $T$ é uma triangulação robusta de $\mathrm{D}$, são válidos os teoremas 6.1 e 6.2 .

Diz-se que 0 é valor regular de $\mathrm{F}_{\mathrm{T}}: \mathrm{D} \rightarrow \mathbf{R}$ se o $\nabla \mathrm{F}_{\sigma}$ é não nulo ou, de modo análogo, a matriz

$$
\left[\begin{array}{cccc}
1 & 1 & 1 & 1 \\
F\left(v_{0}\right) & F\left(v_{1}\right) & F\left(v_{2}\right) & F\left(v_{3}\right)
\end{array}\right]
$$

possui posto 2 para todo ponto $\mathrm{v} \in \mathrm{F}_{\mathrm{T}}^{-1}(0)$. É fácil ver que a matriz acima tem posto 2 se existirem dois 
Indices distintos $i$ e $j$ tais que $F\left(v_{i}\right) \neq F\left(v_{j}\right)$ para $i, j=0, \ldots, 3$

Teorema 6.3 - Se (D,T) é uma variedade triangulada de dimensão 3 e $0 \in \mathbf{R}$ é valor regular de $F_{T}$, então $S_{\mathrm{T}}=\mathrm{F}_{\mathrm{T}}^{-1}(0)$ é uma superfície linear por partes [Ea76].

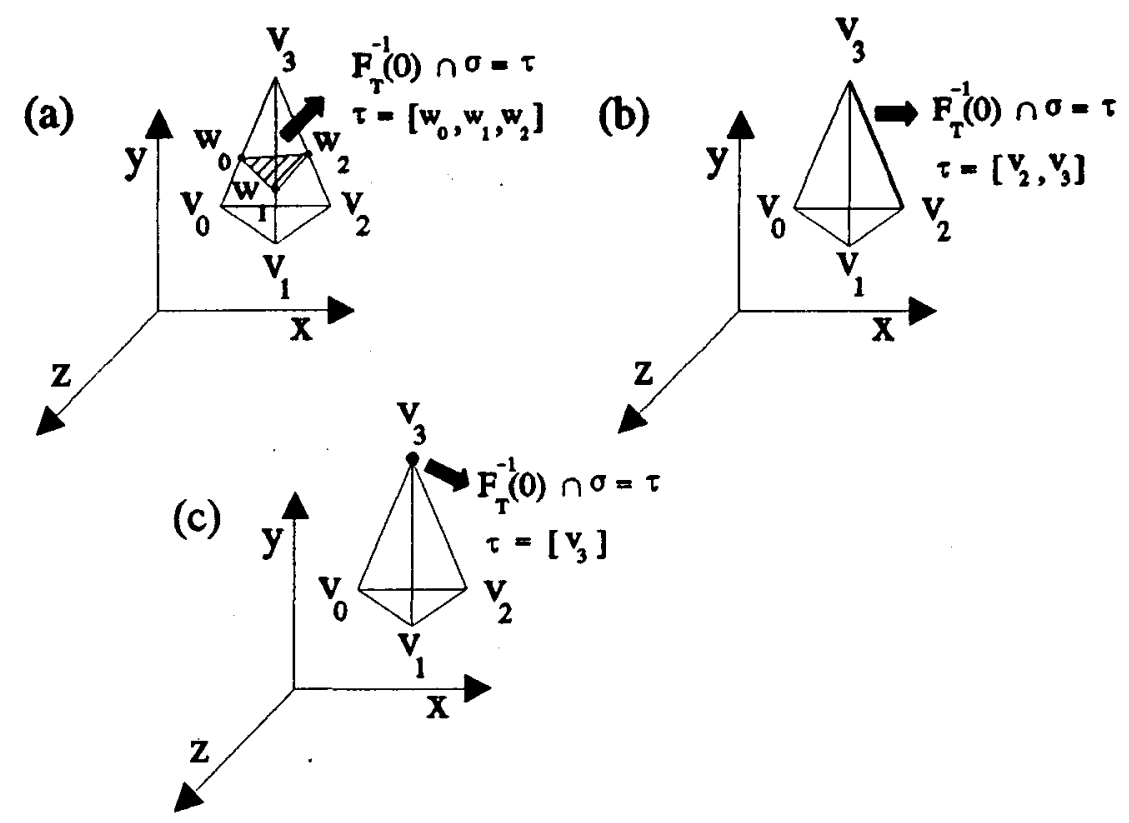

Figura 6.1: células de dimensão: (a) 2, (b) 1 e (c) 0 , resultantes de $F_{T}{ }^{-1}(0) \cap \sigma$

Note que o teorema 6.3 não garante que $F_{\mathrm{T}}{ }^{-1}(0) \cap \sigma$ seja uma célula de dimensão $\mathrm{k}$ se $\sigma$ é um simplexo de dimensão $1+k$ para $k \in\{1,2\}$. Os ftens (a), (b) e (c) da figura 6.1 ilustram a interseção $\mathrm{F}_{\mathrm{T}}^{-1}(0) \cap \sigma$, onde $\sigma=\left[\mathrm{v}_{0}, \ldots, \mathrm{v}_{3}\right]$, resultando em células $\tau$ de dimensões 2,1 e 0 respectivamente.

Teorema 6.4 - Para quase toda triangulação robusta T de D com diâmetro suficientemente pequeno, temse que todo simplexo de dimensão maior ou igual a 1 tem interior transversal a $S$ e $S_{\mathrm{T}}$; e se intercepta $S$, então também intercepta $S_{\mathrm{T}}[\mathrm{Fr} 91]$.

O teorema 6.4 tem como consequência duas importantes propriedades: para quase toda triangulação $\mathrm{T}$ de $\mathrm{D}$ com diâmetro suficientemente pequeno, tem-se que:

- se $\sigma$ é um simplexo de dimensão 1 (aresta) de $\mathrm{T}$ e $u \in \sigma \cap S$, existe $v \in \sigma \cap S_{\mathrm{T}}$ tal que 
$\|\mathrm{u}-\mathrm{v}\| \leq \rho(\sigma) \leq \rho(\mathrm{T})$

- se $\sigma$ é um simplexo de dimensão $1+\mathrm{k}(0 \leq \mathrm{k} \leq 2)$ de $\mathrm{T}$, tem-se que se $\mathrm{F}_{\mathrm{T}}^{-1}(0) \cap \sigma \neq \varnothing$, então $\mathrm{F}_{\mathrm{T}}^{-1}(0) \cap \sigma$ é uma célula convexa afim de dimensão $k$.

Também com relação à aproximação entre $S$ e $S_{T}$, tem-se o seguinte teorema:

Teorema 6.5 - Sejam $u \in S$ e $v \in S_{T}$. Se $\|u-v\| \leq 1 / m \alpha$, então $\|u-v\| \leq \alpha m \rho^{2}(T)$, onde $\mathrm{m}=\max (1 /\|\nabla \mathrm{F}(\mathrm{x})\|)$ para todo $\mathrm{x} \in \mathrm{D}[\mathrm{AlGe80}]$.

Como decorrência dos teoremas 6.1, 6.2, 6.3, 6.4 e 6.5, para toda variedade triangulada robusta de dimensão 3, (D,T), a superfície linear por partes $S_{\mathrm{T}}=\mathrm{F}_{\mathrm{T}}^{-1}(0)$ é uma aproximação linear por partes de $\mathrm{S}$ de ordem quadrática.

\section{6 - Amostragem}

A fronteira de um sólido abstrato descrito por semi-espaços no $(\mathrm{SM})^{2}$ pode conter uma ou mais componentes conexas, sendo que uma componente pode ser a fronteira do domínio (paralelepípedo) D, $\partial(D)$, ou $S=F^{-1}(0)$, ou constituída por $S=F^{-1}(0)$ e parte de $\partial(D)$, onde $F$ é a função característica do semi-espaço correspondente ao sólido abstrato e $D$ éo domínio de F. As figuras 4.3 e 4.6 exemplificam modelos cuja fronteira possui componentes constitufdas por $S$ e parte de $\partial(D)$, apenas $S$ e apenas $\partial(D)$.

Se uma componente conexa da fronteira do sólido abstrato é a fronteira de $D, \partial(D)$, não há necessidade de calcular uma aproximação para esta componente, pois $\partial(D)$ é uma superfície linear por partes resultante da triangulação do próprio $\mathrm{D}$, cujas faces pertencem aos simplexos da triangulação e, portanto, os vértices podem ser obtidos a partir da triangulação. A figura 6.2 ilustra as superficies lineares por partes correspondentes à fronteira de $D, \partial(D)$, resultantes das triangulações $K_{1}$ e $J_{1}$ de $D$.

Se uma componente conexa da fronteira do sólido abstrato é constiturda de parte de $\partial(D)$ e $S=F^{-1}(0)$, apenas $S$ é aproximada. A aproximação de $S$ resulta em uma superfície linear por partes com fronteira, onde a fronteira é uma curva linear por partes resultante da interseção da superfície com $\partial(D)$. A parte de $\partial(D)$ pertencente à componente conexa é uma superfície linear por partes com a mesma fronteira da superfície resultante da aproximação de $S$ e cujas faces são faces "inteiras" ou "recortadas" 
(clipped) da superfície linear por partes correspondente a $\partial(D)$. Para exemplificar, considere a aproximação da fronteira do sólido abstrato descrito por $F(x, y, z)=(x-1)^{2}+(y-1)^{2}+(z-1)^{2}-1$, $D=[-1,1] \times[-1,1] \times[-1,1] e^{"}>$ ", ilustrada na figura 6.3 .

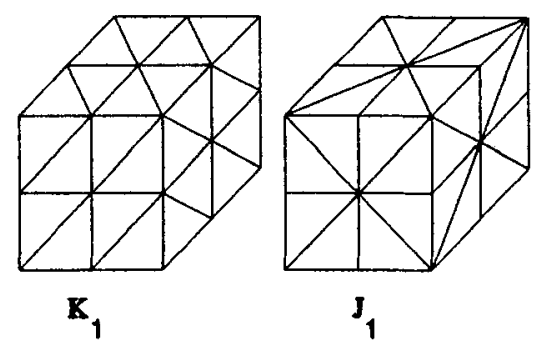

Figura 6.2: superfícies LP resultantes das triangulações $K_{1}$ e $J_{1}$ de $D$

Os verrtices das faces "recortadas" são obtidos a partir da triangulação, assim como os vértices das faces "inteiras", e a partir do cálculo dos vértices da superfície linear por partes que aproxima $S$. Portanto, o cálculo dos vértices resultantes da aproximação de cada componente conexa da fronteira do sólido abstrato corresponde ao cálculo dos vértices da superfície linear por partes que aproxima $S$.

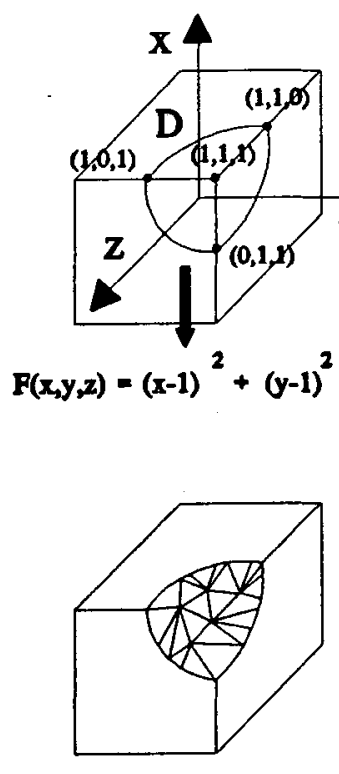

aproximaçăo LP de $S$

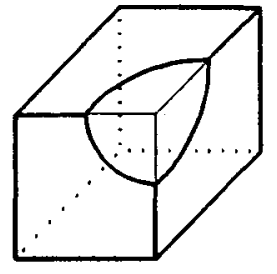

$\mathbf{F}(\mathbf{x}, \mathbf{y}, \mathbf{z}) \geq \mathbf{0}$

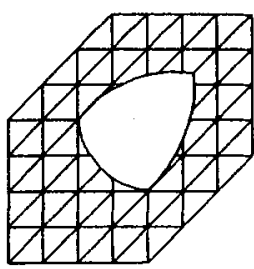

aproximaçäo LP de d(D)

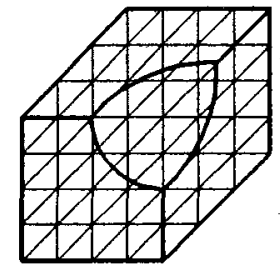

triangulação $K_{1}$ de $D$

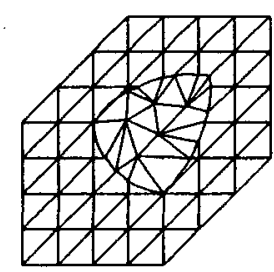

aproximacảo LP da fronteira

Figura 6.3: aproximação de fronteira constituída por $S=F^{-1}(0)$ e parte de $\partial(D)$

Considere a aproximação $S_{T}$ de $S=F^{-1}(0)$, onde $F: D \rightarrow R$ e $T$ é a triangulação $K_{1}(D, K)$ ou 
$J_{1}(D, K), K \in \mathbb{N}^{3}$, tal que para todo simplexo $\sigma$ de dimensão 3 de $T$ que intercepta $S$, tem-se que $\sigma \cap S_{T}$ é uma célula convexa afim de dimensão 2.

Dado um simplexo de dimensão 3 de $T, \sigma=\left[v_{0}, \ldots, v_{3}\right]$, cada vértice das duas possíveis células de dimensão $2, \tau_{1}=\left[w_{0}, w_{1}, w_{2}\right]$ e $\tau_{2}=\left[w_{0}, w_{1}, w_{2}, w_{3}\right]$, resultantes da interseção $\tau=\sigma \cap S_{T}$, é obtido através da resolução da equação

$$
\lambda_{i} F\left(v_{i}\right)+\lambda_{j} F\left(v_{j}\right), \quad \lambda_{i}+\lambda_{j}=1 \text { e } \lambda_{i}, \lambda_{j} \geq 0
$$

para cada aresta $\left[v_{i}, v_{j}\right.$ ] de $\sigma$ transversal a $S$, como ilustrado na figura 6.4.

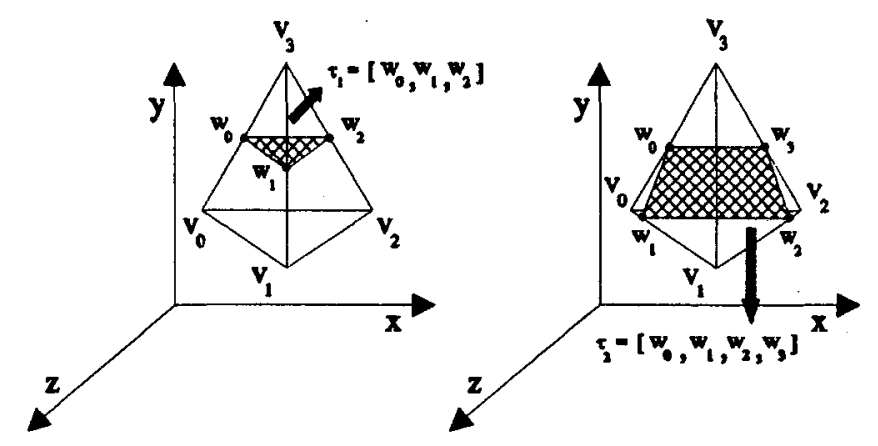

Figura 6.4: as duas possiveis células de dimensão 2 resultantes de $\sigma \cap S_{T}$

Os vértices de $\tau$ podem ser melhor aproximados utilizando, por exemplo, o método regula falsi na determinação de $\lambda_{i}$ e $\lambda_{j}$ na equação 6.1 , como exemplificado na figura 6.5 .

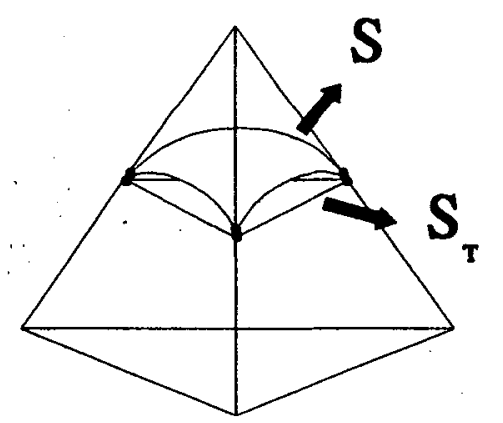

Figura 6.5: aproximação com o auxílio do método regula falsi

A determinação a priori do diâmetro $\rho(\mathrm{T})$ para o qual a triangulação $\mathrm{T}$ satisfaz o teorema 6.4 não é possível. Se o diâmetro for inadequado, a aproximação $S_{\mathrm{T}}$ de $\mathrm{S}$ pode ser ruim ou não pode ser obtida. Por outro lado, o diâmetro pode ser adequado, mas a disposição dos simplexos na triangulação faz com 
que $S$ intercepte um vértice, uma aresta ou uma face de dimensão 2 de $\sigma$, e não seja transversal a seu interior, como mostrado na figura 6.6. Isto inviabilizaria o cálculo das faces $\tau=\sigma \cap S_{\mathrm{T}}$ através da equação 6.1. Para evitar este tipo de problema, substitui-se $K_{1}(D, K)$ por $K_{1}\left(D, K, I^{m}{ }_{\varepsilon}\right)$ ou $J_{1}(D, K)$ por $J_{1}\left(D, K, I_{\varepsilon}{ }_{\varepsilon}\right)$ através de perturbaçôes.

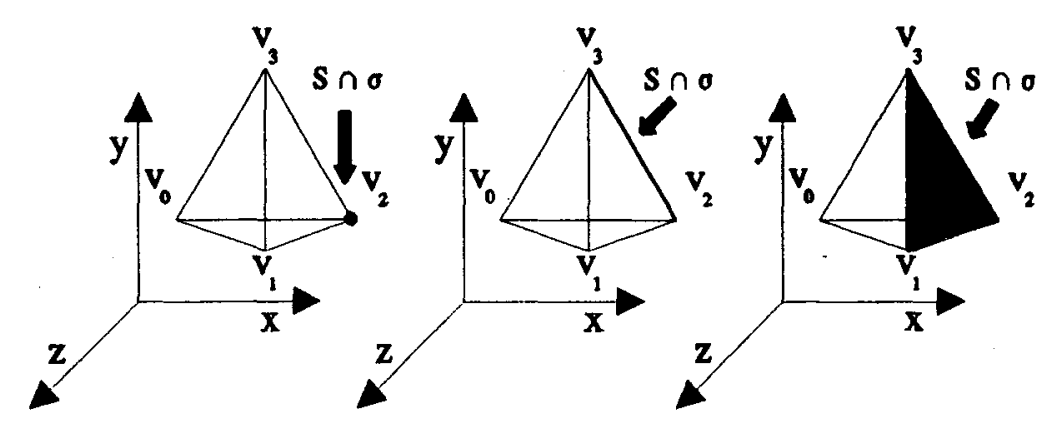

Figura 6.6: exemplos de interseção $\sigma \cap S$ quando $S$ não é transversal ao interior de $\sigma$

\section{7 - Estruturação}

A superfície linear por partes resultante da aproximação da fronteira do sólido abstrato é representada em uma estrutura de dados denominada esqueleto combinatório. Esta estrutura foi desenvolvida por Castelo ([Ca92]) e implementada, no (SM) ${ }^{2}$, como um conjunto de sete árvores AVL ([Wi76]). Os. nós de cada uma das sete árvores contêm informações sobre os vértices, as arestas e as faces da superfície linear por partes obtidas em um determinado bloco da triangulação de $D$, bem como uma identificação para o bloco.

As informações em cada nó estão organizadas hierarquicamente da seguinte maneira: os dados sobre o bloco estão no primeiro nível, os dados sobre as faces no segundo, os dados sobre as arestas no terceiro e os dados sobre os vértices no quarto e último nível, como mostrado na figura 6.7. Há uma "ligação" do primeiro para o segundo nível, do segundo para o terceiro nível, e deste para o quarto nível, de forma que, a partir dos dados do bloco (primeiro nível), é possível ter acesso aos dados das faces, arestas e vértices. Cada elemento é representado na estrutura por um identificador. Para os vértices, além do identificador, é armazenado o valor de suas coordenadas.

Os elementos (vértices, arestas e faces) resultantes da aproximação de $S=F^{-1}(0)$, onde $F$ é a 
função característica do semi-espaço correspondente ao sólido abstrato, são armazenados em uma das sete árvores da estrutura esqueleto combinatório. Cada uma das seis árvores restantes armazena os elementos obtidos em um dos seis "lados" do paralelepipedo correspondente ao domínio D onde F é considerada. Isto significa que se a fronteira do modelo é constitufda apenas por $\mathbf{S}$, a estrutura possuirá apenas uma árvore; se a fronteira corresponde a $\partial(\mathrm{D})$, a estrutura possuirá seis árvores, uma para cada "lado" de D; e se a fronteira é formada por $S$ e parte de $\partial(D)$, a estrutura é constituída da árvore que representa os elementos da superfície linear por partes que aproxima $S$ e de cada uma das seis árvores correspondente a um "lado" de D interceptado por S.

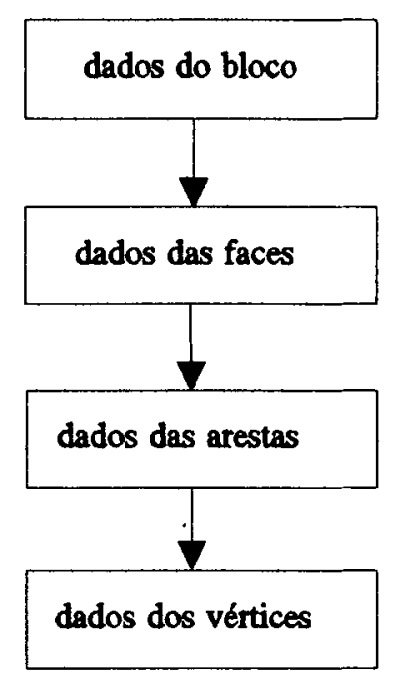

Figura 6.7: organização hierárquica das informaçōes nos nós da árvore

Os elementos das triangulações $\mathbf{K}_{1}$ e $\mathbf{J}_{1}$ podem ser identificados por números inteiros (rótulos) através de um processo de rotulagem, como foi visto na seção 5.5. Os elementos da superfície linear por partes correspondente à aproximação da fronteira do sólido abstrato armazenados na estrutura esqueleto combinatório podem ser identificados através dos rótulos dos elementos das triangulações $K_{1}$ ou $J_{1}$ de $D$. A rotulagem dos elementos da superficie linear por partes que aproxima $S$ difere da rotulagem dos elementos das superfícies lineares por partes correspondentes à parte de $\partial(D)$ ou a $\partial(D)$.

Cada bloco $q(g)$ de $K_{1}(D, K)$ ou $J_{1}(D, K), K \in \mathbb{N}^{3}$, é identificado na estrutura esqueleto combinatório pelo seu rótulo $\mathrm{l}(\mathrm{g})$ obtido pelo processo de rotulagem. Uma face $\tau$ da superfície linear por partes $S_{\mathrm{T}}$ que aproxima $S=F^{-1}(0)$ obtida como $\tau=\sigma \cap S_{\mathrm{T}}$, onde $\sigma$ é um simplexo de dimensão 3 de $\mathrm{K}_{1}(\mathrm{D}, \mathrm{K})$ ou $\mathrm{J}_{1}(\mathrm{D}, \mathrm{K})$, é identificada na estrutura pelo rótulo $\mathrm{l}(\sigma)$ de $\sigma$. Cada aresta de $\tau$ é resultante da 
interseção de $S_{T}$ com uma face de dimensão 2 de $\sigma$ e é identificada na estrutura pelo rótulo da face de dimensão 2 de $\sigma$ que a originou. Analogamente, cada vértice de $\tau$ corresponde à interseção de $S_{\mathrm{T}}$ com uma aresta de $\sigma$ e é identificado na estrutura pelo rótulo da aresta de $\sigma$ que o originou.

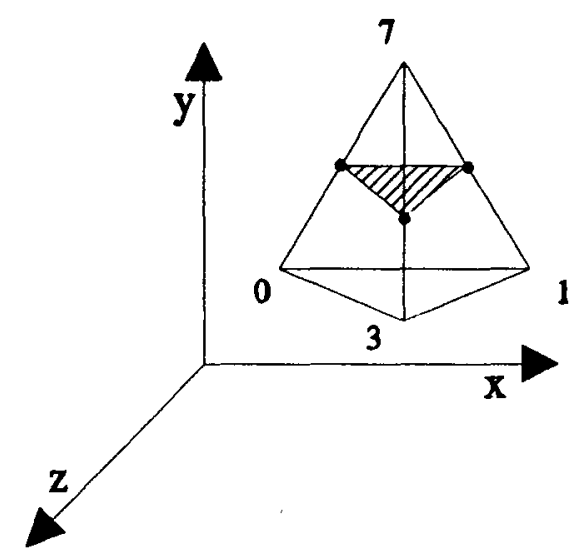

Figura 6.8: simplexo $\sigma$ de dimensão 3 com rótulo $\mathrm{l}(\sigma)=(0,1,3,7)$

Para exemplificar, considere o simplexo de $\sigma$ de dimensão 3 mostrado na figura 6.8. O rótulo de $\sigma$ é $\mathrm{l}(\sigma)=(0,1,3,7)$, então a face $\tau$ resultante de $\tau=\sigma \cap \mathrm{S}_{\mathrm{T}}$ é identificada por $\mathrm{l}(\sigma)$. As arestas de $\tau$ são identificadas com os rótulos $(0,1,7),(0,3,7)$ e $(1,3,7)$ das faces de dimensão 2 de $\sigma$ interceptadas por $S_{\mathrm{T}}$. Os vértices de $\tau$ são identificados pelos rótulos $(0,7),(1,7)$ e $(3,7)$ das arestas de $\sigma$ interceptadas por $S_{\mathrm{T}}$. Estas informações estão organizadas no nơ da árvore como ilustrado na figura 6.9.

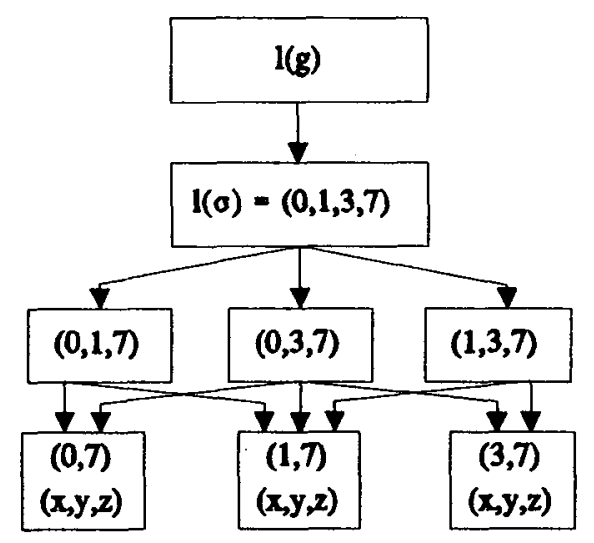

Figura 6.9: organização das informações do nó contendo a face da figura 6.8

Cada um dos seis "lados" do domínio (paralelepípedo) D subdividido por $\mathbf{K}_{1}$ ou $\mathbf{J}_{1}$ pode ser visto 
como uma região bidimensional compacta que possui uma triangulação $\mathrm{K}_{1}$ ou $\mathrm{J}_{1}$ resultante da triangulação de $\mathrm{D}$, de modo que é possível rotular os blocos (quadriláteros) e simplexos (pontos, segmentos de reta e triângulos) de cada "lado" de $D$ de forma semelhante à utilizada nas triangulações $K_{1}$ e $J_{1}$ do $\mathbf{R}^{2}$.

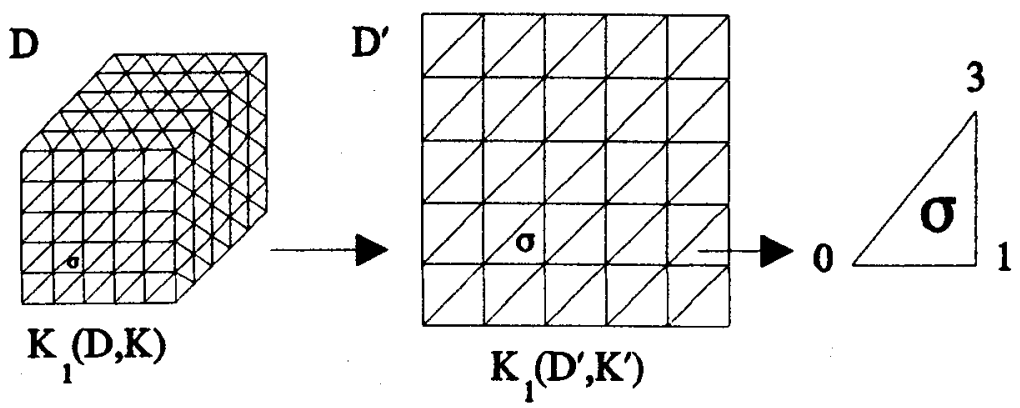

Figura 6.10: simplexo $\sigma$ de dimensão 2 com rótulo $l(\sigma)=(0,1,3)$

Considere o domínio compacto $D$ ' correspondente a um "lado" de $D$ e a triangulação $K_{1}(D, K)$ ou $J_{1}(D, K), K \in \mathbb{N}^{3}$, que define a triangulação $K_{1}\left(D^{\prime}, K^{\prime}\right)$ ou $J_{1}\left(D^{\prime}, K^{\prime}\right), K^{\prime} \in \mathbb{N}^{2}$, respectivamente. Cada bloco $q(g)$ de $K_{1}\left(D^{\prime}, K^{\prime}\right)$ ou $J_{1}\left(D^{\prime}, K^{\prime}\right)$ é identificado na estrutura esqueleto combinatório pelo seu rótulo $\mathrm{I}(\mathrm{g})$ obtido pelo processo de rotulagem. Uma face $\tau$ "inteira" pertencente à superfície linear por partes correspondente à parte de $\partial(\mathrm{D})$ ou $\partial(\mathrm{D})$ equivale a um dos dois simplexos $\sigma$ de um bloco $\mathrm{q}(\mathrm{g})$ de $\mathrm{K}_{1}\left(\mathrm{D}^{\prime}, \mathrm{K}^{\prime}\right)$ ou $\mathrm{J}_{1}\left(\mathrm{D}^{\prime}, \mathrm{K}^{\prime}\right)$ e é identificada na estrutura pelo rótulo de $\sigma$ na triangulação, $\mathrm{l}(\sigma)$. As arestas de $\tau$ são as arestas de $\sigma$ e os vértices de $\tau$ são os vértices de $\sigma$, portanto são identificados pelos próprios rótulos da triangulação.

Para exemplificar, considere o simplexo $\sigma$ de dimensão 2 ilustrado na figura 6.10. O rótulo de $\sigma$ é $l(\sigma)=(0,1,3)$, portanto a face $\tau$ correspondente a $\sigma$ é identificada por $l(\sigma)$. As arestas de $\tau$ são identificadas por $(0,1),(1,3)$ e $(0,3)$. Os vértices de $\tau$ são identificados por 0,1 e 3 . Estas informações estão organizadas no nó da árvore como mostrado na figura 6.11 .

Uma face $\tau$ "recortada" pertencente à superfície linear por partes correspondente à parte de $\partial$ (D) é identificada na estrutura esqueleto combinatório assim como uma face "inteira", ou seja, pelo rótulo do simplexo $\sigma, l(\sigma)$, que a originou através do "recorte". Um vértice de $\tau$ pode ser um vértice de $\sigma$ ou um vértice resultante da interseção de $S_{\mathrm{T}}$ com uma das arestas de $\sigma$. Os vértices de $\sigma$ são identificados na estrutura pelo próprio rótulo da triangulação e os vértices resultantes da interseção são identificados pelo rótulo da aresta de $\sigma$ que os originou. As arestas de $\tau$ são identificadas na estrutura pelos rótulos de seus dois vértices extremos que podem ser vértices de $\sigma$ ou vértices resultantes da interseção das arestas 
de $\sigma \operatorname{com} S_{\mathrm{T}}$.

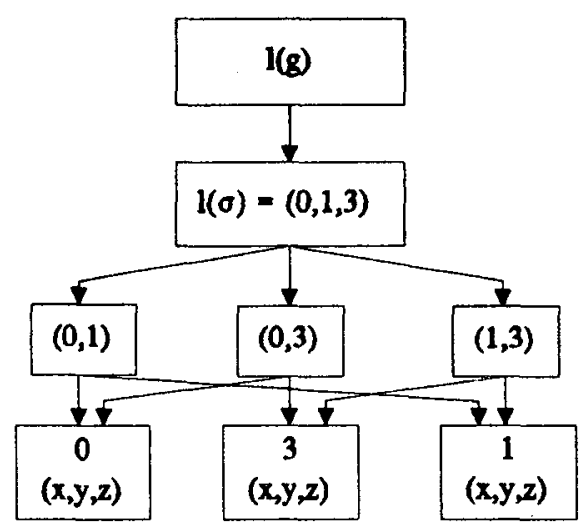

Figura 6.11: organização das informaçōes do nó contendo a face da figura 6.10

Para exemplificar, considere o simplexo $\sigma$ de dimensão 2 mostrado na figura 6.12. O rótulo de $\sigma$ é $l(\sigma)=(0,1,3)$, portanto a face "recortada" $\tau$ é identificada por $l(\sigma)$. As arestas de $\tau$ são identificadas pelos rótulos $(0,1),(1,(1,3)),((1,3),(0,3))$ e $((0,3), 0)$. Os vértices de $\tau$ são identificados por $0,1,(1,3)$ e $(0,3)$. Estas informações estâo organizadas no nó da árvore como ilustrado na figura 6.13 .

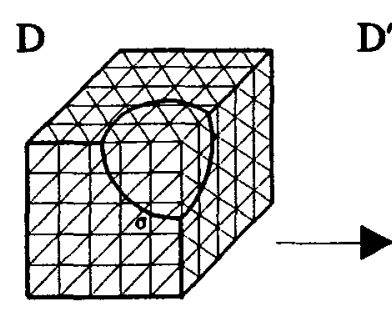

$\mathbf{K}_{1}(\mathbf{D}, \mathbf{K})$
$\mathrm{D}^{\prime}$

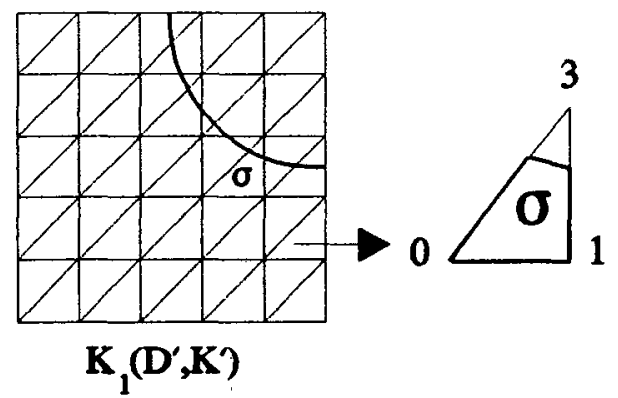

Figura 6.12: face "recortada" identificada pelo rótulo $l(\sigma)=(0,1,3)$ de um simplexo $\sigma$ de dimensão 2

A identificação dos componentes da estrutura esqueleto combinatório através dos rơtulos das triangulações $K_{1}$ e $J_{1}$ permite não apenas uma representação compacta das informações, mas também a aplicação das regras de pivoteamento das triangulações $K_{1}$ e $J_{1}$ para obter as informações sobre as relações de adjacência entre os vértices, arestas e faces da superfície representada na estrutura. Por exemplo, dada uma face $\tau$, é possível saber qual é a face adjacente a $\tau$ por uma de suas arestas, pois o rótulo da face $\tau$, bem como os rớtulos de suas arestas, são derivados do processo de rotulagem da triangulação $K_{1}$ ou $\mathrm{J}_{1}$. 


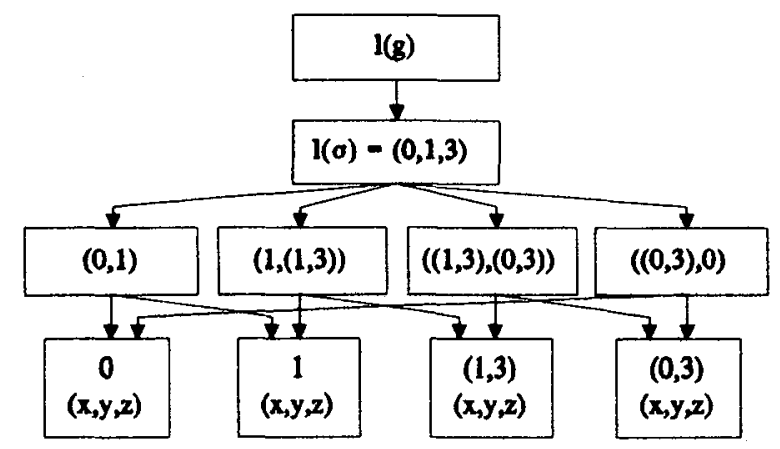

Figura 6.13: organização das informações do nó contendo a face da figura 6.12

\section{8 - Considerações Finais}

Neste capítulo, foi apresentado o método para gerar uma superfície linear por partes que aproxima a superfície correspondente à fronteira do sólido abstrato. Os vértices, arestas e faces da superfície linear por partes são calculados utilizando interpolação linear nos simplexos das triangulações $K_{1}$ e $J_{1}$. do paralelepípedo (domínio) D onde é considerada a função característica $F$ do semi-espaço correspondente ao sólido abstrato. A superfície resultante é representada em uma estrutura de dados denominada esqueleto combinatório, capaz de capturar suas informações geométricas e topológicas.

No capítulo 7 é apresentado o algoritmo do procedimento de conversão da representação implícita para a BRep poliedral. Este procedimento gera a superfície linear por partes que aproxima a fronteira do sólido abstrato e armazena seus elementos na estrutura esqueleto combinatório. Em seguida, recupera as informações armazenadas nesta éstrutura e gera uma sequência de operadores de Euler para criar a estrutura de dados da BRep poliedral, a estrutura semi-aresta*, com as informações geométricas e topologicas da fronteira do modelo contidas na estrutura esqueleto combinatório. 


\section{Capítulo 7}

\section{O Procedimento de Conversão}

\section{1 - Considerações Iniciais}

Este capítulo é dedicado ao procedimento do submódulo semi-espaços do $(\mathrm{SM})^{2}$ que realiza a conversão da representação implícita de cada modelo descrito por semi-espaços no modelador para a BRep poliedral correspondente. Na seção 7.2 são descritos os dados de entrada do procedimento de conversão. Na seção 7.3 são apresentadas as etapas deste procedimento. Nas seções 7.4, 7.5 e 7.6 são abordados os algoritmos correspondentes à primeira, segunda e terceira etapas, respectivamente. Na seção 7.7 é abordado o algoritmo correspondente à quarta e última etapa do procedimento. Na seção 7.8 é descrita a sequência de operadores capaz de gerar a BRep poliedral e que é obtida durante as quatro etapas do procedimento. Na seção 7.9 são mostradas imagens "realísticas" de alguns modelos gerados no (SM) ${ }^{2}$.

\section{2 - Os Dados de Entrada}

Na descrição de sólidos abstratos por semi-espaços no (SM) ${ }^{2}$ devem ser fornecidos os seguintes dados: o domínio (paralelepípedo) D, o número de funçōes (semi-espaços), a expressão numérica de cada função, a expressão lógica de F (a função característica do semi-espaço correspondente ao modelo), o interior do modelo ("<" ou "> "), o número de componentes conexas definidas por $F$ em $D$, um ponto pertencente a cada componente, uma triangulação para $D\left(K_{1}\right.$ ou $\left.J_{1}\right)$ e o refinamento $K$ da triangulação escolhida.

A expressão lógica de $\mathrm{F}$ é necessária se o número de funções (semi-espaços) fornecidas é maior do que 1. Neste caso, F é dada como união, interseção e diferença das funções fornecidas. O número de componentes conexas definidas por $\mathrm{F}$ em $\mathrm{D}$ e um ponto pertencente a cada componente são informações opcionais. Estes dados são fornecidos quando for desejado uma indicação explícita de quais dos sólidos abstratos definidos por F, D e "<" ou " >" devem ser criados. Caso contrário, todos os modelos 
definidos por F, D e "<" ou " $>$ " serão considerados.

A representação implícita é gerada pelo procedimento tradutor (ver capítulo 4) e contém o número de funções (semi-espaços), o número de símbolos do código gerado para F, o código da(s) espressão(ões) numérica(s), o código da expressão lógica (se o número de semi-espaços é maior do que 1), D e "<" ou " $>$ ". O número de componentes conexas da fronteira do sólido abstrato correspondente à representação e um ponto pertencente a cada componente não são dados inclufdos pelo tradutor. Apenas uma representação implícita é gerada para a descrição F, D e "<" ou " >". Isto significa que a representação gerada é ambígua, pois F, D e " < " ou " > " podem definir mais de um modelo (ver figura 4.2).

O procedimento de conversão recebe a triangulação $\left(\mathrm{K}_{1}\right.$ ou $\left.\mathrm{J}_{1}\right)$, o refinamento $\mathrm{K}$ da triangulação e a representação implícita gerada pelo tradutor como dados de entrada. $O$ número de componentes conexas definidas por $\mathrm{F}$ em $\mathrm{D}$ e um ponto pertencente a cada componente são utilizados caso sejam fornecidos. A representação implícita gerada pelo tradutor contém o código de F, D e "<" ou "> ". Um ponto pertencente a cada componente conexa permite ao procedimento de conversão identificar quais as componentes que devem ser aproximadas. Se esta informação não for fornecida, todas as componentes definidas por F, D e "<" ou " > " contidas na representação implícita são aproximadas.

\section{3 - As Etapas do Procedimento}

A fronteira de um sólido abstrato descrito por semi-espaços no $(\mathrm{SM})^{2}$ pode conter uma ou mais componentes conexas (ver capítulo 4). Uma componente pode ser definida por $S=F^{-1}(0)$, onde $F$ é a função característica do semi-espaço correspondente ao modelo; por $S$ e parte da fronteira de $D, \partial(D)$, onde D é o domínio (paralelepípedo) de F; ou por $\partial(D)$. O método para calcular os vértices da superfície linear por partes que aproxima S, parte de $\partial(D)$ e $\partial(D)$ foi mostrado no capítulo 6.

A primeira etapa do procedimento de conversão calcula os vértices pertencentes à superfície linear por partes que aproxima $S$ e a cada componente conexa da fronteira do modelo definida por $S$ ou por $S$ e parte de $\partial(D)$. O cálculo dos vértices é realizado pela equação 6.1, como mostrado no capítulo 6, e o valor de $\mathrm{F}$ utilizado nesta equação é obtido pelo procedimento interpretador. Os vértices são combinados para formar as arestas e as faces da superfície resultante da aproximação. Cada componente da superfície resultante é representada em uma estrutura esqueleto combinatório. 
A segunda etapa do procedimento de conversão encontra os vértices pertencentes à superfície linear por partes correspondente à parte de $\partial(D)$ contida em cada componente conexa da fronteira do modelo definida por $S$ e parte de $\partial(D)$. Os vértices são interpolados para formar as arestas e as faces de cada superfície correspondente a uma parte de $\partial(D)$ aproximada. Os elementos (vértices, arestas e faces) da superfície linear por partes correspondente à parte de $\partial(D)$ que pertencem a uma determinada componente conexa da fronteira do modelo definida por $S$ e parte de $\partial(D)$ são armazenados na mesma estrutura esqueleto combinatório que contém os elementos pertencentes à componente e à superfície linear por partes que aproxima $S$.

A terceira etapa do procedimento de conversão verifica se $\partial(D)$ é uma componente conexa da fronteira de algum modelo descrito por $\mathrm{F}, \mathrm{D}$ e " <" ou " $>$ ". Em seguida, determina as componentes aproximadas que pertencem à fronteira de um mesmo sólido abstrato e gera a sequência de operadores de Euler para criar a estrutura semi-aresta* (estrutura de dados da BRep poliedral) correspondente a cada modelo. A sequência de operadores de Euler referente a cada componente é gerada durante a primeira e segunda etapas.

A quarta etapa do procedimento de conversão gera uma representação implícita para cada sólido abstrato cuja fronteira foi determinada na terceira etapa. Cada representação implícita contém as mesmas informações da representação implícita ambigua gerada pelo tradutor e é acrescida do número de componentes conexas do modelo e um ponto pertencente a cada componente. Estas informações garantem a não ambiguidade das representaçōes implícitas geradas pelo procedimento de conversão.

\section{4 - O Algoritmo da Primeira Etapa}

No algoritmo correspondente à primeira etapa do procedimento de conversão, os elementos (vértices, arestas e faces) pertencentes à superfície linear por partes que aproxima $S$ e também a cada componente conexa definida por $S$ ou por $S$ e parte de $\partial(D)$ são encontrados e armazenados em uma árvore AVL da estrutura esqueleto combinatório que representa a componente conexa.

$O$ algoritmo considera o domínio (paralelepípedo) D subdividido pela triangulação $K_{1}\left(D, K, 1_{\varepsilon}^{3}\right)$ ou $J_{1}\left(D, K, P_{s}\right)$. Então, processa uma componente definida por $F$ em $D$ de cada vez. Se um ponto pertencente a componente foi fornecido, o algoritmo encontra o bloco resultante da triangulação e o simplexo do bloco que contêm o ponto. Caso contrário, procura um bloco resultante da triangulação e 
um simplexo do bloco que interceptem uma componente definida por $\mathrm{F}$ em $\mathrm{D}$. Isto é realizado através da avaliação de $F$ nos vértices de cada bloco de $K_{1}\left(D, K, I_{\varepsilon}{ }^{3}\right)$ ou $J_{1}\left(D, K, 1_{\varepsilon}^{3}\right)$. O valor de $F$ é obtido através do procedimento interpretador.

Cada vértice da componente é obtido pela equação $6.1 \mathrm{e}$, em seguida, é aplicado o método regula falsi ([Ca92]) para obter uma aproximação melhor das coordenadas do vértice. Este cálculo é iniciado no bloco e simplexo encontrados que são denominados bloco inicial e simplexo inicial. Os vértices calculados são interpolados para formar as arestas e a face resultantes da interseção da superfície linear por partes que aproxima $\mathrm{S}$ com o simplexo inicial. A identificação (rótulo) do bloco é inserida em um nó da árvore da estrutura esqueleto combinatório, bem como o rótulo do simplexo, o qual equivale a identificação da face resultante da interseção. As informações do bloco e das faces, arestas e vértices nele obtidos são organizadas hierarquicamente em cada nó da árvore, como descrito no capítulo 6.

As regras de pivoteamento são utilizadas para encontrar os simplexos adjacentes ao simplexo inicial por suas faces de dimensão 2 interceptadas pela superfície linear por partes que aproxima S. A identificação dos blocos que contêm os simplexos adjacentes, bem como a identificação desses simplexos são inseridas na árvore. Os blocos cujas identificações estão na árvore são ditos blocos ativos ou blocos a serem analisados. Estes blocos contêm simplexos que interceptam a superfície linear por partes que aproxima $S$.

Após o cálculo dos vértices da face, o simplexo inicial é marcado como passivo. Em seguida, outro simplexo que pertence ao bloco inicial e intercepta a superfície linear por partes que aproxima $S$ é escolhido para ser analisado, ou seja, para serem calculados os vértices da face resultante de sua interseção com a superfície. Quando todos os simplexos do bloco inicial forem analisados, o bloco é marcado como passivo e o nó correspondente ao bloco é eliminado da árvore. Os simplexos contidos nos nós da árvore para serem analisados são denominados simplexos ativos.

O procedimento continua com a escolha de um bloco qualquer da árvore, isto é, um bloco ativo. Os simplexos deste bloço são analisados da mesma forma que o simplexo inicial. Portanto, novos blocos e simplexos são encontrados através das regras de pivoteamento e inseridos na árvore. $O$ cálculo das faces encerra quando não houver na árvore mais blocos a serem analisados. Isto significa que todos os vértices, arestas e faces da componente pertencentes à superfície linear por partes que aproxima $S$ foram encontrados.

Para cada face da superfície linear por partes correspondente a $\partial(D)$ interceptada durante o cálculo dos vértices que pertencem à componente e à superfície linear por partes que aproxima $S$, são inseridas 
na árvore da estrutura esqueleto combinatório equivalente ao "lado" D' de D que contém a face interceptada e a identificação do bloco bidimensional de $K_{1}\left(D^{\prime}, K^{\prime}, I_{\varepsilon}^{2}\right)$ ou $J_{1}\left(D^{\prime}, K^{\prime}, I_{\varepsilon}^{2}\right)$, ao qual a face pertence, a identificação da face, a identificação da aresta resultante da interseção, a identificação dos vértices da aresta e as coordenadas desses vértices. A face interceptada corresponde a uma face "recortada". Estas informações são utilizadas na segunda etapa do procedimento de conversão.

Uma sequência de operadores de Euler é gerada após o cálculo e armazenagem de cada face da componente. Esta sequência é capaz de criar os vértices e as arestas da face calculada, bem como a própria face, na estrutura semi-aresta* que representa o modelo cuja fronteira possui a componente que contém a face calculada. Um arquivo temporário é criado na primeira etapa do procedimento de conversão para armazenar todas as sequências geradas durante a determinação dos elementos de cada componente aproximada.

O trecho correspondente à primeira etapa do algoritmo do procedimento de conversão é mostrado no quadro 7.1. As variáveis utilizadas para armazenagem de dados no algoritmo são:

- BATV $_{1}$ : apontador para a árvore contendo os blocos ativos de $\mathrm{K}_{1}\left(\mathrm{D}, \mathrm{K}, \mathrm{I}_{\varepsilon}^{3}\right)$ ou $\mathrm{J}_{1}\left(\mathrm{D}, \mathrm{K}, \mathrm{I}_{\varepsilon}^{3}\right)$.

- BATV $_{\mathrm{i}}$ : apontador para a árvore contendo os blocos ativos de $\mathrm{K}_{1}\left(\mathrm{D}^{\prime}, \mathrm{K}^{\prime}, \mathrm{I}_{\varepsilon}^{2}\right)$ ou $J_{1}\left(\mathrm{D}^{\prime}, \mathrm{K}^{\prime}, \mathrm{I}_{\varepsilon}^{2}\right)$, onde D' corresponde ao "lado" i de D $(2 \leq \mathrm{i} \leq 7)$.

- BPAS; : conjunto dos blocos passivos de $\mathrm{K}_{1}\left(\mathrm{D}^{\prime}, \mathrm{K}^{\prime}, \mathrm{I}_{\varepsilon}{ }_{\varepsilon}\right)$ ou $\mathrm{J}_{1}\left(\mathrm{D}^{\prime}, \mathrm{K}^{\prime}, \mathrm{I}_{\varepsilon}{ }_{\varepsilon}\right)$, onde $\mathrm{D}^{\prime}$ corresponde ao "lado" i de $\mathrm{D}(2 \leq \mathrm{i} \leq 7)$.

- SATV: conjunto dos simplexos ativos de um dado bloco.

- SPAS: conjunto dos simplexos passivos de um dado bloco.

Os elementos do conjunto BPAS são os rótulos dos blocos passivos. Analogamente, os elementos do conjunto SATV são os rótulos dos simplexos ativos e os elementos de SPAS são os rótulos dos simplexos passivos de um dado bloco. 
para cada componente conexa

início 1

inicialize BATV $_{1}$ e cada BATV $_{i}$ como apontadores nulos

inicialize cada $B P A S_{i}$ como vazio

encontre o bloco inicial $q(g)$ e o simplexo inicial $\sigma$

inicialize SATV e SPAS de $\mathrm{q}(\mathrm{g})$ como vazios

insira $\mathrm{l}(\mathrm{q}(\mathrm{g}))$ e $\mathrm{l}(\sigma)$ na árvore apontada por $\mathrm{BATV}_{1}$

insira $1(\sigma)$ em SATV de $q(g)$

enquanto $\mathrm{BATV}_{1}$ não é nulo faça

ińcio 2

escolha um bloco $\mathrm{q}(\mathrm{g})$ de $\mathrm{BATV}_{1}$

enquanto SATV de $q(\mathrm{~g}) \neq \varnothing$ faça

início 3

escolha um simplexo $\sigma$ de $q(g)$

calcule os vértices resultantes da interseção de $\sigma$ com a superfície linear por partes que aproxima $S$

forme as arestas e a face a partir da interpolação dos vértices

insira a identificação dos vértices, arestas e face em BATV

insira a identificação dos simplexos adjacentes a $\sigma$ e de seus blocos ainda

não analisados em BATV

insira $1(\sigma)$ dos simplexos adjacentes em SATV de seus respectivos blocos $q(\mathrm{~g})$

gere a sequência de operadores de Euler correspondente à face calculada

se $\sigma \cap S_{\mathrm{T}}$ intercepta o "lado" i de D correspondente a D'

insira a identificação da face $\tau$ de $\sigma$ interceptada em BATV

se o bloco $\mathrm{q}(\mathrm{g})$ de $\mathrm{D}^{\prime}$ contendo $\tau$ não pertence a BPAS $_{\mathrm{i}}$

insira $l(q(g))$ em BATV

fim do se

fim do se

retire $l(\sigma)$ de SATV de $q(g)$

insira $l(\sigma)$ em SPAS de $q(g)$

fim 3

elimine o nó de $\mathrm{BATV}_{1}$ correspondente a $\mathrm{q}(\mathrm{g})$

fim 2

fim 1

Quadro 7.1: trecho correspondente à primeira etapa do algoritmo do procedimento de conversão

Se a função $F$ não definir uma superfície (a representação implícita está semanticamente incorreta), o algoritmo poderá não obter a face resultante no simplexo inicial através da equação 6.1 e acusará o erro. Se $\mathrm{F}^{-1}(0)$ em $\mathrm{D}$ contém pontos críticos, mas define uma superfície em alguma região de D, então esta superfície poderá ser aproximada, porém o algoritmo poderá acusar erro ou obter uma aproximação geométrica e até topologicamente errada da superfície em regiões próximas aos pontos críticos. Se a função $\mathrm{F}$ define em $\mathrm{D}$ uma superfície que não $e$ de classe $\mathrm{C}^{2}$, $\mathrm{o}$ algoritmo aproximará a 
superfície, mas não continuam válidos os teoremas 6.1, 6.2 e 6.5, que estimam o erro da aproximação de $S$.

\section{5 - O Algoritmo da Segunda Etapa}

No algoritmo correspondente à segunda etapa do procedimento de conversão, os elementos (vértices, arestas e faces) da superfície linear por partes correspondentes à parte de $\partial(D)$ contida em cada componente conexa definida por $S$ e parte de $\partial(D)$ são encontrados e armazenados na estrutura esqueleto combinatório que contém a componente. A segunda etapa do procedimento não é necessária às componentes que foram aproximadas na primeira etapa definidas apenas por $\mathrm{S}$.

A estrutura esqueleto combinatório possui seis árvores AVL para armazenar os elementos (vértices, arestas e faces) da superfície linear por partes correspondente à parte de $\partial(D)$ contida nas componentes definidas por parte de $\partial(D)$ ou $\partial(D)$, como descrito no capftulo 6. Cada uma das seis árvores é associada a um "lado" de D. Os elementos de uma componente obtidos em um determinado "Iado" de D são armazenados na árvore correspondente a este "lado".

As árvores da estrutura esqueleto combinatório correspondentes a cada "lado" D' de D interceptado pela componente representada na estrutura são criadas ainda na primeira etapa. Isto porque a identificação de cada face $\tau$ "recortada", do bloco bidimensional de $K_{1}\left(D^{\prime}, K^{\prime}, I_{\varepsilon}^{2}\right)$ ou $J_{1}\left(D^{\prime}, K^{\prime}, I_{\varepsilon}^{2}\right)$ contendo a face, da aresta resultante da interseção do simplexo (face de dimensão 2) do bloco que contém $\tau$ com a superfície linear por partes que aproxima $S$, e dos vértices extremos da aresta, bem como as coordenadas dos vértices, são informações inseridas na árvore durante a obtenção dos elementos da superficie linear por partes que aproxima $S$ pertencentes à componente.

Para cada componente resultante da primeira etapa que intercepta $\partial(D)$ (componente definida por $S$ e $\partial(D))$, o algoritmo correspondente à segunda etapa do procedimento de conversão escolhe uma das árvores correspondente a um "lado" de D interceptado pela componente e pertencente à estrutura esqueleto combinatório que representa a componente. Em seguida, encontra e armazena na árvore todos os elementos (vértices, arestas e faces) da superfície linear por partes correspondente à parte de $\partial(D)$ contida na componente e no "lado" de D associado à arvore escolhida. Este passo é refeito para as demais árvores da estrutura esqueleto combinatório que correspondem aos outros "lados" de D interceptados pela componente. 
Cada árvore escolhida contém, inicialmente, a identificação de todas as faces "recortadas" contidas na componente e no "lado" D' de D correspondente a árvore, bem como a identificação da aresta de cada face "recortada" correspondente ao segmento de "recorte" da face, a identificação dos vértices da aresta, e as coordenadas dos vértices. Os vértices restantes das faces "recortadas" pertencem a $K_{1}\left(D^{\prime}, K^{\prime}, I_{\varepsilon}^{2}\right)$ ou $J_{1}\left(D^{\prime}, K^{\prime}, I_{\varepsilon}^{2}\right)$, bem como todos os vértices das faces "inteiras" que pertencem à componente e à superfície linear por partes correspondente à parte de $\partial(D)$ contida em $D^{\prime}$.

Apos a escolha da árvore, o algoritmo escolhe um bloco bidimensional e uma face do bloco contidos na árvore para serem analisados. $O$ bloco e a face são ditos bloco inicial e face inicial, respectivamente. A identificação dos vértices e arestas da face inicial ainda não aproximados, bem como as coordenadas dos vértices, são encontradas e inseridas na árvore. A face inicial é marcada como passiva.

As regras de pivoteamento são utilizadas para encontrar as faces adjacentes à face inicial. A identificação de cada face adjacente é inserida na árvore juntamente com a identificação da aresta compartilhada com a face inicial, a identificação dos vértices da aresta e as coordenadas do vértice. As faces contidas na árvore para serem analisadas são ditas faces ativas.

Quando a outra face do bloco inicial pertence à árvore, ela é escolhida para ser analisada. Após a análise das faces do bloco inicial, este é marcado como bloco passivo. Um bloco e uma face do bloco contidos na árvore são escolhidos e analisados. Novas informações sobre blocos, faces, arestas e vértices são encontradas através das regras de pivoteamento e inseridas na árvore. $O$ processamento das faces continua até que sejam analisados todos os blocos de $K_{1}\left(D^{\prime}, K^{\prime}, I_{\varepsilon}^{2}\right)$ ou $J_{1}\left(D^{\prime}, K^{\prime}, I_{\varepsilon}^{2}\right)$ do "lado" $D^{\prime}$ de $D$ associado à árvore.

Uma sequência de operadores de Euler é gerada após o cálculo e armazenagem de cada face da componente, assim como no algoritmo do quadro 7.1. Esta sequência é capaz de criar os vértices e as arestas de cada face calculada, bem como a propria face, na estrutura semi-aresta* que representa o modelo cuja fronteira é composta pela componente que contém a face calculada. $\mathrm{O}$ arquivo temporário criado na primeira etapa para armazenar a sequência de operadores de Euler da componente é alterado para incluir a sequência gerada para cada face determinada na segunda etapa.

O trecho correspondente à segunda etapa do algoritmo do procedimento de conversão é mostrado no quadro 7.2. As variáveis utilizadas para armazenagem de dados no algoritmo são:

- BPASAUX: conjunto de blocos passivos resultantes de $K_{1}\left(D^{\prime}, K^{\prime}, I^{2}{ }_{g}\right)$ ou $J_{1}\left(D^{\prime}, K^{\prime}, I^{2}\right)$ de todos 
os "lados" D' de D.

- BATV $_{\mathrm{i}}$, BPAS $_{\mathrm{i}}$, SATV e SPAS.

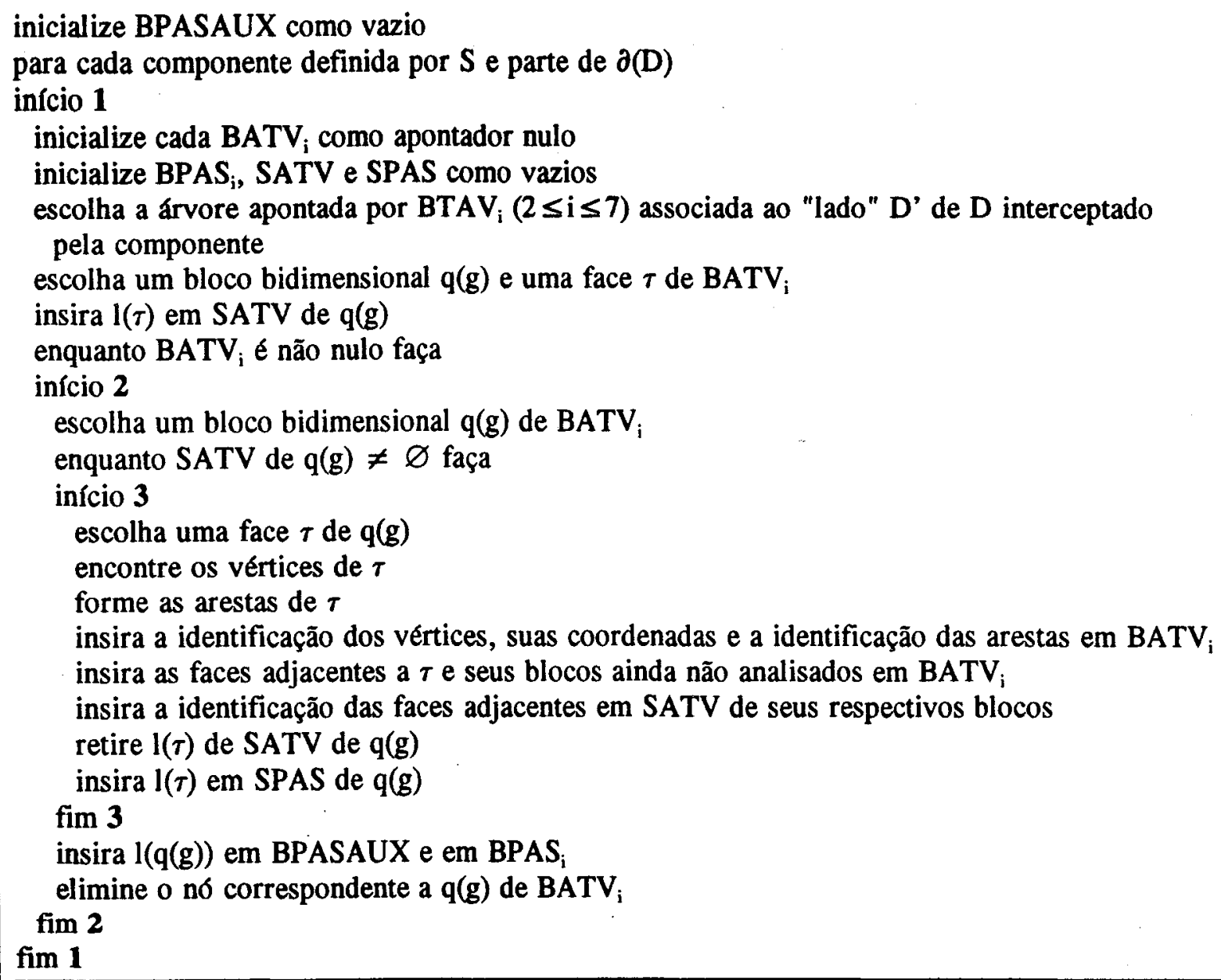

Quadro 7.2: trecho correspondente à segunda etapa do algoritmo do procedimento de conversão

É possível que uma componente conexa da fronteira definida por $S$ e parte de $\partial(D)$ seja composta por duas ou mais componentes conexas com fronteira de $S$. Para exemplificar este fato, considere o modelo descrito por $F=F_{1}$ união $F_{2}, D=[-2,2] \times[-2,2] \times[-2,2] e^{~ "}>$ ", onde $F_{1}(x, y, z)=(x-2)^{2}+$ $(y-2)^{2}+(z-2)^{2}-1$ e $F_{2}(x, y, z)=(x+2)^{2}+(y-2)^{2}+(z-2)^{2}-1$, mostrado na figura 7.1. A fronteira do modelo é formada por apenas uma componente conexa definida por $S$ e parte de $\partial(D)$. A componente da fronteira é composta pelas duas componentes conexas com fronteira de $S=F^{-1}(0)$ em $D$ dadas por $F_{1}^{-1}(0)$ e $F_{2}^{-1}(0)$.

As componentes de $\mathrm{F}^{-1}(0)$, no modelo da figura 7.1 , são aproximadas na primeira etapa do 
procedimento de conversão. Na segunda etapa, uma das componentes de $\mathrm{F}^{-1}(0)$ resultante da primeira etapa é processada primeiro. Suponha que seja $\mathrm{F}_{1}{ }^{-1}(0)$. Então, uma componente com fronteira composta das faces da superfície linear por partes correspondente à parte de $\partial(D)$ e das faces da superfície linear por partes que aproxima $F_{1}^{-1}(0)$ é gerada como resultado do processamento de $F_{1}^{-1}(0)$. A curva da fronteira desta componente é identica a curva da fronteira da superfície linear por partes que resulta da aproximação de $\mathrm{F}_{2}^{-1}(0)$ na primeira etapa.

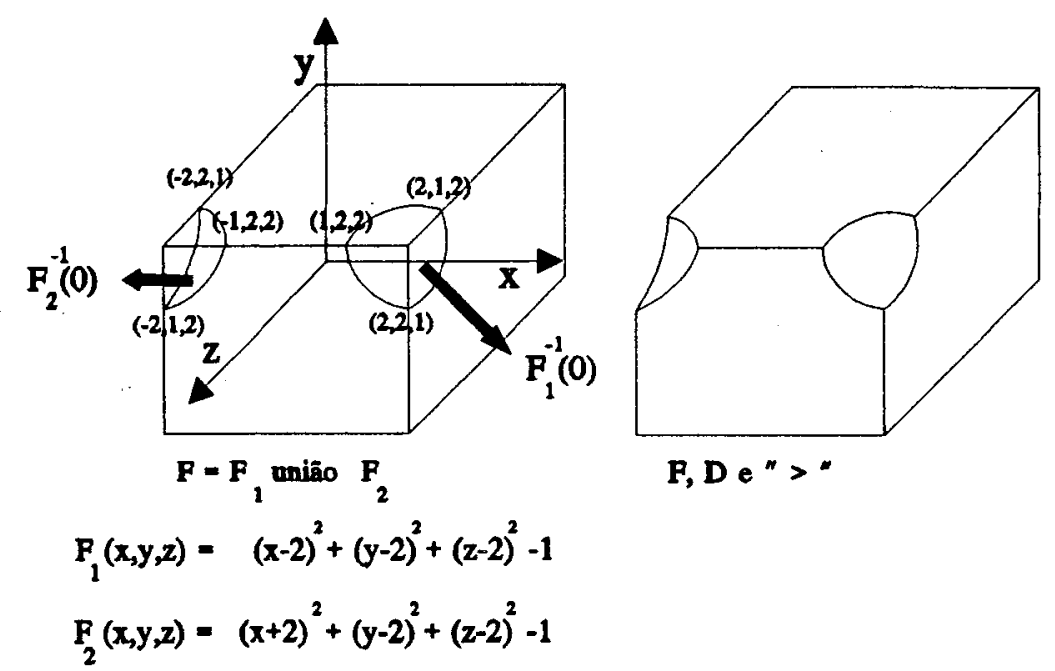

Figura 7.1: modelo cuja fronteira possui duas componentes conexas de $S=F^{-1}(0)$

A superfície linear por partes que aproxima $\mathrm{F}_{2}{ }^{-1}(0)$, quando processada na segunda etapa do procedimento de conversão, resulta nela própria, pois os blocos bidimensionais que contém as faces da superficie linear por partes correspondente à parte de $\partial(D)$ estão marcados como "passivos". Para obter a componente conexa da fronteira do modelo, a superfície linear por partes que aproxima $F_{2}^{-1}(0)$ deve ser "colada" na componente resultante na segunda etapa do processamento da superficie linear por partes que aproxima $F_{1}^{-1}(0)$ obtida na primeira etapa. A "colagem" é realizada na fronteira de cada componente. A figura 7.2 exemplifica o processo de "colagem" para o modelo da figura 7.1

O processo de "colagem" é realizado logo após o trecho do algoritmo de conversão apresentado no quadro 7.2. Uma componente deve ser "colada" se ainda possuir fronteira após ser processada por este trecho do algoritmo. Para determinar se a componente possui fronteira, o procedimento de conversão mantém uma lista para cada curva de fronteira de cada componente conexa processada na primeira e segunda etapas. Esta lista é denominada lista de arestas de fronteira. Cada nó da lista armazena a 
identificação de uma aresta da curva de fronteira correspondente à lista. A identificação da aresta é a mesma utilizada na estrutura esqueleto combinatório.

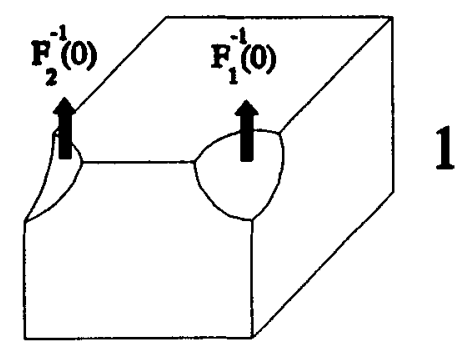

modelo

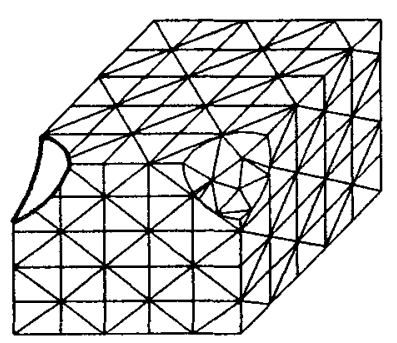

14 componente processada

na $2 \mathbf{2}$ etapa

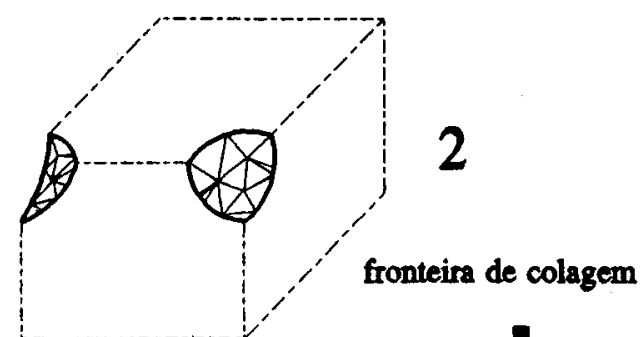

aproximação de $F_{1}^{-1}(0)$ e $F_{2}^{-1}(0)$ na $1^{1}$ etapa

3

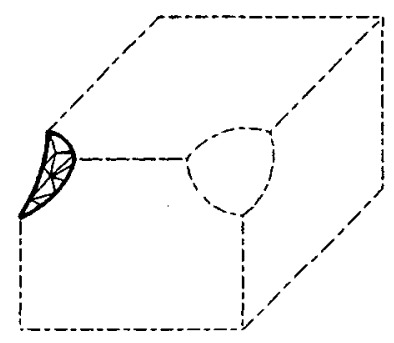

$2^{2}$ componente processada

na 2: etapa

Figura 7.2: o processo de "colagem de duas componentes conexas

As listas de arestas de fronteira correspondentes às curvas da fronteira de uma determinada componente resultante do trecho do algoritmo do quadro 7.2 devem estar vazias ao final deste trecho. Caso contrário, a componente deve ser "colada" a outras componentes através das curvas de sua fronteira. Para isso, o procedimento de conversão compara cada lista de arestas de fronteira da componente com as listas das outras componentes. Quando uma lista da componente é identificada com a lista de outra componente (possuem as mesmas arestas), as duas são "coladas" pela curva de fronteira correspondente à lista.

Os arquivos temporários que contêm a sequência de operadores de Euler de duas componentes "coladas" são unidos. Um operador próprio é adicionado à sequência de operadores do arquivo para indicar a operação de "colagem". $O$ arquivo temporário resultante da união dos arquivos das componentes "coladas" passa a ser o arquivo temporário que contém a sequência de operadores de Euler da componente resultante da "colagem". 


\section{6 - O Algoritmo da Terceira Etapa}

As componentes conexas resultantes da primeira e segunda etapas do procedimento de conversão podem ser classificadas como externas ou internas. Uma componente é dita externa quando pode ser visualizada por um observador localizado no exterior do sólido abstrato cuja fronteira contém a componente, considerando o objeto modelado como sendo opaco. Por outro lado, uma componente é dita interna quando é "ocultada" por uma componente externa, ou seja, pode ser visualizada por um observador localizado no exterior do sólido abstrato apenas se o objeto modelado é transparente.

Para exemplificar, considere o modelo descrito por $F=F_{1}$ diferença $F_{2}, D=[-3,3] \times[-3,3] \times$ $[-3,3]$ e " $<$ ", onde $F_{1}(x, y, z)=x^{2}+y^{2}+z^{2}-4$ e $F_{2}(x, y, z)=x^{2}+y^{2}+z^{2}-1$, como mostrado na figura 7.3. A fronteira do modelo possui duas componentes, $F_{1}^{-1}(0)$ e $F_{2}^{-1}(0)$. A componente $F_{1}^{-1}(0)$ é externa, enquanto $F_{2}^{-1}(0)$ é interna. $A$ fronteira de todo sólido abstrato possui uma única componente externa e pode possuir nenhuma, uma ou mais de uma componente interna.

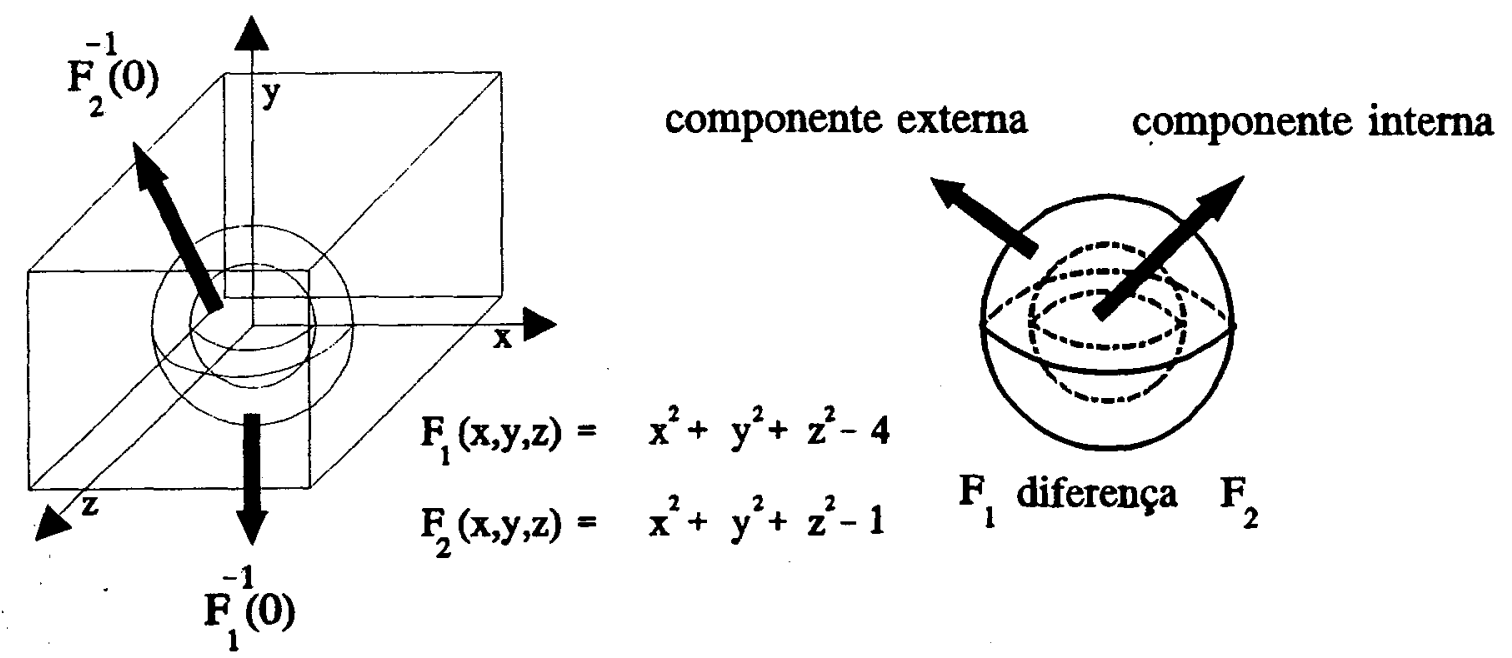

Figura 7.3: modelo cuja fronteira possui duas componentes, uma externa e outra interna.

No algoritmo correspondente à terceira etapa do procedimento de conversão, as componentes conexas resultantes da primeira e segunda etapas são classificadas como externas ou internas. Cada componente classificada como externa corresponde à componente externa da fronteira de um modelo descrito por F, D e "<" ou " $>$ ". As componentes classificadas como internas são associadas às componentes externas que pertencem a uma mesma fronteira. As componentes definidas por $S$ e parte de $\partial(D)$ ou por $\partial(D)$ são sempre externas. Portanto, apenas as componentes definidas por $S$ devem ser 
verificadas.

Quando somente componentes internas são obtidas na primeira e segunda etapas do procedimento de conversão ou quando uma ou mais componentes internas não forem associadas a uma das componentes externas encontradas, a superfície linear por partes correspondente a $\partial(D)$ é criada para ser a componente externa da fronteira de um novo modelo que possui as componentes internas restantes.

Para classificar uma componente como externa ou interna, o procedimento de conversão encontra o menor paralelepípedo P contido no domínio (paralelepípedo) D que contém todos os blocos resultantes de $K_{1}\left(D, K, I_{\varepsilon}^{3}\right)$ ou $J_{1}\left(D, K, I_{\varepsilon}^{3}\right)$ interceptados pela componente. $O$ paralelepípedo $P$ é encontrado através do conjunto de blocos passivos da componente, que contém os blocos interceptados pela componente durante a primeira e segunda etapas.

Um dos oito vértices do paralelepípedo é escolhido e a função $\mathrm{F}$ é avaliada neste vértice. Se o valor de $\mathrm{F}$ é menor do que zero e a indicação de interior contida na representação implícita é o sinal " <" ou se o valor de F é maior do que zero e a indicação de interior é o sinal ">", a componente é classificada como interna. Caso contrário, a componente é classificada como externa. Para exemplificar o processo de classificação, considere o exemplo em $\mathbf{R}^{2}$ contido na figura 7.4.
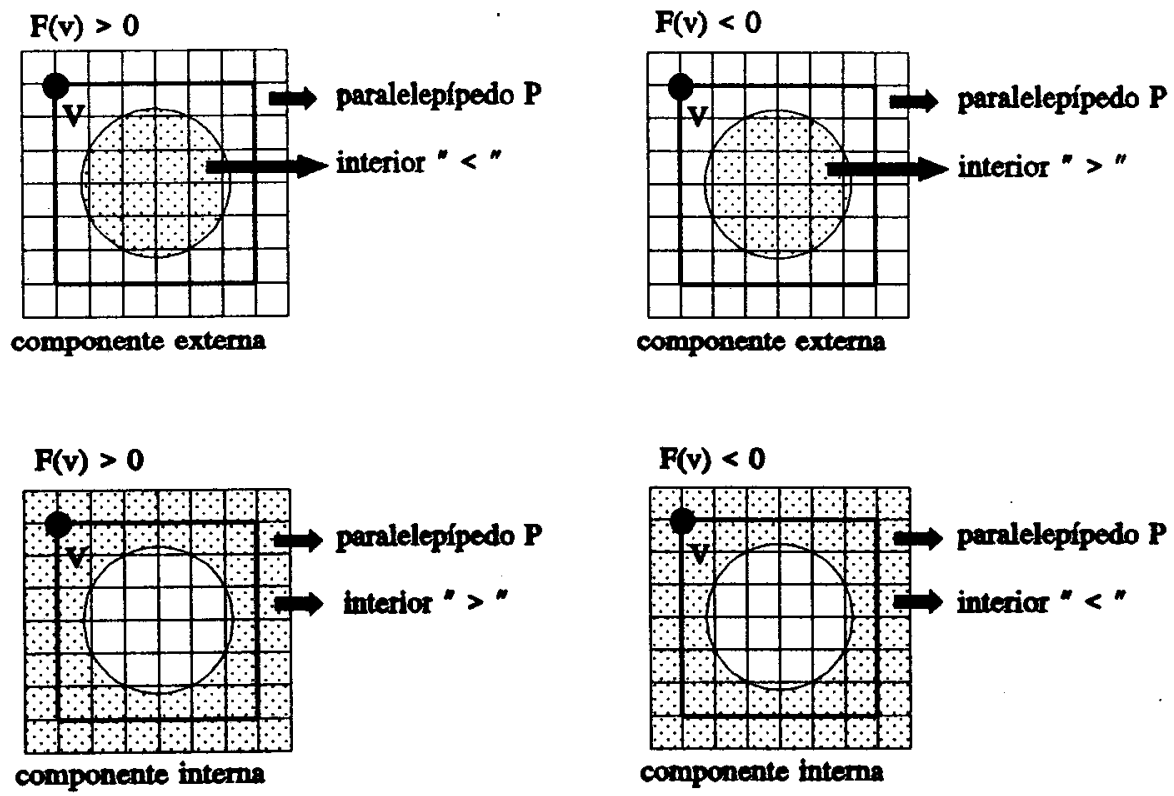

Figura 7.4: processo de classificação de componentes em $\mathbf{R}^{2}$

Cada componente classificada como externa ou interna recebe um número natural que passa a ser 
ser a identificação da componente. Em seguida, o procedimento de conversão cria duas listas, uma referente às componentes externas e outra referente às componentes internas. Estas listas são denominadas listas de componentes. Cada nó da lista de componentes contém a identificação de uma componente, o paralelepípedo $\mathrm{P}$ que a contém, um ponto pertencente à componente, o nome do arquivo temporário contendo a sequência de operadores de Euler correspondente à componente e uma variável numérica inicializada com o valor 1 . O ponto pertencente à componente é o mesmo ponto fornecido durante à descrição do modelo. Caso o ponto não tenha sido fornecido, um dos vértices da componente calculado na primeira ou segunda etapa do procedimento de conversão é considerado.

$\mathrm{O}$ paralelepípedo $\mathrm{P}$ contido em cada nó da lista de componentes internas é comparado com o paralelepípedo $\mathrm{P}$ contido em cada nó da lista de componentes externas. A componente externa correspondente ao nó da lista possuindo o menor paralelepípedo que contém o paralelepípedo comparado da lista de componentes internas pertence à mesma fronteira que contém a componente interna correspondente ao nó da lista que possui o paralelepípedo comparado.

Os nós da lista de componentes internas correspondentes às componentes identificadas com uma componente externa durante o passo de agrupamento são eliminados da lista. A sequência de operadores de Euler correspondente a cada componente interna identificada é anexada ao arquivo temporário que contém a sequência de operadores da componente externa pertencente à mesma fronteira que contém a componente interna. O ponto pertencente à componente interna é armazenado no nó da lista referente à componente externa com a qual ela foi identificada. A variável numérica de cada nó da lista de componentes externas é incrementada de 1 toda vez que uma componente interna for identificada com a componente externa correspondente ao nó. Este passo é denominado agrupamento.

Se a lista de componentes internas não estiver vazia após o passo de agnupamento, a superfície linear por partes correspondente a $\partial(D)$ é criada, bem como um nó na lista de componentes externas correspondente a esta componente. As componentes internas correspondentes aos nós restantes da lista de componentes internas são identificadas com a superfície linear por partes correspondente a $\partial(D)$, assim como foi feito para as demais componentes internas. Em seguida, o passo de agrupamento é realizado para as componentes restantes.

O trecho correspondente à terceira etapa do algoritmo do procedimento de conversão é mostrado no quadro 7.3. As variáveis utilizadas para armazenagem dos dados no algoritmo são:

- LI: apontador para a lista de componentes internas. 
- LE: apontador para a lista de componentes externas.

inicialize LI e LE como apontadores nulos

para cada componente

início 1

calcule o paralelepipedo $P$

classifique a componente como interna ou externa

crie um nó para a lista de componentes

se a componente é interna

insira o nó na lista apontada por LI

senão

insira o nó na lista apontada por LE

fim do se

fim 1

para cada paralelepípedo $\mathrm{P}$ contido na lista apontada por LI

início 2

encontre o menor paralelepípedo contido na lista apontada por LE que contém

o paralelepípedo $P$

se encontrou

anexe 0 arquivo temporário correspondente à componente interna ao arquivo temporário

correspondente à componente externa

incremente de 1 a variável numérica contida no nó correspondente à componente externa

elimine o nó da lista de componentes internas contendo o paralelepípedo $\mathrm{P}$

fim do se

fim 2

se LI é nâo nulo

gere a superfície linear por partes correspondente a $\partial(D)$

crie um nó correspondente a esta superfície

insira o nó na lista apontada por LE

identifique cada componente correspondente a um nó de LI com a superfície gerada

elimine todos os nós restantes da lista apontada por LI

fim do se

Quadro 7.3: trecho correspondente à terceira etapa do algoritmo do procedimento de conversão

Cada nó da lista de componentes externas resultante do algoritmo do quadro 7.3 contém informações relativas à fronteira de um modelo, e não apenas a uma componente externa, pois possui o nome do arquivo temporário contendo a sequência de operadores de Euler capaz de representar todas as componentes da fronteira na estrutura semi-aresta*, um ponto pertencente a cada componente e o número de componentes da fronteira, dado pela variável numérica armazenada no nó. 


\section{7 - O Algoritmo da Quarta Etapa}

No algoritmo correspondente à quarta etapa do procedimento de conversão, a lista de componentes externas é percorrida e, para cada nó encontrado, é criada uma cópia da representação implícita gerada pelo tradutor. Em cada cópia, são adicionados o número de componentes e um ponto pertencente a cada componente. Estas informações estão no nó da lista. Os dados de cada representação são gravados em disco na forma de arquivo texto. $O$ nome do arquivo de cada representação é composto pelo nome do sólido abstrato (fornecido pelo usuário) representado seguido da extensão ".int". O nó encontrado é eliminado da lista.

Todos os arquivos temporários, cujos nomes estão na lista de componentes externas, são transformados em arquivos definitivos. Cada arquivo temporário tem o nome modificado para o nome do sólido, cuja fronteira pode ser gerada pela sequência de operadores de Euler contida no arquivo, seguido da extensão ".log". Estes arquivos podem ser lidos por um procedimento do módulo de representação do $(\mathrm{SM})^{2}$ denominado carregador. Este procedimento é capaz de ler a sequência de operadores de Euler contida no arquivo e ativar os procedimentos correspondentes a cada operador, gerando a estrutura de dados semi-aresta* em memória.

Para cada modelo descrito por semi-espaços no $(\mathrm{SM})^{2}$ são gerados, portanto, dois arquivos. Um arquivo contém os dados da representação implícita e o outro contém a sequência de operadores de Euler capaz de gerar a estrutura de dados da BRep poliedral, a estrutura semi-aresta*. A sequência de operadores de Euler que gera a estrutura semi-aresta* contém informações tais como a cor do modelo, a constituição material do objeto modelado e o nome do arquivo contendo a representação implícita do modelo, além das informações geométricas e topológicas dos elementos da fronteira do modelo. O nome do arquivo contendo a representação implícita é uma informação adicional inserida na estrutura semiaresta* gerada pela sequência de operadores de Euler com o intuito de permitir que a representação implícita do modelo possa ser consultada através de sua BRep poliedral.

O trecho correspondente à quarta etapa do algoritmo do procedimento de conversão é mostrado no quadro 7.4. A variável usada para armazenagem de dados no algoritmo é:

- LE: apontador para a lista de componentes externas. 
para cada nó da lista apontada por LE

início 1

gere uma cópia da representação implícita

inclua na cópia o número de componentes e um ponto pertencente a cada componente

grave os dados da cópia da representação implícita em um arquivo

mude o nome armazenado no nó do arquivo temporário contendo a sequência de operadores de

Euler

elimine o nó da lista apontada por LE

fim 1

Quadro 7.4: trecho correspondente à quarta etapa do algoritmo do procedimento de conversão

\section{8 - A Sequência de Operadores de Euler}

A estrutura semi-aresta* é inicialmente construlda pelo operador MVFSS (Make Vertex Face Shell Solid) que cria um elemento vértice, um elemento face, um elemento casca e um elemento sólido na hierarquia da estrutura. Um modelo possuindo apenas estes elementos pode não capturar a noção de "solidez", no entanto o propósito do operador MVFSS é estabelecer uma estrutura inicial para a utilização dos demais operadores.

Nenhuma face, aresta ou vértice pode ser incluído na estrutura semi-aresta* sem que tenham sido representados os elementos iniciais através do operador MVFSS. Portanto a sequência de operadores de Euler de cada componente processada na primeira etapa do procedimento de conversão é iniciada pelo operador MVFSS. Isto significa que a sequência correspondente a cada componente resultante da primeira etapa é capaz de gerar a estrutura semi-aresta* que representa um modelo de sólido cuja fronteira é composta apenas pela componente resultante.

O modelo associado à sequência de operadores de Euler de cada componente gerada na primeira etapa pode não capturar a noção de "solidez", pois as componentes podem possuir fronteira e a definição dada no capítulo 2 para sólido abstrato afirma que as componentes da fronteira são topologicamente equivalentes à esfera ou ao n-toro. No entanto, isto não impede que a estrutura possa ser gerada, como será visto a seguir.

As componentes com fronteira são representadas na estrutura semi-aresta* como se não possuíssem fronteira. Isto é possível porque as arestas das curvas da fronteira da componente são representadas como arestas compartilhadas com uma face "fictícia". Para exemplificar, considere a 
superfície linear por partes com fronteira mostrada na figura 7.5. Esta superfície possui cinco faces, mas é representada na estrutura semi-aresta* como possuindo seis faces. A sexta face é "fictícia" e suas arestas são as arestas da fronteira da superfície. A superfície representada na estrutura é topologicamente equivalente a uma esfera, entretanto o conjunto de pontos limitado pela superfície não é regular.
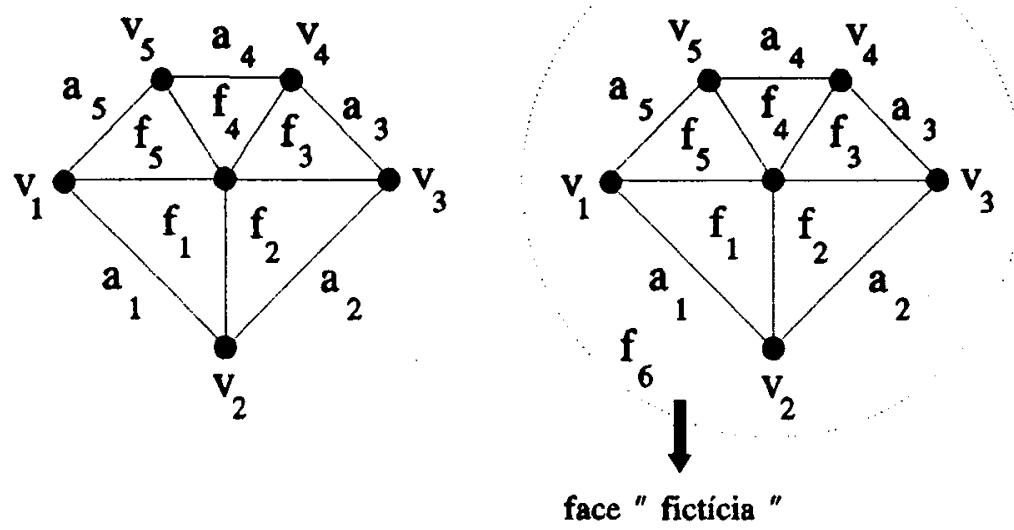

Figura 7.5: superfície com fronteira representada na estrutura semi-aresta*

Para cada face calculada na primeira e segunda etapas, são inseridos na sequência correspondente à componente que a contém os operadores de Euler capazes de representá-la na estrutura semi-aresta*. Os operadores inseridos e a ordem de inserção na sequência são determinados através das listas de arestas de fronteira de cada componente. Os operadores necessários para criar as faces são MEV (Make Edge Vertex), MEF (Make Edge Face), KFMRH (Kill Face Make Ring Hole) e MEKR (Make Edge Kill Ring).

As faces calculadas pelo procedimento de conversão podem pośsuir três ou quatro vértices (ver capítulo 6). As faces com quatro vértices nem sempre são planares, portanto são particionadas em duas faces com três vértices cada. A partição é realizada após o cálculo da face e os operadores de Euler são gerados para as faces particionadas. Além disso, cada face calculada possui pelo menos uma aresta em comum com uma face da mesma componente calculada anteriormente.

Os operadores de Euler gerados para uma face calculada são determinados através da verificação de quais vértices e arestas da face foram inseridos na sequência de operadores correspondente à superfície, pois é possível que algumas ou até todas as suas faces adjacentes já tenham sido calculadas e, portanto, alguns ou todos os vértices e arestas serão criados por operadores inseridos anteriormente. O procedimento de conversão utiliza as listas de arestas de fronteira da componente para identificar quais 
arestas e vértices da face calculada já foram calculados e inseridos na sequência.

Cada lista de arestas de fronteira de uma componente contém as arestas de uma curva de fronteira da componente. Portanto, as arestas contidas em cada uma dessas listas seriam as arestas de uma face "fictícia" da componente, caso a componente estivesse representada em uma estrutura semi-aresta*. Como as faces calculadas são sempre adjacentes a uma face calculada anteriormente, as faces que fossem adicionadas à estrutura seriam "coladas" sempre em uma, duas ou três das arestas de uma face "fictícia". Portanto, é necessário apenas "simular" as operações de "colagem" que ocorreriam nas faces "fictícias" através das listas de arestas de fronteira.

(a)
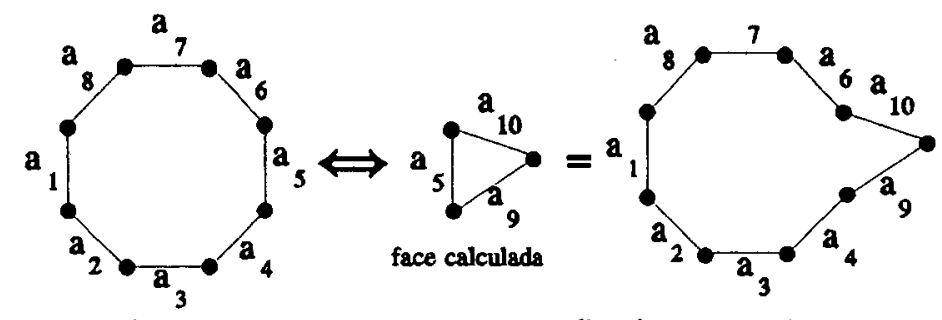

lista de arestas

lista de arestas resultanie

(b)

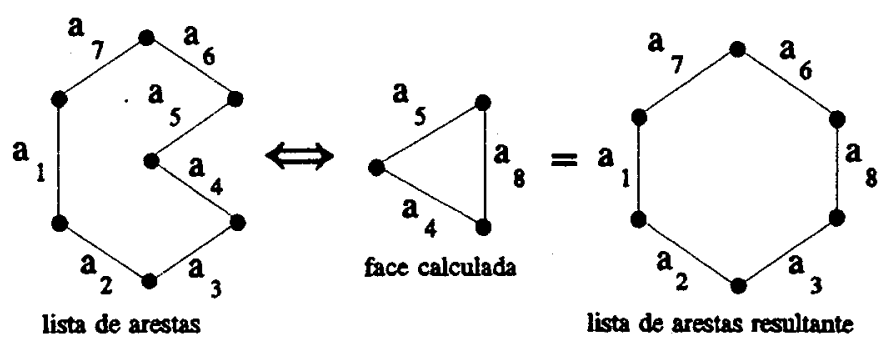

(c)
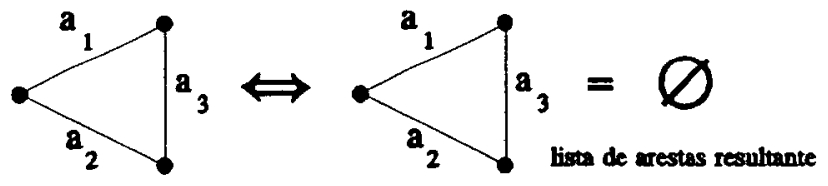

lista de arestas

face calculada

Figura 7.6: colagem de faces com: (a) uma, (b) duas e (c) três arestas pertencentes à componente

Se apenas uma aresta da face calculada pertence às listas de arestas de fronteira da componente, os operadores MEV e MEF são inseridos, nesta ordem, na sequência de operadores de Euler correspondente à componente para criar o vértice, as duas arestas e a face na componente, como mostrado na figura 7.6a. Se duas arestas da face calculada pertencem às listas de arestas da componente, o operador MEF é inserido na sequência, como mostrado na figura 7.6b. Se as três arestas da face 
pertencem a uma lista de arestas da componente, esta face é a própria face "fictícia" correspondente a lista, como mostrado na figura 7.6c.

Se uma aresta e um vértice da face calculada pertencem às listas de arestas da componente, sendo que a aresta pertence a uma lista e o vértice à outra, os operadores KFMRH, MEKR e MEF são inseridos, nesta ordem, na sequência correspondente à componente para criar as duas arestas restantes e a face. A lista contendo a aresta e a lista contendo o vértice são combinadas após a inserção destes operadores na sequência resultando em uma única lista, como mostrado na figura 7.7.

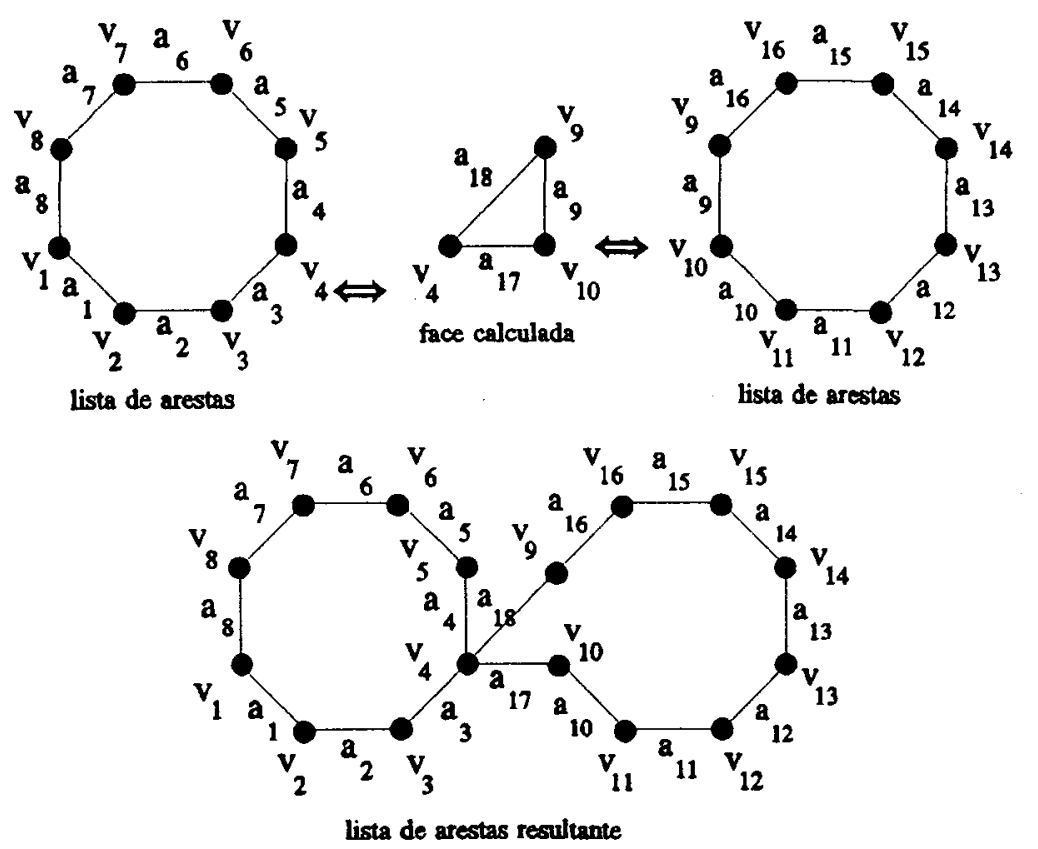

Figura 7.7: junção de duas listas de arestas de fronteira

As componentes definidas por S e $\partial(D)$ podem ser obtidas através da "colagem" de outras componentes, como descrito na seção 7.5. A "colagem" é realizada na fronteira das componentes. A sequência de operadores de Euler correspondente à componente resultante da "colagem" é composta pela sequência referente a todas as componentes "coladas" e pelo operador GSolid (glue) [Mä88]. .

$O$ operador GSolid une a componente externa da fronteira de um dado modelo à componente externa da fronteira de outro modelo através de duas faces, uma de cada componente, que possuem arestas idênticas. A componente resultante da "colagem" passa a ser a componente externa do primeiro modelo, ou seja, a estrutura semi-aresta* do primeiro modelo recebe os elementos da componente externa do segundo modelo, enquanto a estrutura semi-aresta* do segundo modelo é destruída. $O$ segundo modelo 
deve possuir a fronteira composta apenas de uma componente.

No procedimento de conversão, o operador GSolid é inserido na sequência de operadores de Euler correspondente a uma componente resultante da "colagem" de duas outras componentes. A sequência correspondente à componente resultante é composta da sequência das componentes "coladas" seguidas do operador GSolid. As faces indicadas no operador GSolid como as faces da "colagem" são as faces "fictícias" correspondentes as curvas de fronteira de cada componente, onde ocorreria a "colagem" se estas componentes estivessem representadas na estrutura semi-aresta*.
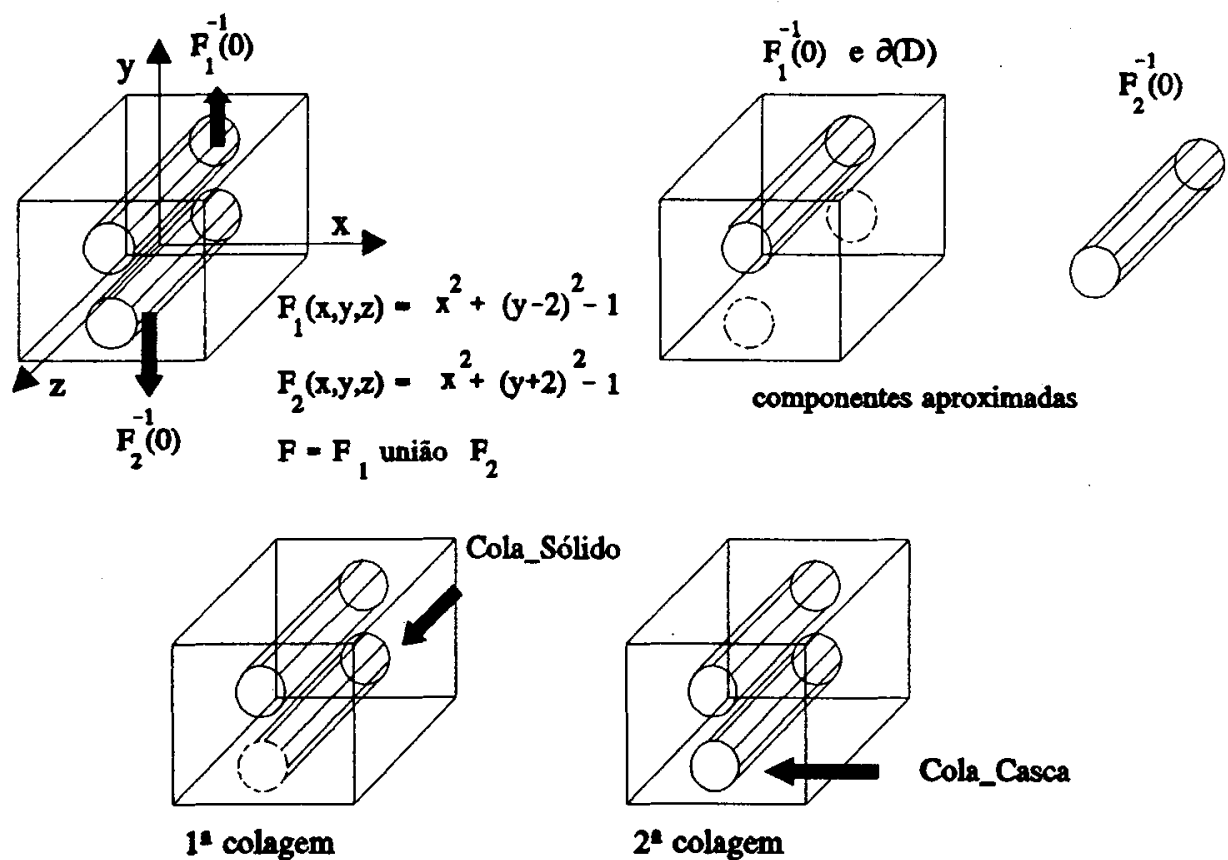

Figura 7.8: componente resultante da "colagem" de duas componentes

É possível que duas componentes sejam "coladas" por mais de uma face. O operador GSolid é inserido na sequência da componente resultante para efetuar a primeira "colagem" e, em seguida, o operador GShell $e$ inserido para realizar as demais "colagens". Este operador elimina da estrutura semiaresta* que contém a componente resultante da primeira "colagem" as faces "fictícias" que contém as arestas correspondentes as outras curvas de fronteira da componente resultante, onde são realizadas as demais "colagens". A inserção de GSolid ou GShell na sequência de operadores de Euler correspondente à componente resultante equivale à destruição das listas de arestas de fronteira correspondentes às faces "fictícias" utilizadas pelos operadores. 0 operador GShell foi desenvolvido durante o trabalho descrito 
nesta dissertação.

A figura 7.8 exemplifica a utilização do operador GShell durante a aproximação da fronteira do modelo descrito por $F=F_{1}$ união $F_{2}, D=[-4,4] \times[-4,4] \times[-4,4]$ e " $>$ ", onde $F_{1}(x, y, z)=x^{2}+(y-2)^{2}-1$ e $F_{2}(x, y, z)=x^{2}+(y+2)^{2}-1$ (as faces das componentes foram omitidas para simplificar o desenho). Na segunda etapa do procedimento de conversão, a superfície linear por partes que aproxima $F_{1}^{-1}(0)$ (supostamente processada primeiro) é unida à superfície linear por partes correspondente à parte de $\partial(\mathrm{D})$ contida na fronteira do modelo durante o trecho do algoritmo de conversão mostrado no quadro 7.2. Por outro lado, a superfície linear por partes que aproxima $F_{2}{ }^{-1}(0)$ resulta nela própria. Após o trecho do quadro 7.2, o operador GSolid é inserido na sequência de operadores correspondente à fronteira do modelo para "colar" as duas componentes por uma de suas curvas de fronteira. O operador GShell é inserido a seguir para "colar" as curvas de fronteira restantes na componente resultante da "colagem" efetuada por GSolid.

No passo de agrupamento, a fronteira de cada modelo definido por F, D e "<" ou " $>$ " é determinada. A sequência de operadores de Euler correspondente à fronteira de cada modelo é composta pela sequência da componente externa e das componentes internas identificadas como pertencentes à fronteira. A sequência de cada componente é capaz de gerar uma estrutura semi-aresta* que representa um modelo cuja fronteira é composta apenas pela componente. Portanto, a simples junção das sequências correspondentes às componentes da fronteira não é capaz de gerar uma única estrutura semi-aresta* que representa um modelo cuja fronteira é composta de todas as componentes.

A sequência de operadores de Euler correspondente a cada fronteira é, então, composta pelas sequências correspondentes às componentes da fronteira e por um operador capaz de transferir uma componente externa contida em uma dada estrutura semi-aresta* para outra estrutura semi-aresta* de forma que a estrutura que continha a componente transferida é destruída e a componente passa a ser uma componente interna da fronteira representada na estrutura destino da transferência. Este operador é denominado MSKS (Make Shell Kill Solid) e também foi desenvolvido, juntamente com o operador inverso KSMS (Kill Solid Make Shell), durante o trabalho descrito nesta dissertação.

Os primeiros operadores da sequência correspondente à fronteira são pertencentes à sequência correspondente à componente externa da fronteira. Em seguida, são encontrados os operadores da sequência correspondente a uma possível componente interna da fronteira e o operador MSKS. Cada nova sequência correspondente a outras possíveis componentes internas da fronteira são seguidas do operador MSKS. Isto significa que se a sequência de operadores correspondente à fronteira for executada, os 
operadores correspondentes à componente externa gerarão uma estrutura semi-aresta* que conterá uma fronteira composta apenas pela componente externa. Analogamente, cada sequência de operadores correspondente a uma possível componente interna da fronteira gerará uma estrutura semi-aresta* que representará uma fronteira composta apenas pela componente interna como sendo a componente externa desta fronteira. Em seguida, MSKS transferirá a componente interna para a estrutura semi-aresta* contendo a componente externa e destruirá a estrutura que continha a componente interna.

\section{9 - Exemplos de Modelos Gerados no (SM) ${ }^{2}$}

Os arquivos contendo a sequência de operadores de Euler capaz de gerar a estrutura semi-aresta* de um modelo de sólido no $(\mathrm{SM})^{2}$ podem ser lidos pelo procedimento carregador do módulo de representação, como visto na seção 7.7. Este procedimento gera a estrutura semi-aresta* na memória principal do computador. A partir daí, os procedimentos do módulo de visualização têm acesso aos dados da estrutura e podem gerar uma imagem "realística" do sólido abstrato utilizando o modelo de iluminação constant shading, o único modelo de iluminação implementado até o presente momento no (SM) ${ }^{2}$. Nesta seção são apresentadas algumas figuras geradas através dos procedimentos de visualização.

O modelo da figura 7.9 é descrito por apenas um semi-espaço. A superfície do semi-espaço não é diferenciável. O modelo da figura 7.10 é descrito através da operação booleana união sobre oito semiespaços. O modelo da figura 7.11 é descrito através da operação booleana diferença sobre dois semiespaços. $\mathrm{O}$ modelo da figura 7.12 é descrito através da operação booleana união sobre três semi-espaços e a componente externa do modelo é definida pela superfície dos semi-espaços e pela fronteira do compacto D.

Os modelos 7.13 e 7.14 são descritos através da operação booleana união sobre os mesmos dois semi-espaços, duas esferas sólidas. O modelo da figura 7.13 foi aproximado utilizando o valor de "p" em $F_{U}$ igual a 2 (ver capítulo 4). Isto provocou um "arredondamento" na região de interseção das duas esferas unidas. $O$ modelo da figura 7.14 foi aproximado usando o valor de "p" em $F_{U}$ igual a 21, o que provocou uma diminuição do efeito de "arredodamento" ocorrido no modelo da figura 7.13. Além disso, as duas esferas do modelo da figura 7.14 foram deslocadas em relação às esferas do modelo da figura 7.13, e obtiveram uma melhor aproximação na região de interseção devido à disposição dos simplexos da triangulação nesta região. 
O modelo da figura 7.15 possui a fronteira com geometria complexa e foi definido através de operações booleanas sobre vários semi-espaços. Isto demonstra o poder da técnica de descrição por semiespaços utilizada no $(\mathrm{SM})^{2}$. Observe que a aproximação precisa ser melhorada nas regiões de grande curvatura da fronteira do modelo. Por outro lado, a fronteira está bem aproximada nas regiōes de baixa curvatura. Como as triangulações $K_{1}$ e $J_{1}$ são uniformes, não há como refinar apenas uma região desejada da triangulação.

A figura 7.9 corresponde ao modelo "coração" descrito pelos seguintes dados: $F(x, y, z)=$ $\left(2 z^{2}+x^{2}+y^{2}-1\right)^{3}-(1 / 10) z^{2} y^{3}-x^{2} y^{3}, D=[-2,2] \times[-2,2] \times[-2,2]$, o sinal " $<$ ", o número de componentes igual a 1 , o ponto $(0,0,0.7071)$, a triangulação $J_{1}$ e o refinamento $K=(20,20,20)$.

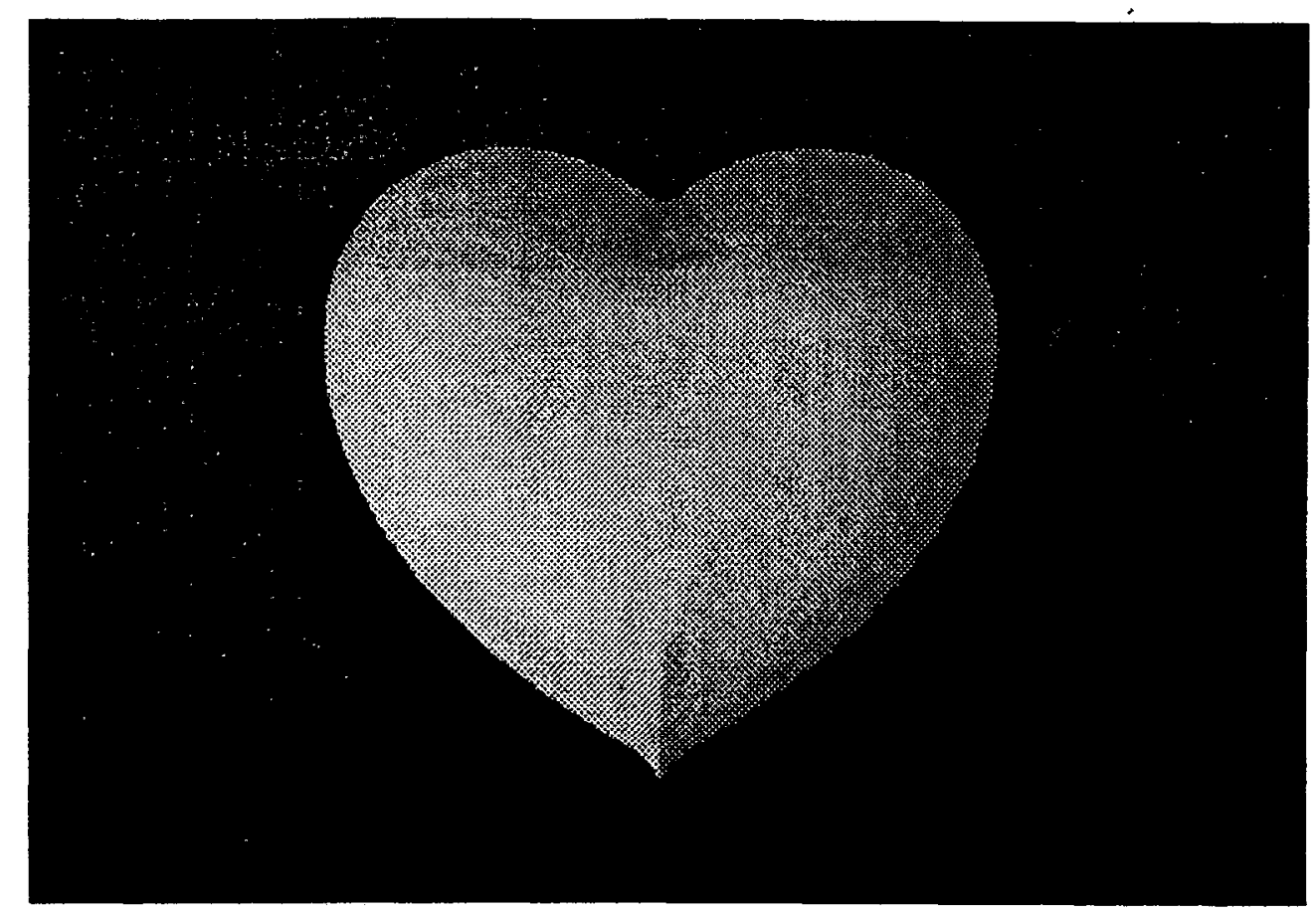

Figura 7.9: o modelo "coração" 
A figura 7.10 corresponde ao modelo "oito toros" descrito pelos seguintes dados: $F=F_{1}$ união $F_{2}$ união $F_{3}$ união $F_{4}$ união $F_{5}$ união $F_{6}$ união $F_{7}$ união $F_{8}$, onde $F_{1}(x, y, z)=\left(\left((x-6)^{2}+y^{2}\right)^{1 / 2}-2\right)^{2}+z^{2}-1$, $F_{2}(x, y, z)=\left(\left((x+6)^{2}+y^{2}\right)^{1 / 2}-2\right)^{2}+z^{2}-1, \quad F_{3}(x, y, z)=\left(\left(x^{2}+(y-6)^{2}\right)^{1 / 2}-2\right)^{2}+z^{2}-1$, $F_{4}(x, y, z)=\left(\left(x^{2}+(y+6)^{2}\right)^{1 / 2}-2\right)^{2}+z^{2}-1, \quad F_{5}(x, y, z)=\left(\left((x-4)^{2}+(y-4)^{2}\right)^{1 / 2}-2\right)^{2}+z^{2}-1$, $F_{6}(x, y, z)=\left(\left((x+4)^{2}+(y-4)^{2}\right)^{1 / 2}-2\right)^{2}+z^{2}-1, F_{7}(x, y, z)=\left(\left((x-4)^{2}+(y+4)^{2}\right)^{1 / 2}-2\right)^{2}+z^{2}-1$ e $F_{8}(x, y, z)=\left(\left((x+4)^{2}\right.\right.$ $\left.\left.+(y+4)^{2}\right)^{1 / 2}-2\right)^{2}+z^{2}-1, D=[-10,10] \times[-10,10] \times[-10,10]$, o sinal " $<$ ", o número de componente igual a 1 , o ponto $(9,0,0)$, a triangulação $J_{1}$ e o refinamento $K=(30,30,30)$.

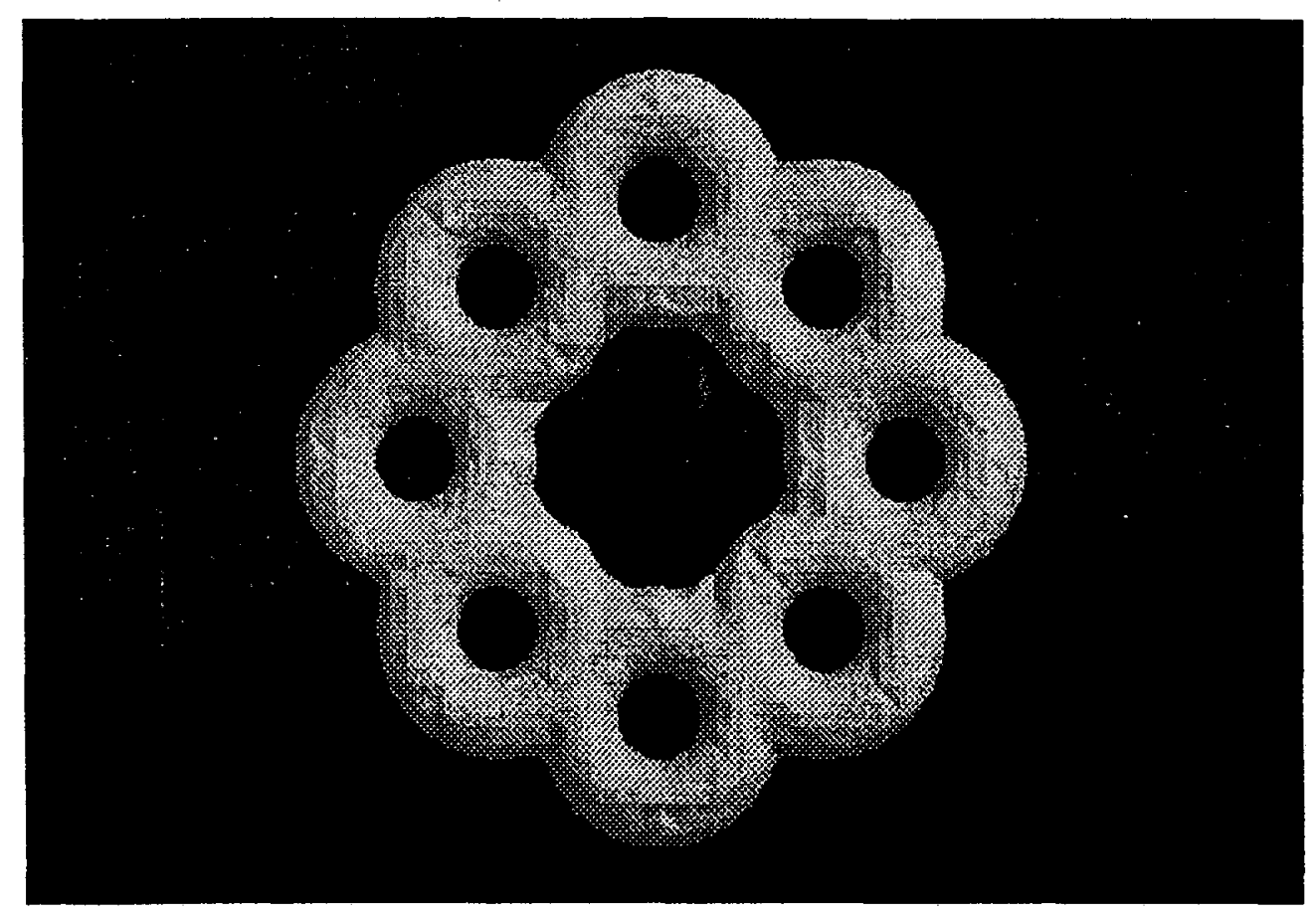

Figura 7.10: o modelo "oito toros" 
A figura 7.11 corresponde ao modelo "telha" descrito pelos seguintes dados: $F=F_{1}$ diferença $F_{2}$, onde $F_{1}(x, y, z)=y-\operatorname{sen}(x)-0.5$ e $F_{2}(x, y, z)=y-\operatorname{sen}(x), D=[-10,10] \times[-2,2] \times[-10,10]$, o sinal " <", o número de componentes igual a 2 , os pontos $(0,0.5,0)$ e $(0,0,0)$, a triangulação $J_{1}$ e o refinamento $K=(20,20,2)$.

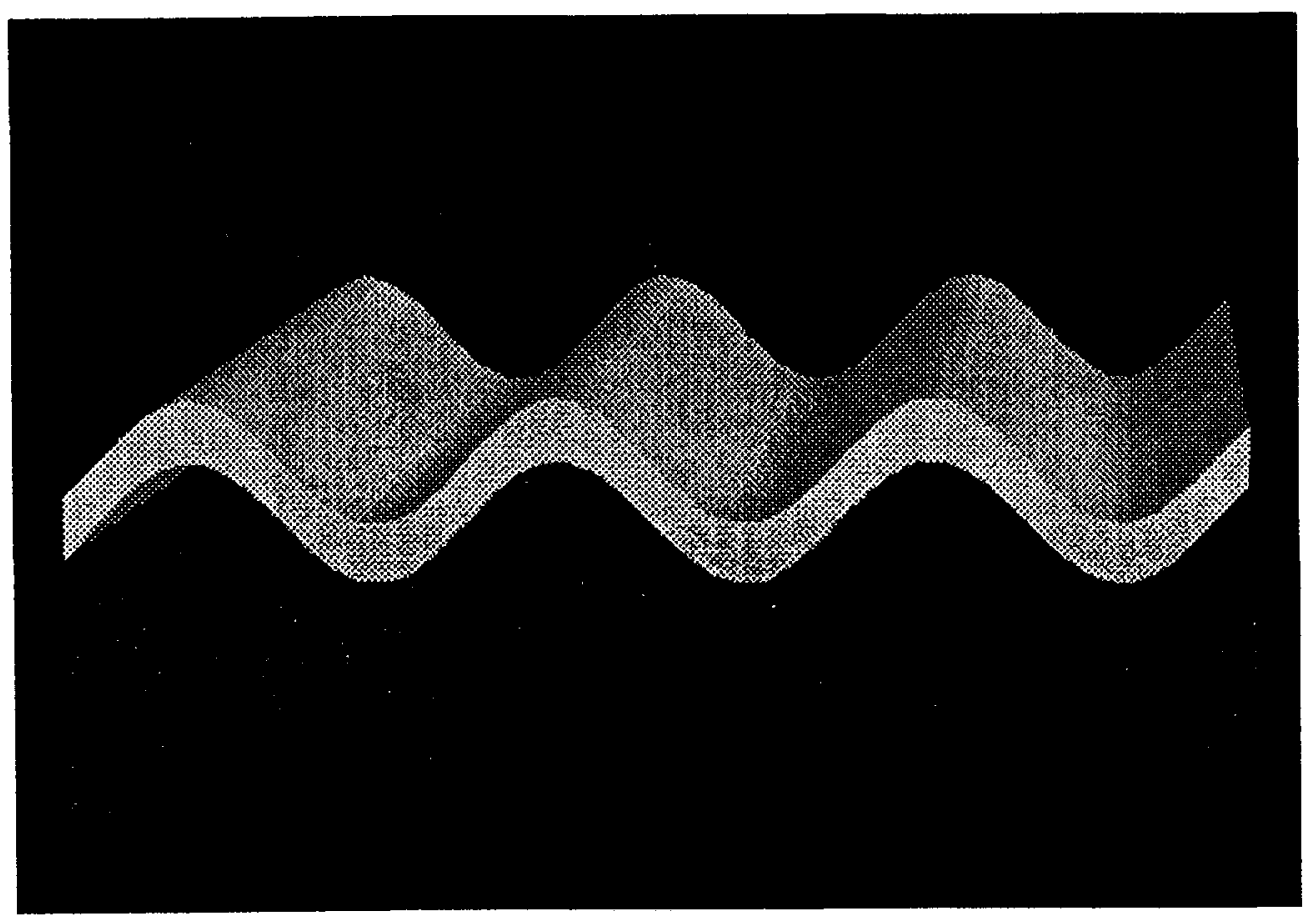

Figura 7.11: o modelo "telha" 
A figura 7.12 corresponde ao modelo "queijo" descrito pelos seguintes dados: $F=F_{1}$ união $F_{2}$ união $F_{3}$, onde $F_{1}(x, y, z)=(x-10)^{2}+(y-10)^{2}+(z-10)^{2}-100, F_{2}(x, y, z)=(x+5)^{2}+(y-5)^{2}-16$ e $F_{3}(x, y, z)=$ $\left(\left((x+10)^{2}+(z-10)^{2}\right)^{1 / 2}-5\right)^{2}+(y+5)^{2}-4, \quad D=[-10,10] \times[-10,10]-[-10,10]$, o sinal " $<"$, o número de componentes igual a 3 , os pontos $(3.8786,-5,3.8786),(-1,5,0)$ e $(-7.8786,-5,7.8786)$, a triangulação $J_{1}$ e o refinamento $K=(30,30,30)$.

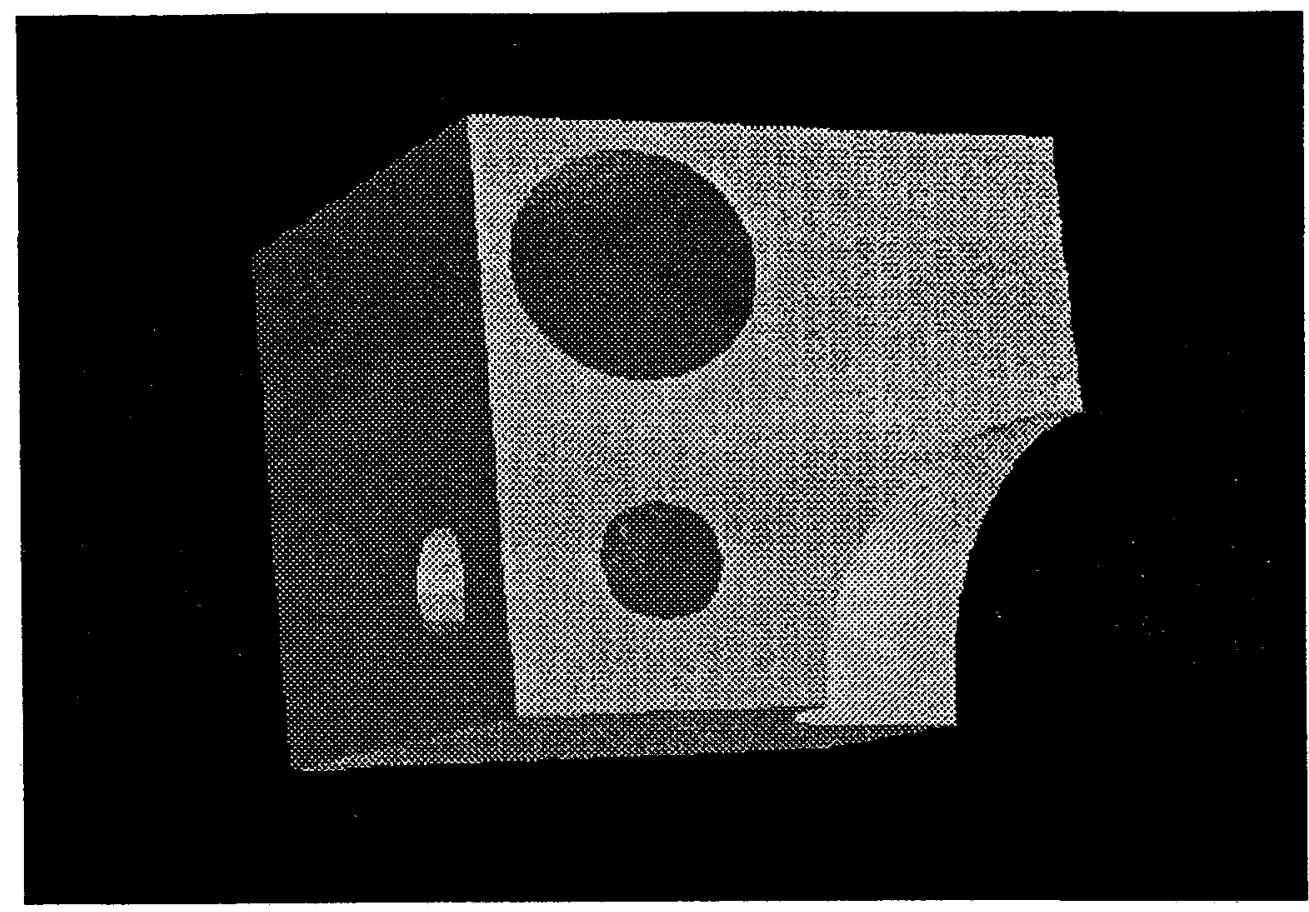

Figura 7.12: o modelo "queijo" 
A figura 7.13 corresponde ao modelo "duas esferas" descrito pelos seguintes dados: $F=F_{1}$ união $F_{2}$, onde $F_{1}(x, y, z)=(x-3)^{2}+y^{2}+z^{2}-9$ e $F_{2}(x, y, z)=x^{2}+y^{2}-z^{2}-9, D=[-10,10] \times[-10,10] \times[-10,10]$, o sinal $"<"$, o número de componentes igual a 1 , o ponto $(3,0,0)$, a triangulação $J_{2}$ e o refinamento $\mathrm{K}=(10,10,10)$.

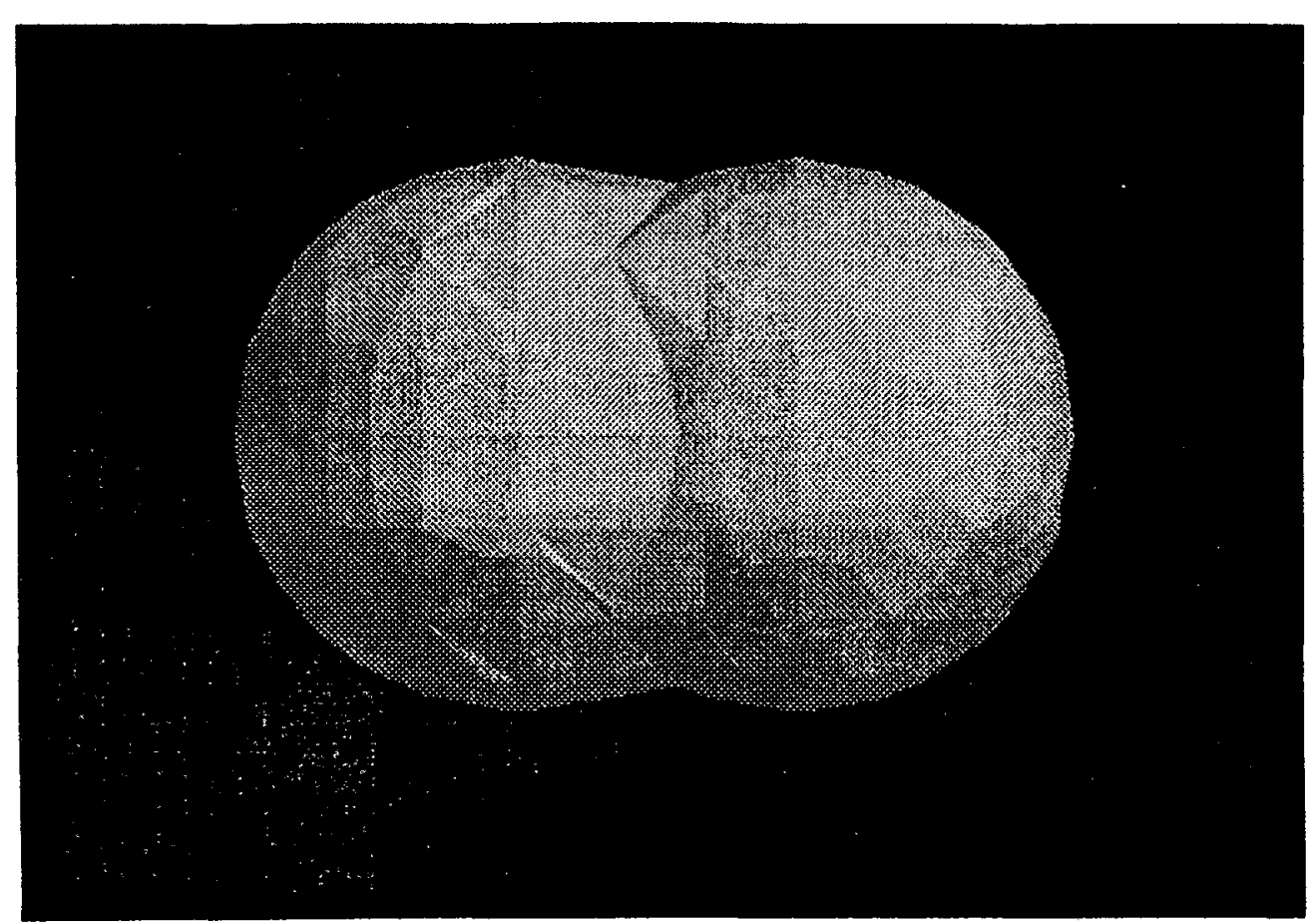

Figura 7.13: o modelo "duas esferas" 
A figura 7.14 corresponde ao modelo "duas esferas deslocado" descrito pelos seguintes dados: $F=F_{1}$ união $\quad F_{2}$, onde $\quad F_{1}(x, y, z)=(x-3.5)^{2}+y^{2}+z^{2}-9$ e $\quad F_{2}(x, y, z)=(x+0.5)^{2}+y^{2}-z^{2}-9$, $D=[-10,10] \times[-10,10] \times[-10,10]$, o sinal " $<$ ", o número de componentes igual a 1 , o ponto $(2.5,0,0)$, a triangulação $J_{1}$ e o refinamento $K=(10,10,10)$.

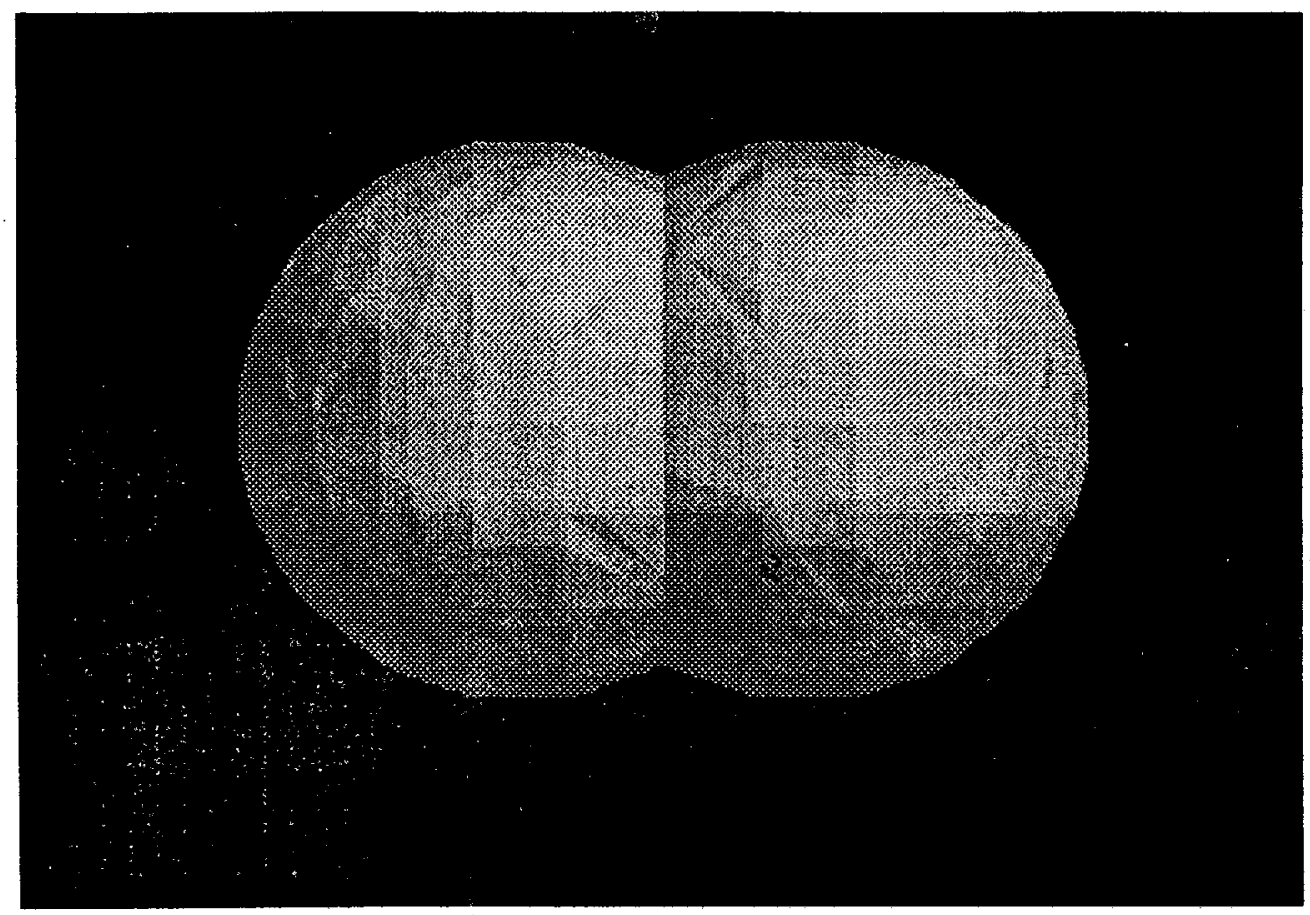

Figura 7.14: o modelo "duas esferas deslocadas" 
A figura 7.15 corresponde a dois modelos, a "tampa" e o "pote" de um "açucareiro". A "tampa" é descrita pelos seguintes dados: $F=F_{1}$ união $F_{2}$ união $F_{3}$, onde $F_{1}(x, y, z)=(x+2)^{2}+(z+2)^{2}+$ $100^{*}(y+0.7)^{2}-0.6944, \quad F_{2}(x, y, z)=(x+2)^{2}+(z+2)^{2}+(y+0.6)^{2}-0.0225 \quad$ e $\quad F_{3}(x, y, z)=\left(\left((x+2)^{2}+(z+2)^{2}\right)^{1 / 2}\right.$ $-0.5416)^{2}+(y+0.8)^{2}-0.015625, \quad D=[-3,-1] \times[-1.3,-0.2] \times[-3,-1]$, o sinal $"<"$, o número de componentes igual a 1 , o ponto $(-2,-0.45,-2)$, a triangulação $J_{1}$ e o refinamento $K=(30,20,30)$. $O$ "pote" é descrito pelos seguintes dados: $F=\left(F_{1}\right.$ união $F_{2}$ união $F_{3}$ união $\left.F_{4}\right)$ diferença $\left(F_{5}\right.$ união $\left.F_{6}\right)$, onde $\quad F_{1}(x, y, z)=x^{2}+y^{2}+z^{3}, \quad F_{2}(x, y, z)=x^{2}+y^{2}+z^{3}-1, \quad F_{3}(x, y, z)=\left(\left((x+1)^{2}+y^{2}\right)^{1 / 2}-0.4\right)^{2}+z^{2}-0.0225$, $F_{4}(x, y, z)=\left(\left((x-1)^{2}+y^{2}\right)^{1 / 2}-0.4\right)^{2}+z^{2}-0.0225, \quad F_{5}(x, y, z)=x^{2}+y^{2}+z^{2}-0.7225 \quad$ e $\quad F_{6}(x, y, z)=x^{2}+y^{2}-z^{3}$, $\mathrm{D}=[-2,2] \times[-1,-1.5] \times[-1.5,-1.5]$, o sinal " $<$ ", a triangulação $J_{1}$ e o refinamento $K=(40,25,30)$. $O$ número de componentes e um ponto pertencente a cada componente na descrição do "pote".

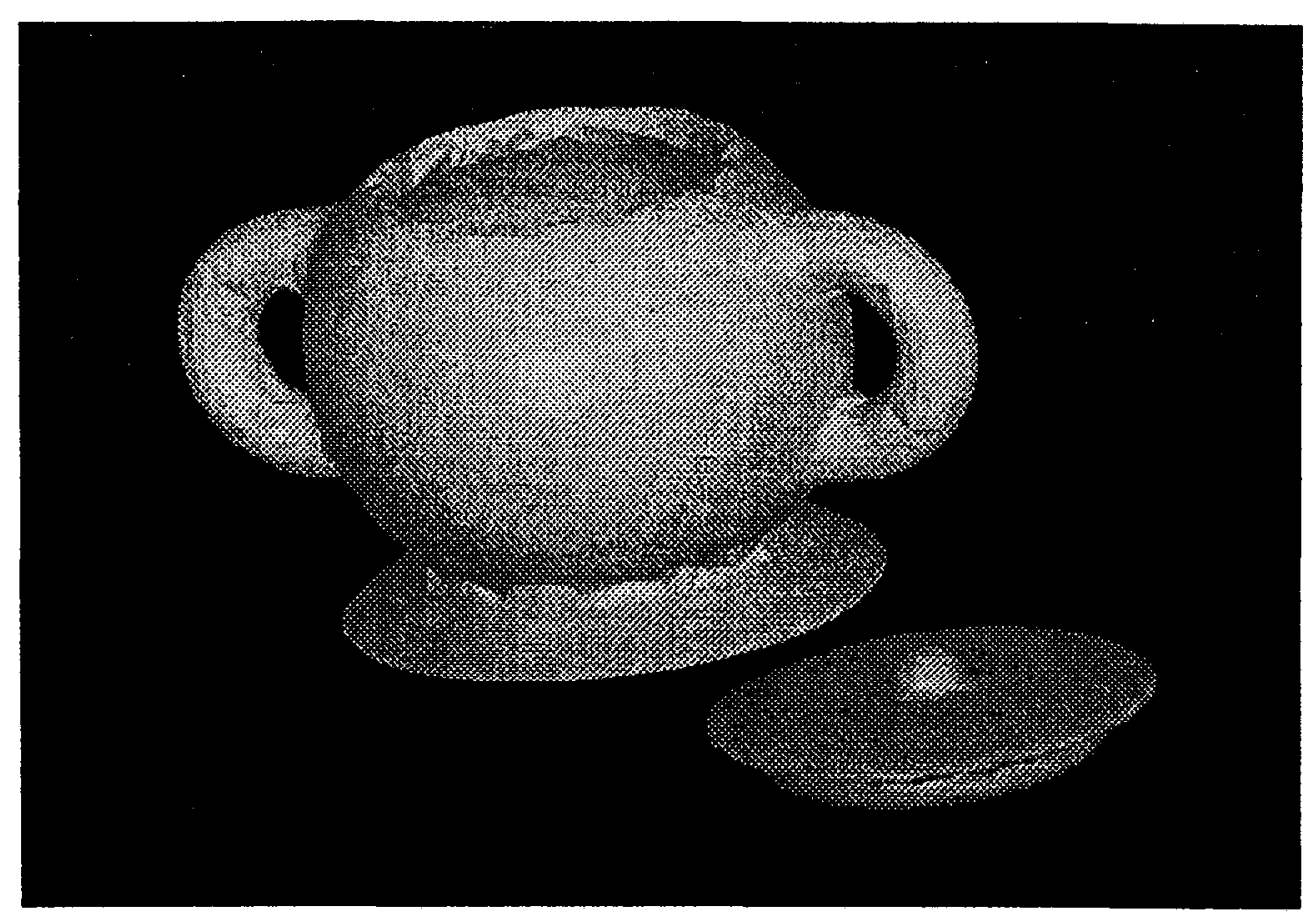

Figura 7.15: o modelo "açucareiro" 


\subsection{0 - Considerações Finais}

Este capítulo descreveu os aspectos de implementação do procedimento de conversão. O algoritmo deste procedimento é constituído de quatro etapas. Na primeira etapa, as componentes de $S=F^{-1}(0)$ são aproximadas, onde F é a função característica do semi-espaço correspondente ao sólido abstrato. Na segunda etapa, as componentes definidas por $S$ e parte da fronteira de $D, \partial(D)$, são aproximadas, onde D é o domínio (paralelepípedo) de F. Na terceira etapa, a componente definida por $\partial(D)$ é aproximada caso faça parte da fronteira de algum modelo descrito. Em seguida, todas as componentes aproximadas são agrupadas para determinar as fronteiras de todos os modelos descritos. Na quarta e última etapa, um arquivo contendo os dados da representação implicita de cada modelo descrito é gerado, bem como um arquivo contendo os operadores Euler capazes de gerar a BRep poliedral de cada modelo descrito.

O capítulo 8 conclui esta dissertação apresentando as contribuições do trabalho aqui descrito, bem como sugestões para sua extensão. 


\section{Capítulo 8}

\section{Conclusões}

\section{1 - Considerações Iniciais}

Como mencionado nos capítulos 1 e 4, o (SM) é um sistema de modelagem de sólidos que está sendo desenvolvido pelo grupo de Computação Gráfica e Processamento de Imagens do ICMSC-USP. Em sua primeira versão operacional, este sistema possufa como única forma de representação a $B R e p$ poliedral, e os modelos podiam ser descritos por varredura rotacional e translacional simples [Sc93].

Atualmente, como resultado do trabalho descrito nesta dissertação, o (SM) ${ }^{2}$ possui uma arquitetura multi-representacional, sendo que a BRep poliedral é a forma de representação principal e a representação implícita é a forma de representação secundária, e os modelos podem ser descritos por semi-espaços. Outro trabalho em andamento está incorporando facilidades de descrição por instanciamento de primitivas e vários tipos de varredura rotacional e translacional [Ma94a et al.].

A representação implícita é associada aos modelos gerados por semi-espaços. Esta representação é convertida para a BRep poliedral correspondente, com o intuito de garantir a consistencia interna do modelador. A conversão é realizada por meio de um procedimento baseado em um método simplicial de aproximação de superfícies definidas implicitamente. Este método é capaz de gerar as informações da BRep poliedral a partir da representação implícita do modelo.

A técnica de modelagem por semi-espaços permite que muitos modelos de sólidos, cuja fronteira possui uma forma complexa, sejam descritos. A disponibilidade de duas formas de representação para os modelos gerados por semi-espaços possibilita que os procedimentos das aplicações baseadas nesses modelos possam optar pela forma de representação mais adequada.

\section{2 - Contribuições do Trabalho}

O trabalho de Mestrado descrito nesta dissertação incorporou a técnica de modelagem por semi- 
espaços e a representação implícita ao (SM) ${ }^{2}$. Isto fez com que a antiga arquitetura do (SM) ${ }^{2}$, constituída de uma única forma de representação, evolússe para uma arquitetura multi-representacional, composta pela representação implícita e a BRep poliedral. O poder de descrição do $(\mathrm{SM})^{2}$ foi ampliado, bem como sua aplicabilidade.

As contribuições deste trabalho são as seguintes:

- a implementação da técnica de modelagem por semi-espaços definidos implicitamente;

- a incorporação da representação implícita e do interpretador (procedimento de manipulação), que é capaz de avaliar o código da função característica do semi-espaço correspondente ao modelo;

- implementação do procedimento de conversão da representação implícita para a BRep poliedral;

- criação e implementação dos operadores de Euler GShell, MSKS e KSMS.

A estrutura de dados semi-aresta* foi desenvolvida e implementada visando à incorporação de outras formas de representação ao (SM) ${ }^{2}$ [Sc93], [Ma94b et al.]. O trabalho descrito nesta dissertação serviu como ponto de partida para a integração de novas formas de representação, visto que o algoritmo que transfere os dados da estrutura esqueleto combinatório para a estrutura semi-aresta* (trecho do algoritmo do procedimento de conversão apresentado no capítulo 7) pode ser reaproveitado por procedimentos de conversão que gerarão a BRep poliedral a partir de outras possíveis representações que venham a ser integradas ao $(\mathrm{SM})^{2}$.

\section{3 - Sugestões para Futuros Trabalhos}

A descrição de modelos por semi-espaços definidos através de funções implícitas exige uma certa familiaridade com matemática e isto pode dificultar seu uso por parte de alguns usuários. Por outro lado, esta forma de descrição permite ao usuário definir uma série de modelos difíceis ou impossíveis de serem descritos em modeladores tradicionais. Soluções alternativas, que conservam o poder de descrição por semi-espaços e são mais amigáveis, foram apresentadas em [BISh91], [BIWy91], [ScPe91].

Notou-se, durante a obtenção e observação dos modelos gerados, que uma triangulação adaptativa é imprescindível para obter uma melhor aproximação em menor espaço de tempo e de 
memória, pois nas triangulações uniformes, como $K_{1} e J_{1}$, as regiões da fronteira do modelo com pequena e grande curvatura são refinadas igualmente, de modo que uma boa aproximação do modelo gera um número de faces desnecessário nas regiões de pequena curvatura. Isto significa mais tempo de processamento e espaço de memória.

Triangulações adaptativas baseadas nas triangulações $K_{1}$ e $J_{1}$ foram apresentadas em trabalhos recentes [Ca92], [Pe93 et al.]. A escolha da região para refinamento adaptativo deve ser feita pelo modelador (sem intervenção do usuário) através de um dado critério. Alguns critérios de escolha são baseados na curvatura da superfície do modelo, nas curvas de interseção resultantes de operações booleanas para definir a superfície e na silhueta da modelo. Em [HeBa87], estes critérios são utilizados para aproximar superfícies parametrizadas. Um critério baseado na curvatura de superfícies definidas implicitamente está sendo estudado [Pe93 et al.].

Uma forma amigável para descrever os semi-espaços sem perder a potência descritiva dos mesmos, a escolha de uma triangulação adaptativa baseada nas triangulações $K_{1}$ e $J_{1}$, e um critério para escolha automática da região da triangulação a ser refinada são sugestões para extensão deste trabalho. 


\section{Referências Bibliográficas}

A

[Ah86 et al.] - AHO, A.V.; SETHI, R. \& ULLMAN, J.D. Compilers - Principles, Techniques and Tools. Addison-Wesley, 1986.

[AIGe80] - ALLGOWER, E. \& GEORGE, K. Homotopy Methods for Approximating Several Solutions to Nonlinear Systems of Equations. In: W. Föster (Ed.) Numerical Solution of Highly Nonlinear Problems, North-Holland Publishing Company, pp 253-70, 1980.

B

[Ba87 et al.] - BARTELS, R.; BEATTY, J. \& BARSKY, B. An Introduction to Splines for Use in Computer Graphics and Geometric Modeling. Morgan Kaufmann, 1987.

[B193] - BLOOMENTHAL, J. An Evaluation of Implicit Surface Tilers. In: IEEE Computer Graphics and Applications, V.13, No 6, November, pp 33-41, 1993.

[BISh91] - BLOOMENTHAL, J. \& SHOEMAKE, K. Convolution Surfaces. In: ACM Computer Graphics - SIGGRAPH'91, V.25, N²4, July, pp 251-56, 1991.

[BIWy90] - BLOOMENTHAL, J. \& WYVILL, B. Interactive Techniques for Implicit Modeling. In: ACM Computer Graphics - SIGGRAPH'90, V.24, No 2, March, pp 109-16, 1990.

C

[Ca9.0] - CASACURTA, A. Sweeping - Representacão de Sólidos Rtgidos. In: Jornada EPUSP-IEEE em Computação Visual, USP, São Paulo, 1990.

[Ca92] - CASTELO FILHO, A. Aproximacoes Adaptativas de Variedades Implicitas com Aplicacðes à Modelagem Implicita e Equacóes Algébrico-Diferenciais. Tese de Doutorado, Departamento de Matemática, Pontifícia Universidade Católica do Rio de Janeiro, 1992. 
[CaC178] - CATMULL, E. \& CLARK, J. Recursively Generated B-Spline Surfaces on Arbitrary Topological Meshes. In: Computer-Aided Design, V.10, Nº, November, pp 350-5, 1978.

[Ce94] - CÉSAR, C.N.L. Um Estudo de Algoritmos de Visualizacão em Computacão Gráfica. MiniDissertação apresentada como parte dos requisitos para obtenção do título de Mestre na área de Ciências da Computação e Matemática Computacional, ICMSC-USP, 1994.

[Ch88] - CHIYOKURA, H. Solid Modeling with DESIGNBASE - Theory and Implementation. AddisonWesley, 1988.

[ChGr84] - CHARROT, P. \& GREGORY, J.A. A Pentagonal Surface Patch for Computer Aided Geometric Design. In: Computer Aided Geometric Design, V.1, No 1, pp 87-94, 1984.

$\mathbf{E}$

[Ea76] - EAVES, B.C. A Short Course in Equations with PL Homotopies. In. R.W. Cottle \& C.E.Lemze (Eds.) Nonlinear Programming - SIAM-AMS Proceedings, V.9, pp 73-143, 1976.

[El78] - ELLIOT, W.S. Interactive Graphical CAD in Mechanical Engineering Design. In: Computer Aided Design, V.10, $\mathrm{N}^{\circ} 2,1978$.

$\mathbf{F}$

[Fi91] - FISCHER, R. GENESIS: Sistema Hibrido para Modelagem de Sólidos. Dissertação de Mestrado, Departamento de Informática, Pontif́́cia Universidade Católica do Rio de Janeiro; 1991.

[FiGo92] - FIGUEIREDO, L.H. \& GOMES, J.M. Physically-Based Sampling of Implicit Objects. In: SIBGRAPI V. Anais, Águas de Lindóia (SP), Brasil, pp 81-87, 1992.

[Fo90 et al.] - FOLEY, J.D. et al. Computer Graphics: Principles and Practice. Second Edition. Addison-Wesley, 1990.

[Fr91] - FREITAS, S.R. Aproximacoes Simpliciais de Variedades Implícitas e Equacoes AlgébricoDiferenciais. Tese de Doutorado, Departamento de Matemática, Pontifícia Universidade Católica do Rio de Janeiro, 1991. 
G

[GoTa89] - GOMES, J.M. \& TAVARES, G. Métodos Simpliciais em Computacão Gráfica. 17º Colóquio Brasileiro de Matemática, IMPA, Rio de Janeiro, 1989.

[GoVe90] - GOMES, J.M. \& VELHO, L.C. Conceitos Básicos de Computacão Gráfica. VII Escola de Computação, IME-USP, São Paulo, 1990.

$\mathbf{H}$

[He91] - HELLER, D. XView Programming Manual for version 11 of the XWindow System. O'Reilly \& Associates Inc., 1991.

[HeBa87] - VON HERZEN, B. \& BARR, A. Accurate Triangulations of Deformed Intersecting Surfaces. In: ACM Computer Graphics - SIGGRAPH'87, V.21, N4, July, pp 103-10, 1987.

[Ho93] - HOFFMANN, C.M. Implicit Curves and Surfaces in CAGD. In: IEEE Computer Graphics and Applications, V.13, No 1, January, pp 79-88, 1993.

[HoHo85] - HOFFMANN, C.M. \& HOPCROFT, J. Automatic Surface Generation in Computer Aided Design. In: The Visual Computer, V.1, No 2, October, pp 92-100, 1985.

[HoU179] - HOPCROFT, J.E. \& ULLMAN, J.D. Introduction to Automata Theory Languages and Computation. Addison-Wesley, 1979.

[HuTa92] - HUI, K.C. \& TAM, S.T. Construction of a Hybrid Sweep-CSG Modeler - the Sweep-CSG Representation. In: Engineering with Computers, V.6, No 2, pp 100-19, 1992.

$\mathbf{K}$

[Ka90] - KAUFMAN, A. The Voxblt Engine: A Voxal Frame Buffer Processor. In: A.A.M. Kuijk \& W. Strasser (Eds.) Advances in Graphics Hardware III , Springer-Verlag, Berlim, pp 85-102, 1990.

[KeRi88] - KERNIGHAN, B.W. \& RITCHIE, D.R. C a Linguagem de Programação: padrão ANSI. Editora Campus, Rio de Janeiro, 1988.

[Ki94] - KING, D. Modeling with Surface Revolutions. In: Computer Graphics World, V.17, $\mathbf{N}^{\circ}$ 1, January, pp 51-4, 1994. 
$\mathbf{L}$

[Li81] - LIMA, E.L. Curso de Análise - Volume 2. IMPA, CNPq, Rio de Janeiro, 1981.

$\mathbf{M}$

[Mä88] - MÄNTYLÄ, M. An Introduction to Solid Modeling. Computer Science Press, 1988.

[Ma93] - MACKRELL, J. Making Sense of a Revolution. In: Computer Graphics World, V.16, No 11 , November, pp 26-38, 1993.

[Ma94a et al.] - MAGALHÃES, A.L.C.C. et al. Desenvolvimento de um Modelador de Sólidos Multirepresentacional com Núcleo B-Rep e Técnicas de Descricáo por Varredura e Semi-espacos. artigo a ser publicado nos anais do VII SIBGRAPI.

[Ma94b et al.] - MAGALHĀES, A.L.C.C. et al. Semi-Aresta*: Uma Estrutura de Dados para Representar Modelos de Solidos. Relatório Técnico (em preparação).

[Me82] - MEAGHER, D.J. Geometric Modeling Using Octree Enconding. In: Computing Graphics and Image Processing, $V^{\circ} 19, \mathrm{pp} 129-47,1982$.

[Me84] - MEAGHER, D.J. The Solids Engine: A Processor for Interactive Solid Modeling. In: Nicograph 84. Proceedings., Tokyo, November, 1984.

[Mi86] - MILNER, J.R. Sculptured Surfaces in Solid Modeling: Issues and Alternative Approaches. In: Computer Graphics and Applicatons, V.6, N 12, December, pp 37-48, 1986.

[Mi89] - MILNER, J.R. Architectural lssues in Solid Modelers. In: IEEE Computer Graphics and Applications, V.9, No 5, September, pp 72-87, 1989.

$\mathbf{P}$

[Pe91 et al.] - PERSIANO, R. et al. Boundary Evaluation of CSG Solids by Simplicial Subdivision. In: COMPUGRAPHICS'91, Sesimbra, Portugal, October, 1991.

[Pe93 et al.] - PERSIANO, R. et al. An Adaptative Triangulation Refinement Scheme and Construction. In: SIBGRAPI VI. Anais, Recife (PE), Brasil, outubro, pp 259-66, 1993. 
$\mathbf{T}$

[Ta92 et al.] - TAVARES, G.; CASTELO FILHO, A. \& LOPES, H. Topological Methods in Geometric Modeling. Mini-Curso do XV Congresso Nacional de Matemática Aplicada e Computacional (CNMAC), São Carlos (SP), Brasil, 1992.

[To76] - TODD, M.J. The Computation of Fixed Points an Application. In: Lectures Notes in Economics and Mathematical Systems, No 124, Springer-Verlag, 1976.

W

[Wa89] - WARREN, J. Blending Algebraic Surfaces. In: ACM Transactions on Graphics, V.8, N $^{\circ}$ 4, October, pp 263-78, 1989.

[Wi76] - WIRTH, N. Algorithms + Data Structures = Programs. Prentice-Hall, 1976.

[Wo93] - WOLFE, L. S. Freeform Surfaces. In: Computer Graphics World, V.16, No 7, July, pp 59-64, 1993. 